Cover. Examples of elevation-derived hydrography in different landscapes. From top to bottom, (1) a stream network running through mountains in Colorado; (2) stream channels flowing near farmland in Delaware; (3) canals and streams in an arid location in Colorado; and (4) waterways and other water features along the coast of Delaware. 


\section{Elevation-Derived Hydrography- Representation, Extraction, Attribution, and Delineation Rules}

By Christy-Ann M. Archuleta and Silvia Terziotti

Chapter 12 of

Section B, U.S. Geological Survey Standards, of

Book 11, Collection and Delineation of Spatial Data

Techniques and Methods 11-B12

Version 1.1, January 2023 


\section{U.S. Geological Survey, Reston, Virginia: 2020 \\ First release: 2020 \\ Revised: 2023 (ver. 1.1)}

For more information on the USGS - the Federal source for science about the Earth, its natural and living resources, natural hazards, and the environment—visit https://www.usgs.gov or call 1-888-ASK-USGS.

For an overview of USGS information products, including maps, imagery, and publications, visit https://store.usgs.gov/.

Any use of trade, firm, or product names is for descriptive purposes only and does not imply endorsement by the U.S. Government.

Although this information product, for the most part, is in the public domain, it also may contain copyrighted materials as noted in the text. Permission to reproduce copyrighted items must be secured from the copyright owner.

Suggested citation:

Archuleta, C.M, and Terziotti, S., 2020, Elevation-Derived Hydrography-Representation, Extraction, Attribution, and Delineation Rules (ver. 1.1, January 2023): U.S. Geological Survey Techniques and Methods, book 11, chap. B12, 60 p., https://doi.org/10.3133/tm11B12.

ISSN 2328-7055 (online) 


\section{Contents}

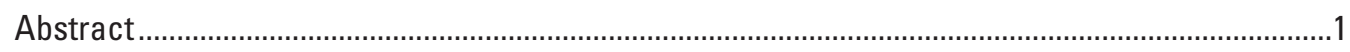

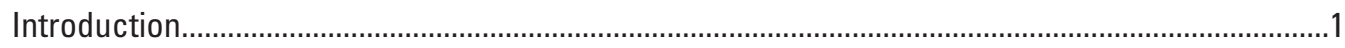

Elevation-Derived Hydrography-Representation, Extraction, Attribution, and Delineation Rules Explanations ………………………..................................................

Field Definitions and Domain Values for Attributes ……..............................................................

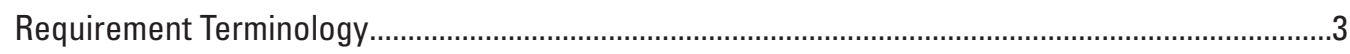

Area of Complex Channels ..................................................................................................

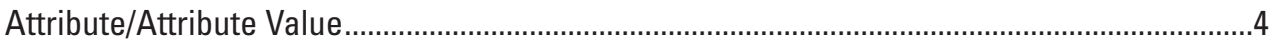

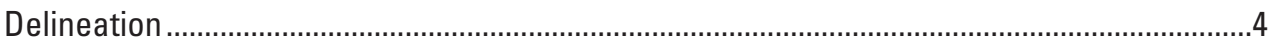

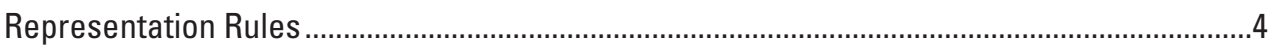

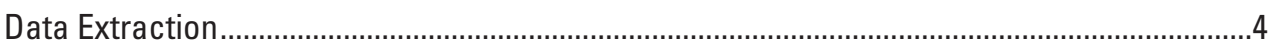

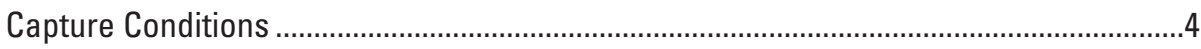

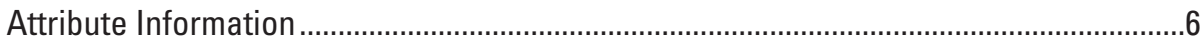

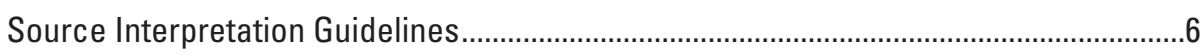

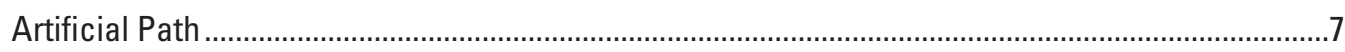

Attribute/Attribute Value...............................................................................................

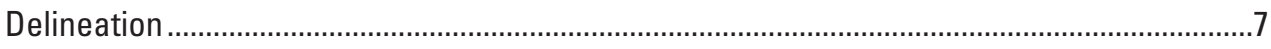

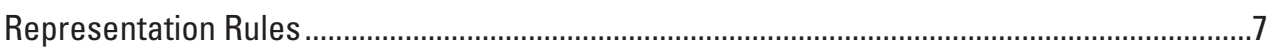

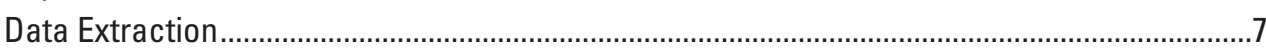

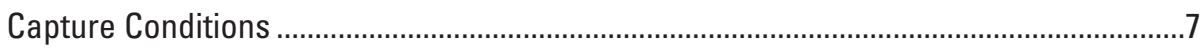

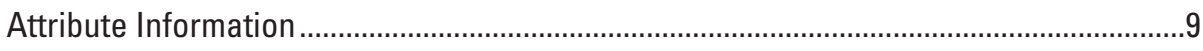

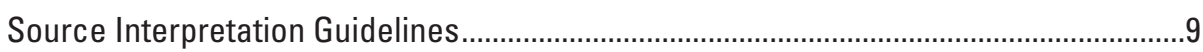

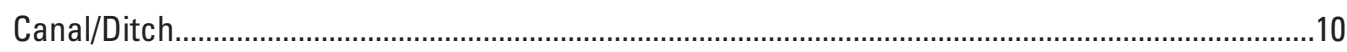

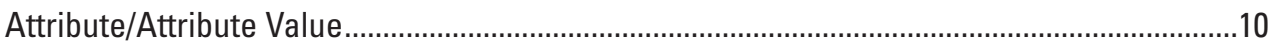

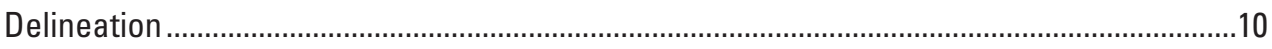

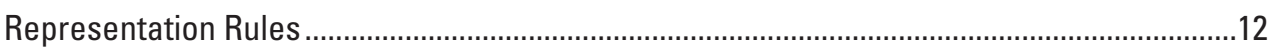

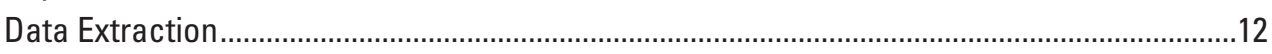

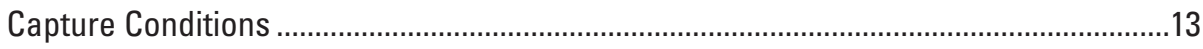

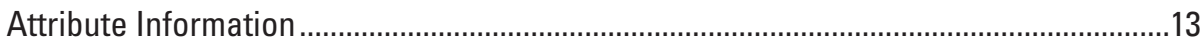

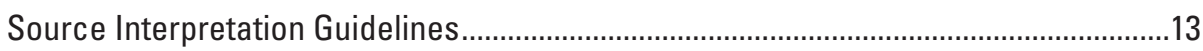

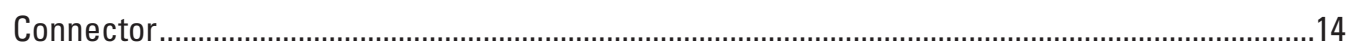

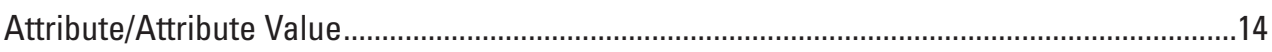

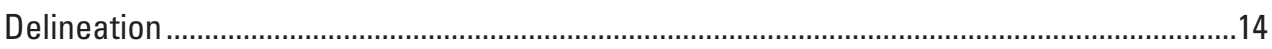

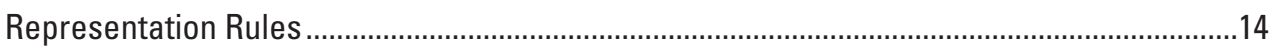

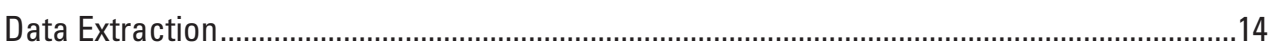

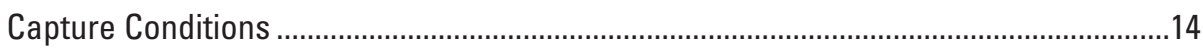

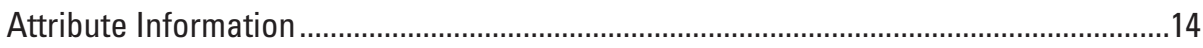

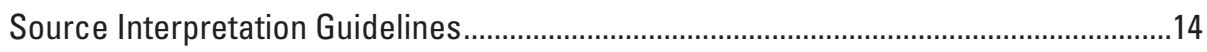

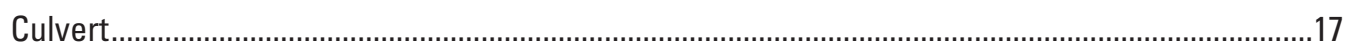

Attribute/Attribute Value.............................................................................................

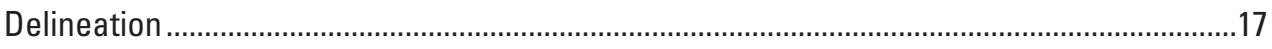

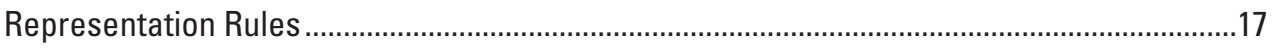

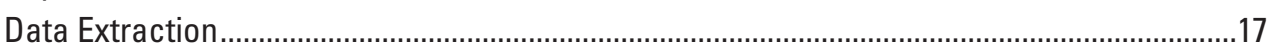

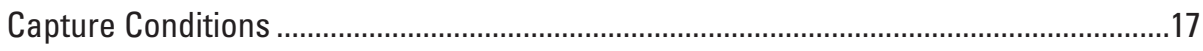




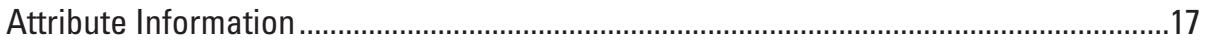

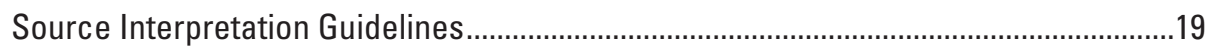

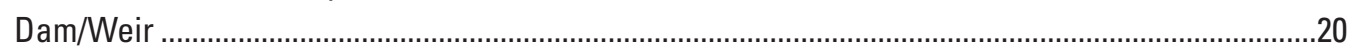

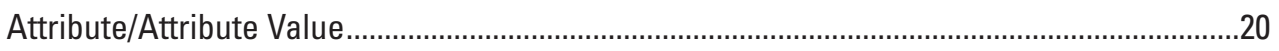

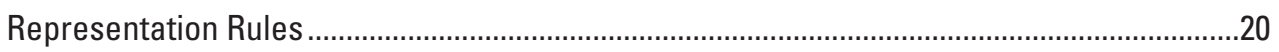

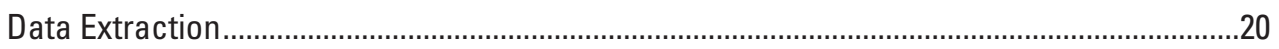

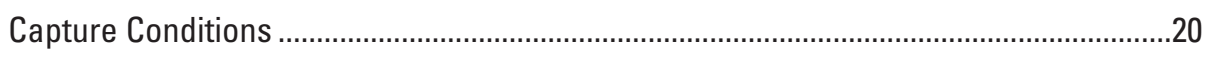

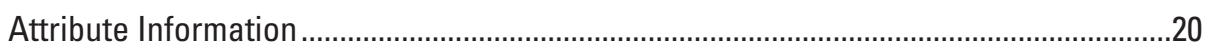

Source Interpretation Guidelines............................................................................20

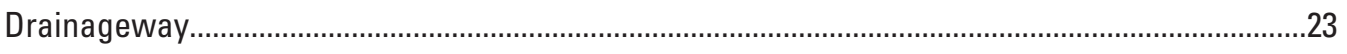

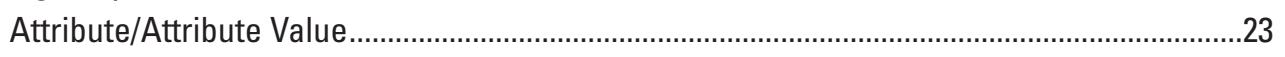

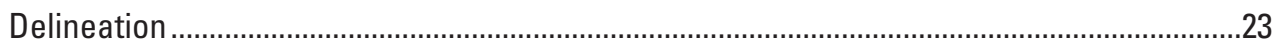

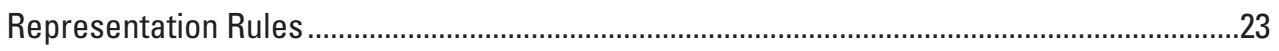

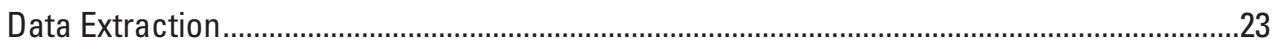

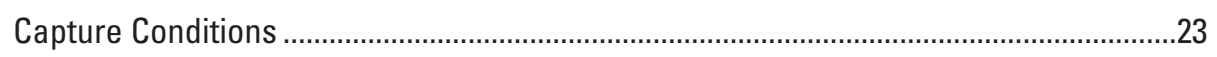

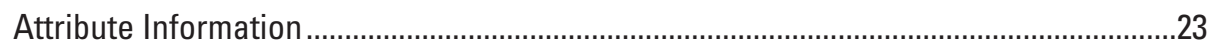

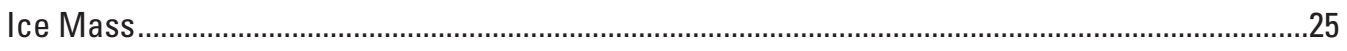

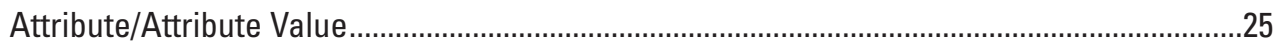

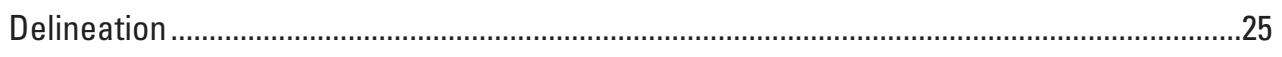

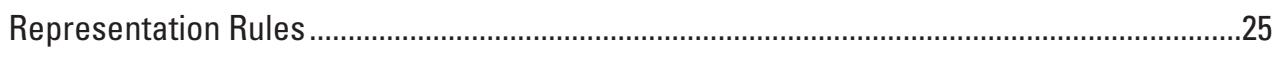

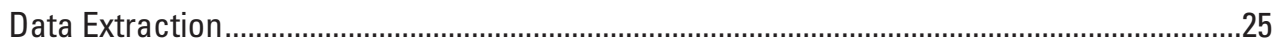

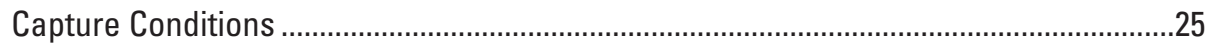

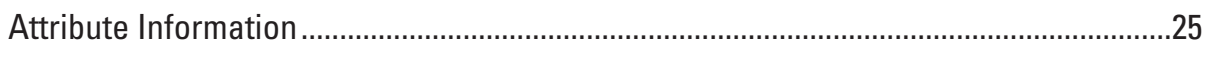

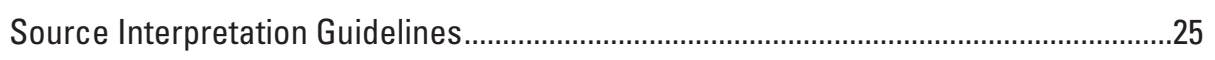

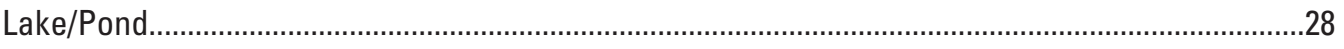

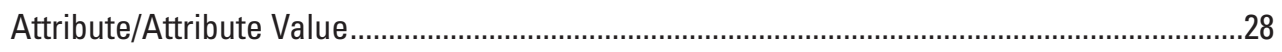

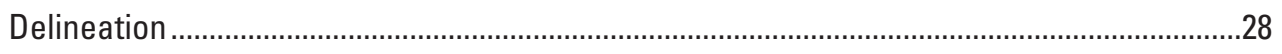

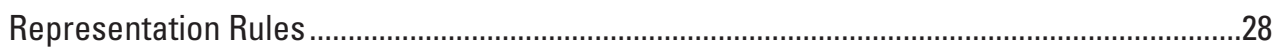

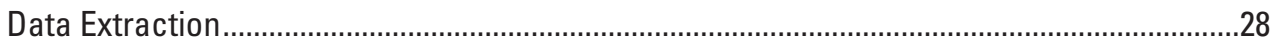

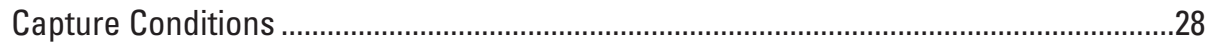

Attribute Information .............................................................................................28

Source Interpretation Guidelines.........................................................................28

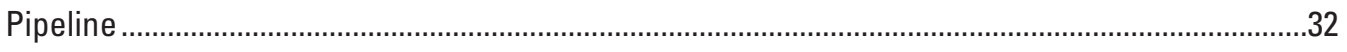

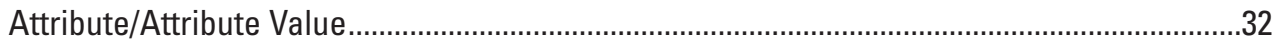

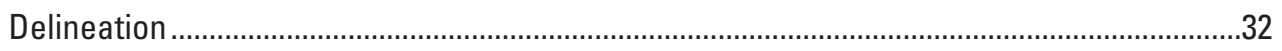

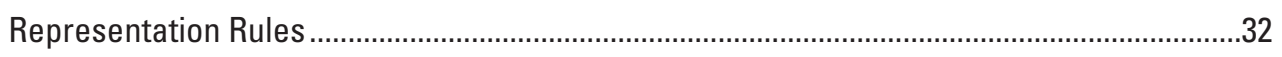

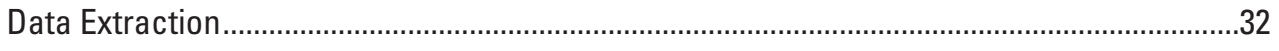

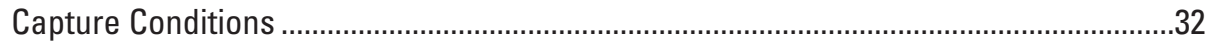

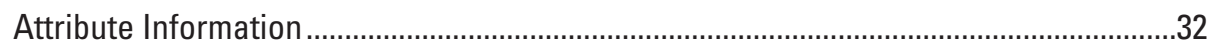

Source Interpretation Guidelines.........................................................................34

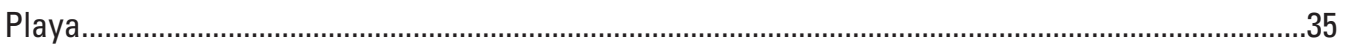

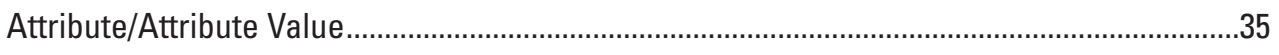

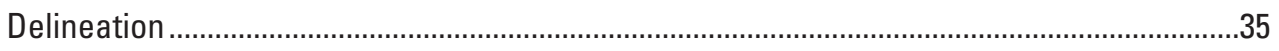

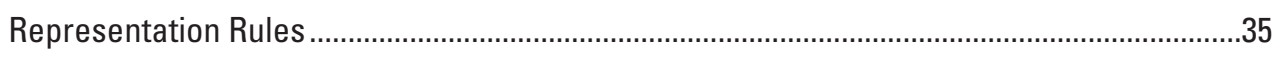

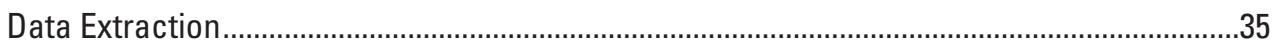




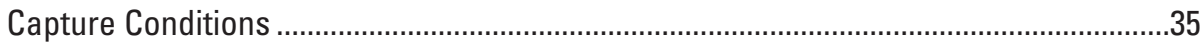

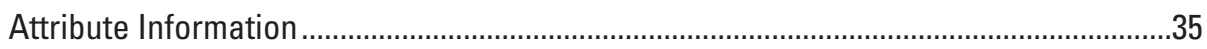

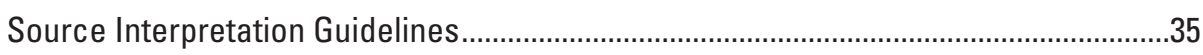

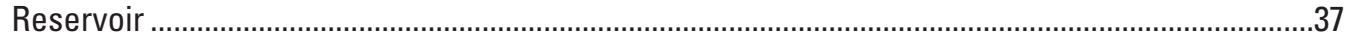

Attribute/Attribute Value...................................................................................................

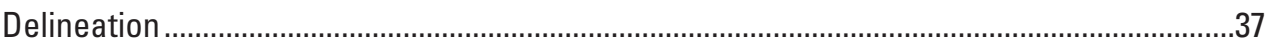

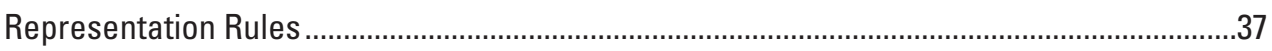

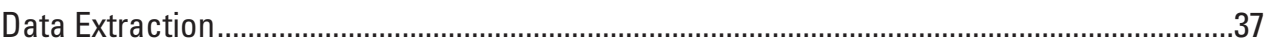

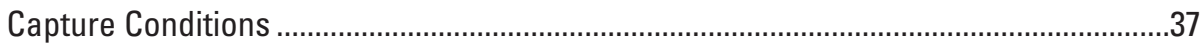

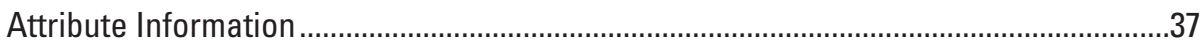

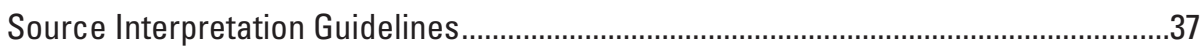

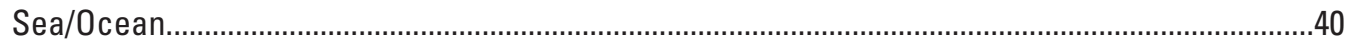

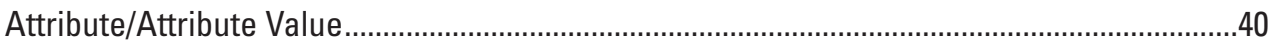

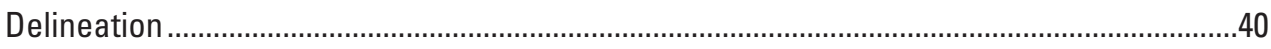

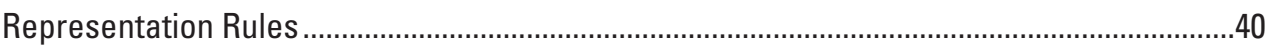

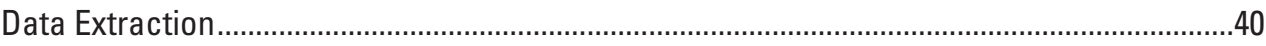

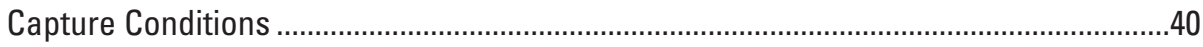

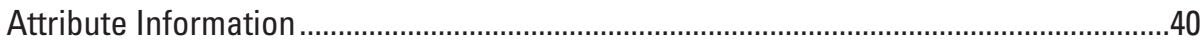

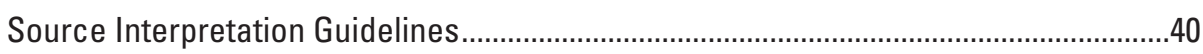

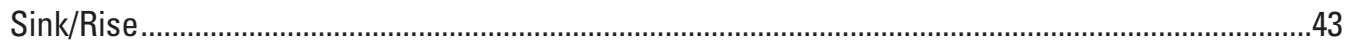

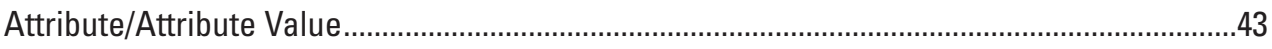

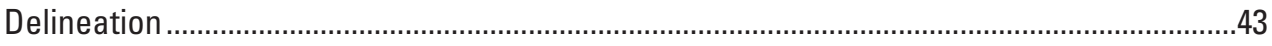

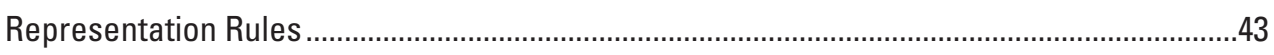

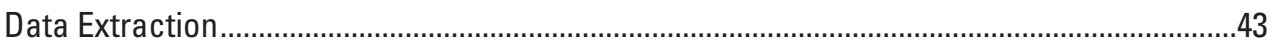

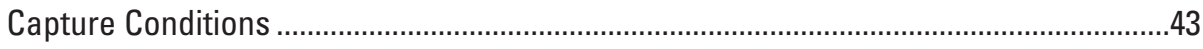

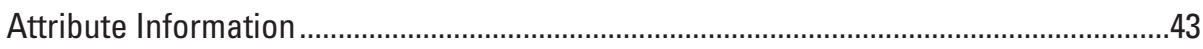

Source Interpretation Guidelines..........................................................................4

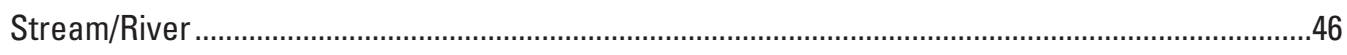

Attribute/Attribute Value ...................................................................................................

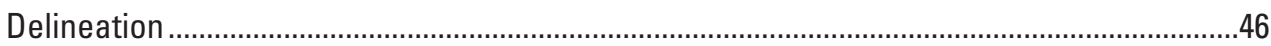

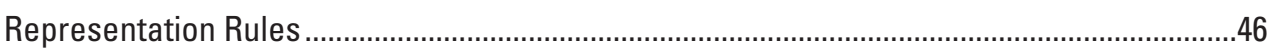

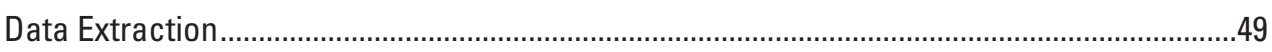

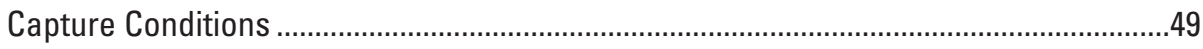

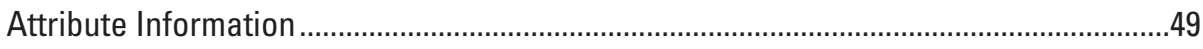

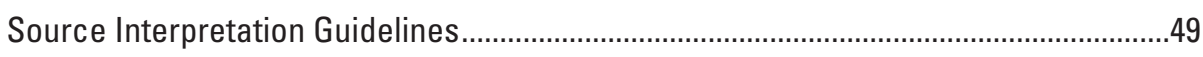

Additional Elevation-Derived Hydrography Treatments and Elevation Specific Features ...............50

Island .

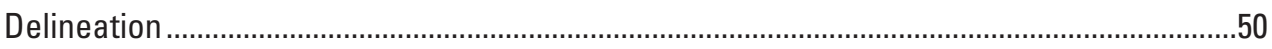

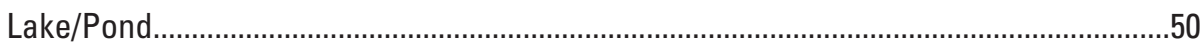

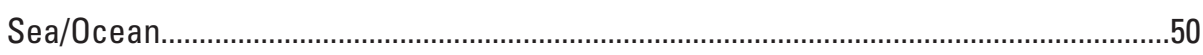

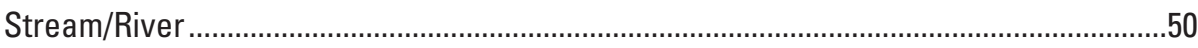

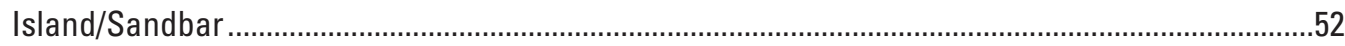

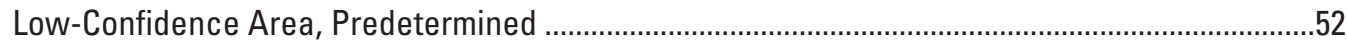

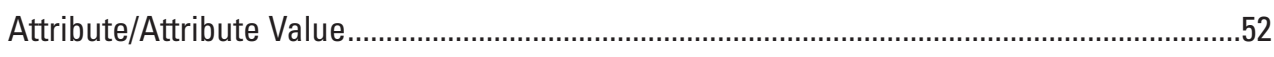

Representation Rules ................................................................................................ 52 


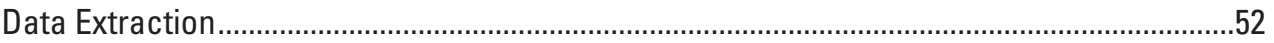

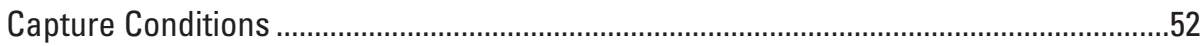

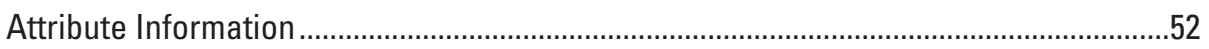

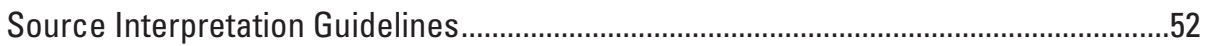

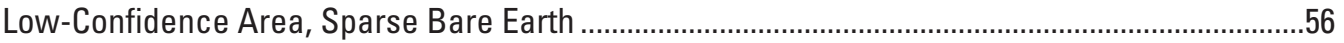

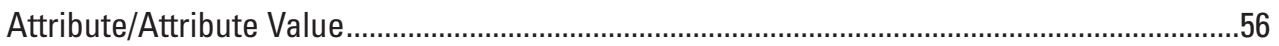

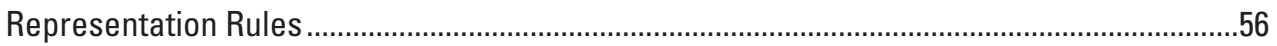

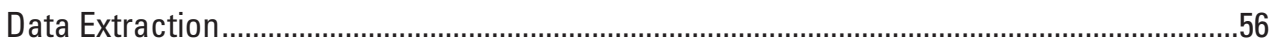

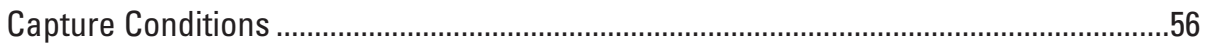

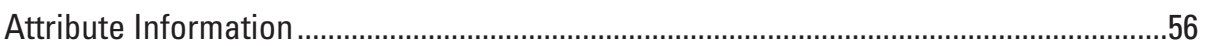

Low-Confidence Area, Snow-Cover ....................................................................................57

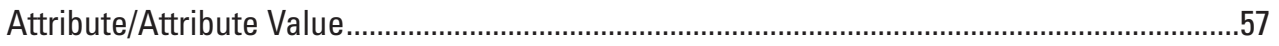

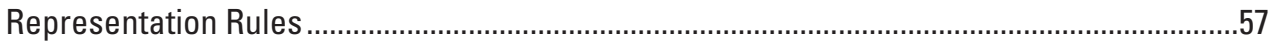

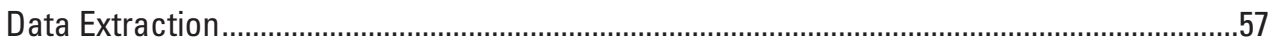

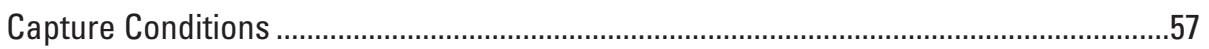

Attribute Information ..............................................................................................

Source Interpretation Guidelines................................................................................

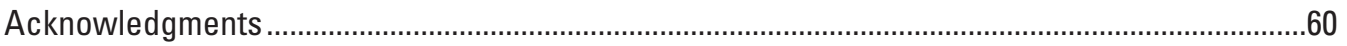

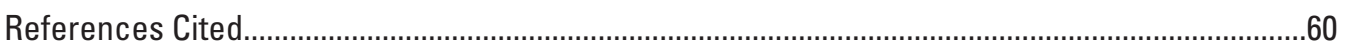

\section{Figures}

1. Diagram showing shortest and longest axes of a lake/pond feature .................................2

2. Photograph showing Toutle River, Washington, shown as an example of area of complex channels feature.

3. Map showing example of an area of complex channels along the Susitna River in Alaska.

4. Diagram showing inflow and outflow points of a lake/pond feature ..................................

5. Map showing example of artificial path features in Lake Fannie in Minnesota .................8

6. Photograph showing Shadroe Canal Weir, Cape Coral, Florida, as an example

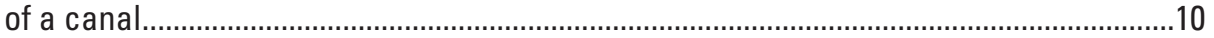

7. Diagram showing shortest and longest axes of a canal/ditch feature ............................10

8. Map showing Courtland and Superior Canals near the Nebraska-Kansas Stateline, as examples of canal/ditch features

9. Image showing New Libby Dam, Kootenai River, Libby, Montana, as an example of where a connector could be used to connect the flow of the river from the bottom left side of the image to the lake on the top right side of the image.

10. Map showing Oroville Dam, California, to provide an example of a connector

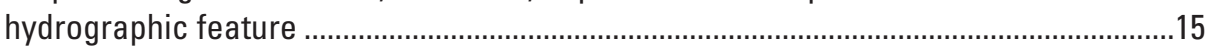

11. Photograph showing example of a culvert on Town Creek, White County, Georgia........17

12. Map showing Highway 211 in Virginia crossing unnamed streams as examples of a culvert hydrographic feature. ...............................................................................18

13. Photograph showing Hoover Dam on Lake Mead, Arizona, as an example of a dam feature

14. Map showing Hoover Dam on Lake Mead in Arizona, as an example of a dam/ weir feature 
15. Photograph showing Mendenhall Glacier, Alaska, as an example of ice mass

feature type.

16. Map showing Mendenhall Glacier in Alaska as an example of an ice mass feature.....26

17. Photograph showing Crater Lake, Oregon, as an example of a lake/pond feature ........28

18. Maps showing examples of natural lake/pond feature .....................................................29

19. Photograph showing example of a pipeline feature ...........................................................32

20. Map showing the various pipelines that form the Governor Edmund G. Brown West Branch California Aqueduct as an example of pipeline features ...........................33

21. Photograph showing Clayton Valley Playa, Nevada, as an example of a playa feature..

22. Map showing Racetrack Playa in Death Valley, California, as an example of playa feature..

23. Photograph showing U.S. Department of Agriculture Harry K. Dupree Stuttgart National Aquaculture Research Center, Arkansas, as an example of a reservoir feature.

24. Map showing Unnamed reservoir in Florida, as an example of reservoir hydrographic feature.....

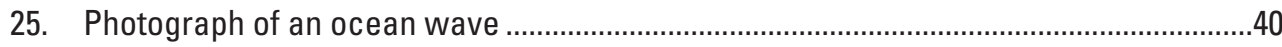

26. Map showing the Pacific Ocean near Yaquina Head, Newport, Oregon, as an example of a sea/ocean hydrographic feature ................................................................41

27. Photograph showing ephemeral sinking stream in Winchester, Virginia .........................43

28. Map showing sink and rise features on Santa Fe River, Florida, as examples of sink/rise hydrographic features ....................................................................................4 44

29. Photograph showing Eagle Creek at Zionsville, Indiana, as an example of a river ........46

30. Diagram showing shortest and longest axes of a stream/river feature...........................46

31. Map showing Nowitna River, Alaska, as an example of a stream/river hydrographic feature.

32. Image of Rikers Island, New York

33. Map showing an island in the Saugatuck Reservoir in Connecticut as an example of treatment for lake/pond features

34. Map showing "Sometimes Islands" in Lake Travis, Texas, as an example of an intermittent island/sandbar.

35. A great white heron standing atop mangrove roots, Boggy Key, a Florida Island ..........54

36. Map showing a mangrove forest in western Florida as an example of a predetermined area of low confidence.

37. Photograph showing snow-cover in the Alaska Interior Mountain Range . .57

38. Map showing an area in the Alaska Range as an example of a low-confidence area, snow-cover. 


\section{Tables}

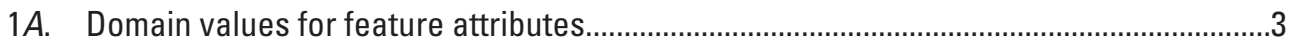

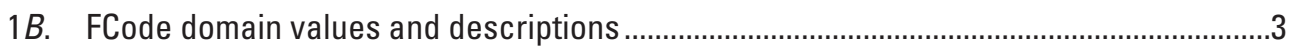

2. Area of complex channels domain codes and attributes ...................................................

3. Area of complex channels representation rules..........................................................

4. Artificial path domain codes and attributes...............................................................

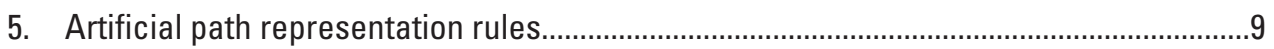

6. Canal/ditch domain codes and attributes for non-National Hydrography

Dataset features that are not used for elevation derivatives.

7. Canal/ditch domain codes and attributes for National Hydrography Dataset features that are used for purposes other than culverts or those used for hydroflattening ...

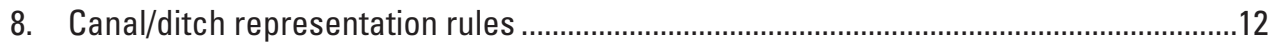

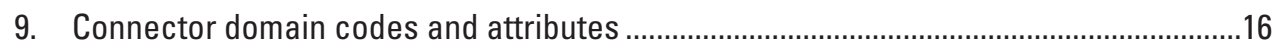

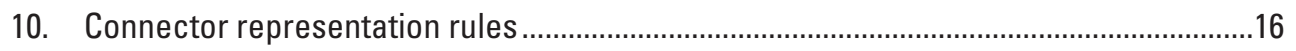

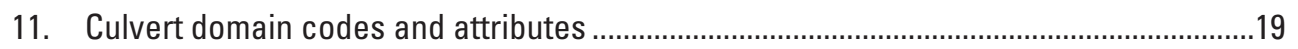

12. Culvert representation rules ....................................................................................19

13. Dam/weir domain codes and attributes for non-National Hydrography dataset features.

14. Dam/weir domain codes and attributes for National Hydrography Dataset features

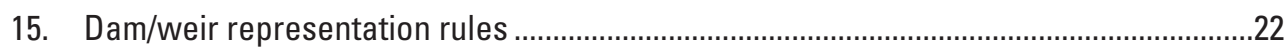

16. Drainageway domain codes and attributes-feature is appropriate for use in hydroenforcement

17. Drainageway domain codes and attributes - feature should not be used for hydroenforcement

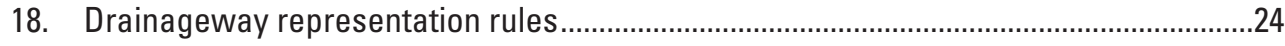

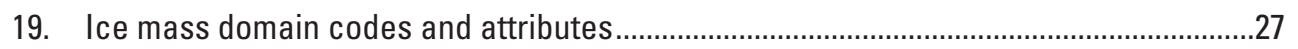

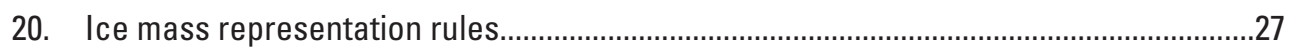

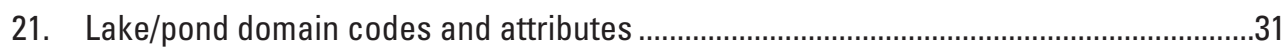

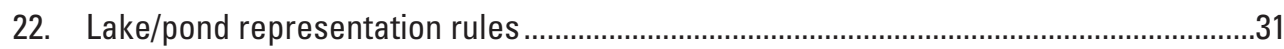

23. Pipeline domain codes and attributes-feature should not be used for hydroenforcement

24. Pipeline domain codes and attributes-feature is appropriate for

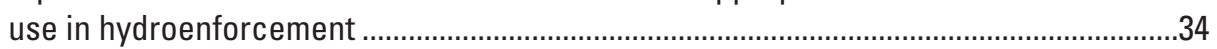

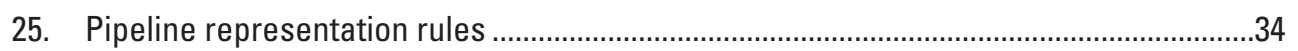

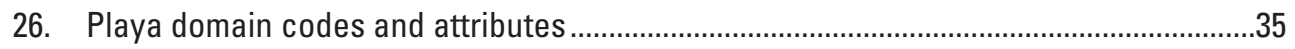

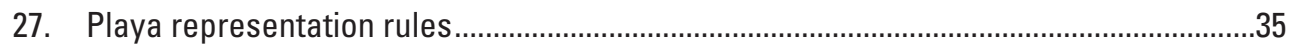

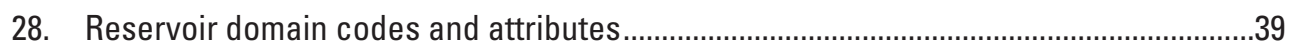

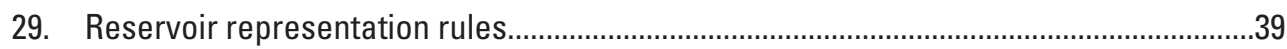

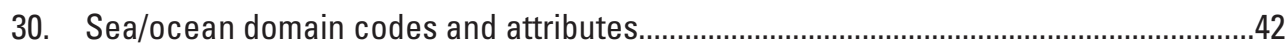

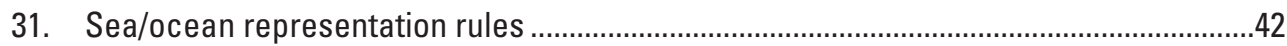

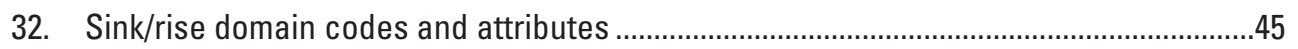

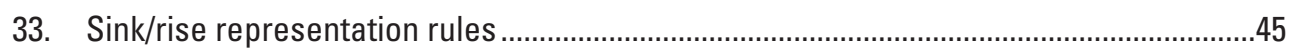


34. Stream/river domain codes and attributes - feature is appropriate for use in hydroenforcement

35. Stream/river domain codes and attributes - feature is appropriate for

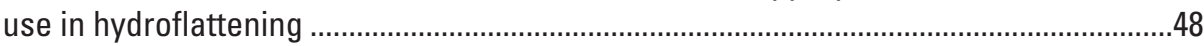

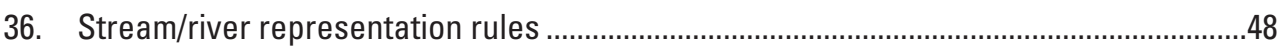

37. Low-confidence area, predetermined, domain codes and attributes .............................54

38. Low-confidence area, predetermined, representation rules............................................54

39. Low-confidence area, sparse bare earth, domain codes and attributes .........................56

40. Low-confidence area, sparse bare earth, representation rules ......................................56

41. Low-confidence area, snow-cover, domain codes and attributes ..................................59

42. Low-confidence area, snow-cover, representation rules ...............................................59

\section{Conversion Factors}

U.S. customary units to International System of Units

\begin{tabular}{llll}
\hline & Multiply & By obtain & To \\
\hline \multicolumn{3}{c}{ Length } \\
\hline foot (ft) & 0.3048 & meter $(\mathrm{m})$ \\
mile (mi) & 1.609 & kilometer $(\mathrm{km})$ \\
\hline \multicolumn{3}{c}{ Area } \\
\hline acre & 0.4047 & hectare (ha) \\
\hline
\end{tabular}

\section{Abbreviations}

3DEP 3D Elevation Program

DEM digital elevation model

EClass Elevation Class

EDH elevation-derived hydrography

FClass Feature Class

FCode Feature Code

lidar light detection and ranging

NHD National Hydrography Dataset

READ Representation, Extraction, Attribution, and Delineation 



\title{
Elevation-Derived Hydrography-Representation, Extraction, Attribution, and Delineation Rules
}

\author{
By Christy-Ann M. Archuleta and Silvia Terziotti
}

\begin{abstract}
With the increasing availability of 3D Elevation Program (3DEP) quality high resolution elevation data across the United States and the pressing need for better integrated elevation and hydrography data, the U.S. Geological Survey is developing guidance to improve the horizontal and vertical alignment of these datasets. The U.S. Geological Survey is providing the Elevation-Derived Hydrography-Acquisition Specifications for the acquisition of elevation-derived hydrography for the United States, and the companion document The Elevation-Derived Hydrography-Representation, Extraction, Attribution, and Delineation (READ) Rules, which describes the parameters for the portrayal of hydrography features as derived from elevation data. The READ Rules provide a definition, example, attribute value list, delineation instructions, representation rules, and data extraction rules for each hydrography feature required to meet the Elevation-Derived Hydrography-Acquisition Specifications.
\end{abstract}

\section{Introduction}

This report lists the representation, extraction, attribution, and delineation rules for elevation-derived hydrographic features for the U.S. Geological Survey and is meant to be used in conjunction with the Elevation-Derived HydrographyAcquisition Specifications (Terziotti and Archuleta, 2020). The intended purpose of the Elevation-Derived HydrographyRepresentation, Extraction, Attribution, and Delineation (READ) Rules is to provide the requirements for collection and representation of elevation-derived hydrography (EDH). The EDH features collected with the READ Rules will be suitable for use as breaklines to hydroflatten digital elevation models (DEMs); for processing for pre-conflation of features to the National Hydrography Dataset (NHD); and for hydroenforcement of DEMs.

The features collected with the READ Rules should also follow the specifications outlined in the EDHAcquisition Specifications (Terziotti and Archuleta, 2020). It should be noted that the READ Rules attribution parameters do not fulfill all the required attribution specifications for the NHD; additionally, the READ Rules does not contain the full suite of features offered by the NHD. The features in this report were selected for acquisition because they can be derived from elevation data, whereas some NHD features cannot be derived in this manner (for example, tunnels). Additional steps must be taken to produce a dataset that may be migrated into the full NHD feature set, including postprocessing steps after data acquisition and quality assurance/ quality control, and running NHD GeoConflation tools (see https://www.usgs.gov/core-science-systems/ngp/nationalhydrography/tools\#GeoConflation).

\section{Elevation-Derived Hydrography- Representation, Extraction, Attribution, and Delineation Rules Explanations}

Feature definition-The official definition of the hydrographic feature.

Attribute/attribute value list-Lists the specific codes that are required to populate the attribute table for each feature type.

Delineation -Describes the limit or extent of a feature that should be delineated. For instance, a lake/pond feature should be delineated along its shoreline boundary, but the shoreline could be defined in different ways for different situations, so the feature delineation rule narrows down what the extent is in the context of the READ Rules.

Representation rules - Explains how to represent features depending on various factors.

Representation conditions - Explains when a feature should be delineated as a point, line, or polygon.

Data extraction - Rules for when a feature should be extracted, what attributes are applied, and how to understand different special-case scenarios based on the source and ancillary datasets.

Capture conditions - Defines the limits for the size of feature that should be captured or delineated for a specific feature type. For instance, lake/pond features should only be captured if they are 30 meters or greater along the shortest axis (see fig. 1 for explanation of shortest/longest axis). 


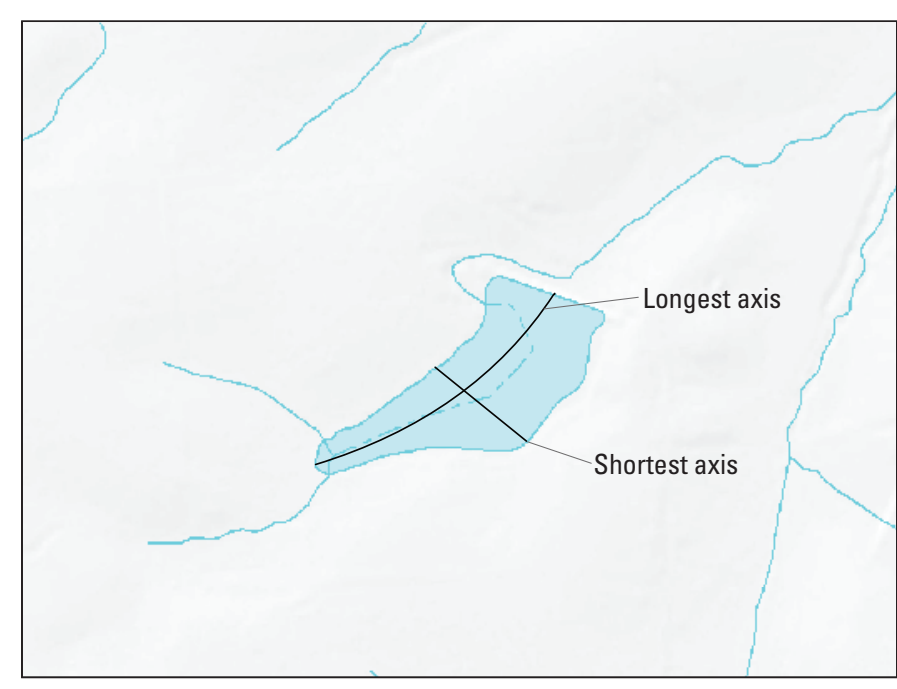

Figure 1. Diagram showing shortest and longest axes of a lake/ pond feature.

Attribute information-Definitions for the codes that should be applied during data extraction.

Source interpretation guidelines-Explains different potential scenarios one may want to consider and how to deal with them when looking at complex situations in the source or ancillary datasets. For instance, if a lake/pond appears to be a dry lake, it should be captured as a playa. Another example is guidance as to the difference between lake/pond and reservoir features, which can be confusing because there are many lake/ pond features with "reservoir" in their name; however, they should still be considered lake/pond features unless they have a geometric shape and are contained by a constructed basin.

\section{Field Definitions and Domain Values for Attributes}

Feature Class (FClass) - A short integer one-digit code (table $1 A$ ) defining whether a feature is intended for use as an NHD feature (1, will be used for conflation), a non-NHD feature (2, outside of the collection criteria and not intended to be used for conflation), or a non-hydrography feature (3, elevation dataset limitation). An example of FClass equal to
1 would be a line feature that represents a stream/river and is suitable for conflation to NHD. An example of FClass equal to 2 would be a canal/ditch that adds too much complexity to the NHD but is collected to fulfill the needs of a funding partner. If a feature is not an NHD feature and is necessary for elevation processing, a 9 is used as the FClass. A polygon representing a low-confidence area is an example of a feature that would not be used in the NHD but may be useful for elevation processing.

Elevation Class (EClass) - A short integer one-digit code (table 1A) indicating whether a feature is used for elevation derivatives, hydroflattening, other non-specified elevation purposes, or an elevation dataset limitation feature. For instance, a low-confidence area is coded as a 9. A culvert is a special case of a feature with no associated NHD coding but is necessary for some elevation treatments. Culverts shall be coded as an EClass of 3.

Feature Code (FCode)_A long integer field containing a coded value (table $1 B$ ). Most of the feature codes are equivalent to the NHD FCode value, which is a five-digit integer code representing various hydrologic feature types. For instance, a lake/pond has FCode type 39000, and a Stream/ River has an FCode of 46000 . The codes that do not have a corresponding NHD code are included to differentiate features that may be useful in describing limitations in the elevation dataset, potentially impacting hydrography and elevation derivatives.

Description - A 250-character free-text field with a text description of FCode and EClass, or user-defined features not included in the domain list.

Source-A 128-character free-text field with a text description of the elevation source data used for deriving the hydrography. Light detection and ranging (lidar) source data should include collection name, date, and quality level.

Method-A 250-character free-text field with a text description of the method used for deriving the hydrography. For instance, software or models could be listed, or, if applicable, digitizing techniques. In addition, this field allows recording of ancillary datasets.

UserCode-A 25-character free-text field with a code designated by the acquisition entity to identify features collected by the data provider (User) outside the scope of features described in this specification document. This field is not required.

Comments - A 250-digit long text field for data provider comments. 
Table 1A. Domain values for feature attributes.

[FClass, feature class; NHD, National Hydrography Dataset; EClass, feature class (elevation); 3D, three dimensional]

\begin{tabular}{|c|c|}
\hline $\begin{array}{l}\text { Domain } \\
\text { value }\end{array}$ & $\begin{array}{l}\text { Feature } \\
\text { description }\end{array}$ \\
\hline \multicolumn{2}{|r|}{ FClass } \\
\hline 1 & NHD feature (will be used for conflation). \\
\hline 2 & Non-NHD feature (outside of collection criteria). \\
\hline 9 & $\begin{array}{l}\text { Nonhydrography feature (elevation dataset } \\
\text { limitation). }\end{array}$ \\
\hline \multicolumn{2}{|r|}{ EClass } \\
\hline 0 & Not used for elevation derivatives. \\
\hline 1 & Used for hydroflattening (3D polygon). \\
\hline 2 & $\begin{array}{l}\text { Hydrographic feature used for elevation purposes, } \\
\text { other than culverts or those used for } \\
\text { hydroflattening. }\end{array}$ \\
\hline 3 & Culvert—used for hydroenforcement. \\
\hline 9 & Elevation dataset limitation. \\
\hline
\end{tabular}

Table 1B. FCode domain values and descriptions.

[FCode, feature code; Desc, description]

\begin{tabular}{cl}
\hline FCode & \\
\hline 0 & User-defined feature ${ }^{1}$ \\
33400 & Connector \\
33600 & Canal/ditch \\
34300 & Dam/weir \\
36100 & Playa \\
37800 & Ice mass \\
39000 & Lake/pond \\
42800 & Pipeline \\
43600 & Reservoir \\
44500 & Sea/ocean \\
45000 & Sink/rise \\
46000 & Stream/river \\
46800 & Drainageway ${ }^{1}$ \\
53700 & Area of complex channels \\
55800 & Artificial path \\
992 & Culvert ${ }^{1}$-adjacent feature description \\
993 & \\
Assigned based on & Low-confidence area (predetermined) \\
adjacent features ${ }^{2}$ & Low-confidence area (sparse bare earth) \\
991 &
\end{tabular}

${ }^{1}$ New feature.

2FCodes include 33400, 42800, 33600, 46000, 46800, and 55800. See figure 11 and table 12 in Terziotti and Archuleta (2020).

\section{Requirement Terminology}

Individual requirements that are defined in this report use "shall" or "will" statements, which have a specific meaning in the context of a specification requirement:

- A "shall" statement means that the requirement must be met.

- A "will" statement indicates that the requirement is expected to be met wherever possible, but exceptions to implementation may exist. 


\section{Area of Complex Channels}

An area where a stream or river flows in an intricate network of interlacing channels with no permanent, primary channel (figs. 2 and 3). Areas of complex channels are commonly found in Alaska, but may be found in other locations as well, and are often associated with glaciation and glacial till.

\section{Attribute/Attribute Value}

Each feature requires domain codes and attributes to be entered into the attribute table for the feature class (table 2). See "Field Definitions and Domain Values for Attributes" section for more information on EDH code definitions.

\section{Delineation}

The limit of area of complex channels is the outer banks of the outermost channels.

\section{Representation Rules}

When delineating a feature, it must be created with the appropriate geometry, either point, line, or polygon, which is determined by the size of the feature or the length along different axes of the feature (table 3).

Special conditions: none.

\section{Data Extraction}

Data extraction rules fall into three categories: capture conditions, attribute information, and source interpretation guidelines. The capture conditions explain the requirements for a feature to be collected, and other pertinent information about acquisition. The attribute information explains the definitions of the codes and attributes that must be applied to a feature if acquired, and the source interpretation guidelines give additional information for special circumstances to help determine whether a feature should be acquired or not. Not all features have source interpretation guidelines, and if this is the case, this will be indicated with "None."

\section{Capture Conditions}

If area of complex channels contains at least five active subchannels (connected to the main channel with water in them, not scarring because of river channel migration) and is greater than or equal to 320 feet (98 meters) along the shortest axis and greater than or equal to 984 feet (300 meters) along the longest axis, then capture.

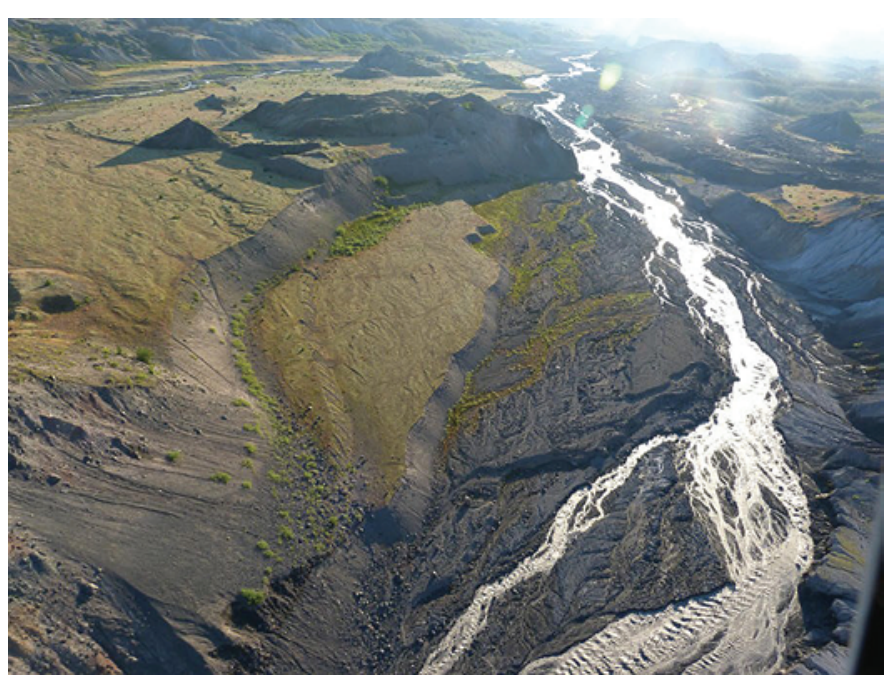

Figure 2. Toutle River, Washington, shown as an example of area of complex channels feature. Photograph by Kurt Spicer, U.S. Geological Survey.

Table 2. Area of complex channels domain codes and attributes.

[FClass, Feature Class; FCode, Feature Code; EClass, Elevation Class; --, no data]

\begin{tabular}{ccccccc}
\hline FClass & FCode & EClass & Description & Source & Method & UserCode \\
\hline 1 & 53700 & 0 & Area of complex channels & Required & Required & -- \\
\hline
\end{tabular}

Table 3. Area of complex channels representation rules.

$[--$, no data $]$

\begin{tabular}{lccc}
\hline \multicolumn{1}{c}{ Kind of feature object } & Area & Shortest axis & Longest axis \\
\hline 0-dimensional (point) & -- & -- & -- \\
1-dimensional (line) & -- & -- & -- \\
2-dimensional (polygon) & greater than 0 & -- & -- \\
\hline
\end{tabular}




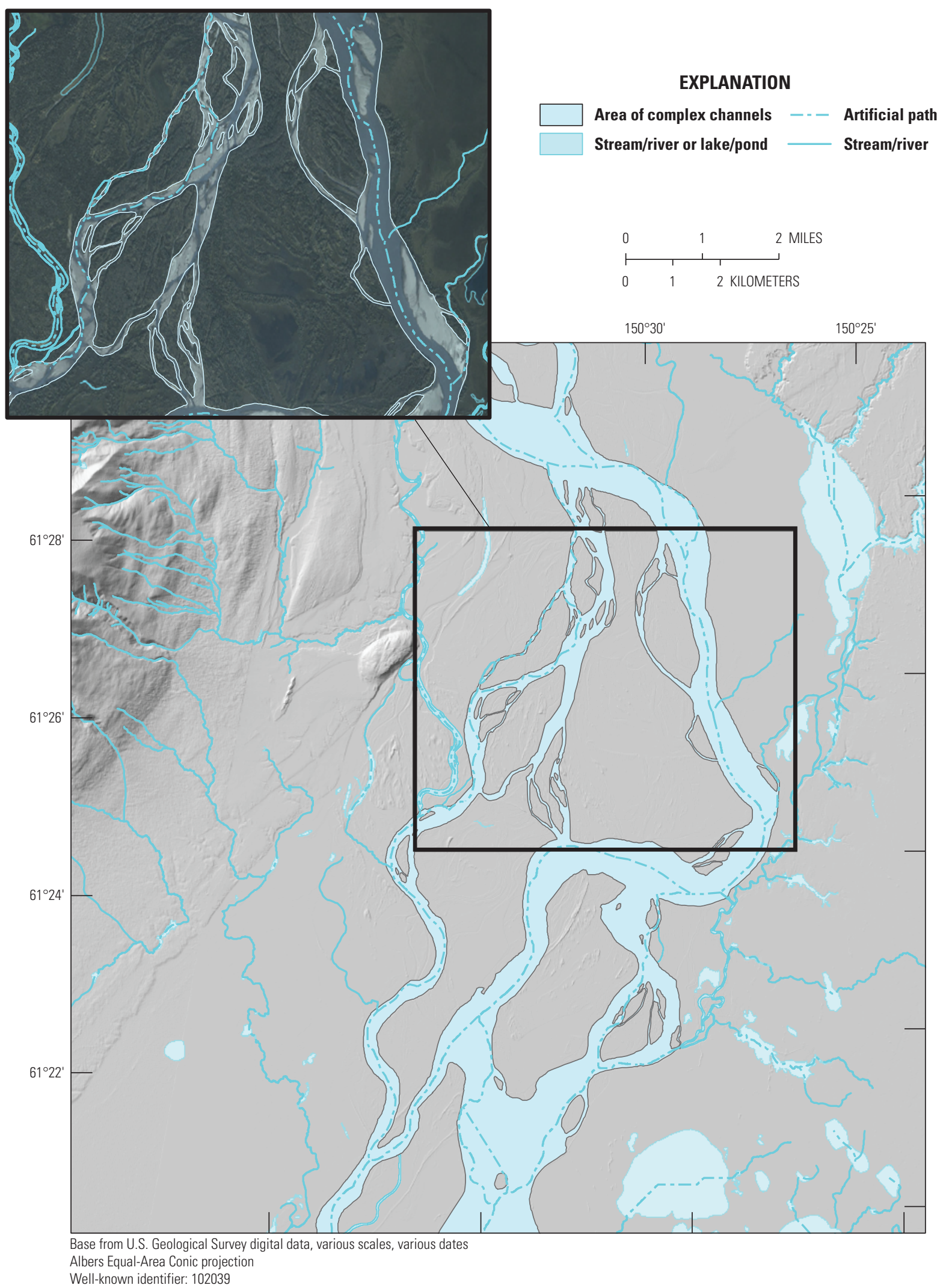

Figure 3. Example of an area of complex channels along the Susitna River in Alaska. Source data are from the National Hydrography Dataset (U.S. Geological Survey, 2020), which is used to provide examples of hydrographic feature types, but may not have the same density and other characteristics of elevation-derived hydrography. 


\section{Attribute Information}

FClass 1-NHD Feature (will be used for conflation).

FCode 53700 - Complex channel (area where a stream or river flows in an intricate network of interlacing channels).

EClass 0-Not used for elevation derivatives.

\section{Source Interpretation Guidelines}

If area of complex channels coincides with a

2-dimensional (polygon) stream/river, then capture both areas of complex channels and the other feature.

For hydroflattening, permanent islands 1 acre $(0.4$ hectare) (approximately equal to a round island 236 feet [72 meters] in diameter) or larger shall be removed from all waterbody polygons. 


\section{Artificial Path}

An abstraction to facilitate hydrologic modeling through open waterbodies (figs. 4 and 5).

\section{Attribute/Attribute Value}

Each feature requires domain codes to be entered into the attribute table for the feature class (table 4). See "Field Definitions and Domain Values for Attributes" section for more information on EDH code definitions.

\section{Delineation}

The limit of artificial path is the connection between the inflow and outflow points of an in-line polygon, the line through a head or terminal open waterbody that connects to the inflow (for terminal), or the outflow point (for head) (fig. 4).

\section{Representation Rules}

When delineating a feature, it must be created with the appropriate geometry, either point, line, or polygon, which is determined by the size of the feature or the length along different axes of the feature (table 5).

Special conditions: none.

\section{Data Extraction}

Data extraction rules fall into three categories: capture conditions, attribute information, and source interpretation guidelines. The capture conditions explain the requirements for a feature to be collected, and other pertinent information about acquisition. The attribute information explains the definitions of the codes and attributes that must be applied to a feature if acquired, and the source interpretation guidelines give additional information for special circumstances to help determine whether a feature should be acquired or not. Not all features have source interpretation guidelines, and if this is the case, this will be indicated with "None."

\section{Capture Conditions}

Artificial paths shall be placed in all polygons except isolated reservoirs, isolated lake/ponds, and isolated basins (reservoirs, lake/ponds, and basins not connected to the stream network). Artificial paths shall represent the shortest path from the inflow to the outflow without crossing through banks or islands.

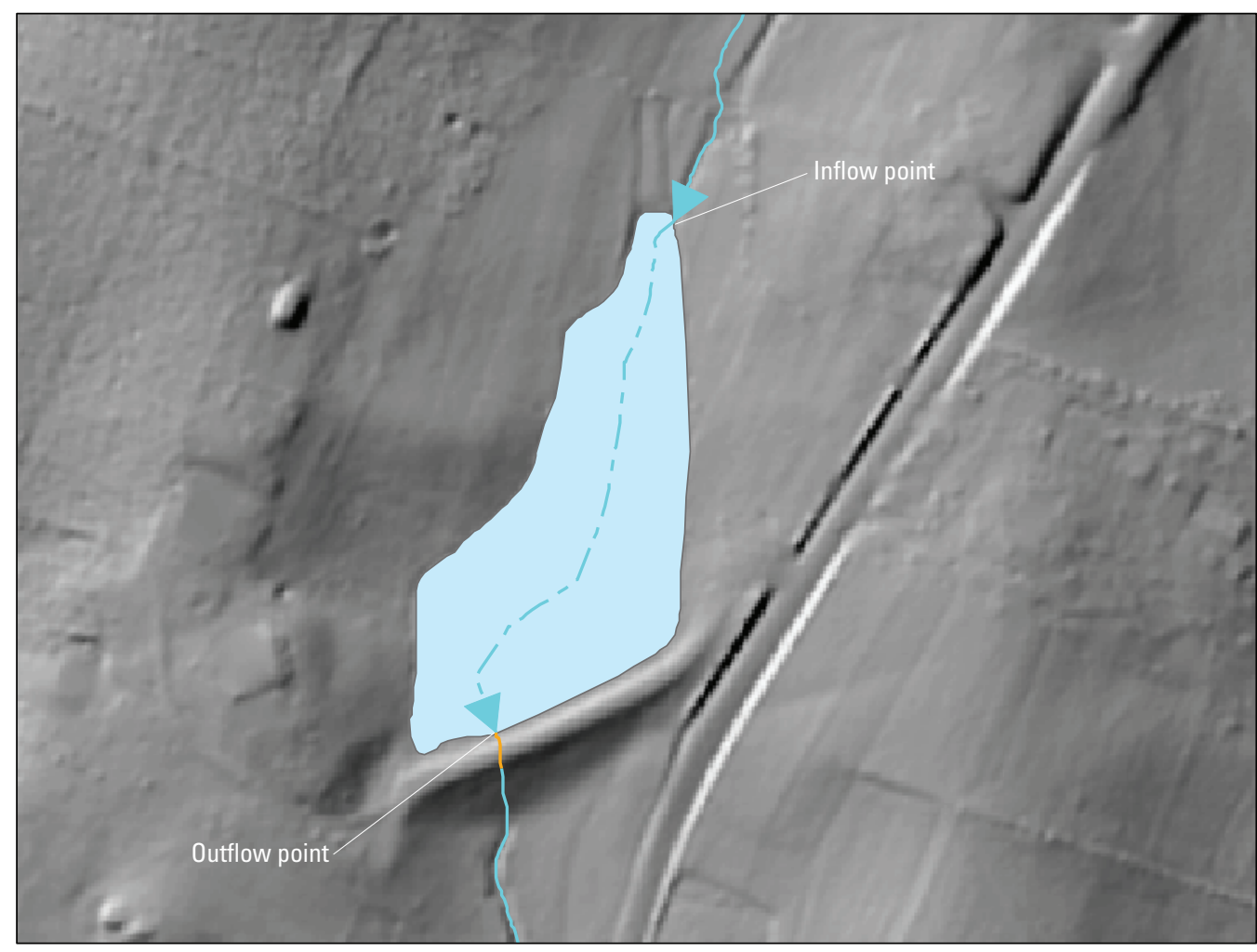

EXPLANATION

Lake/pond

Artificial path

Stream/river

Connector

Figure 4. Diagram showing inflow and outflow points of a lake/pond feature. 


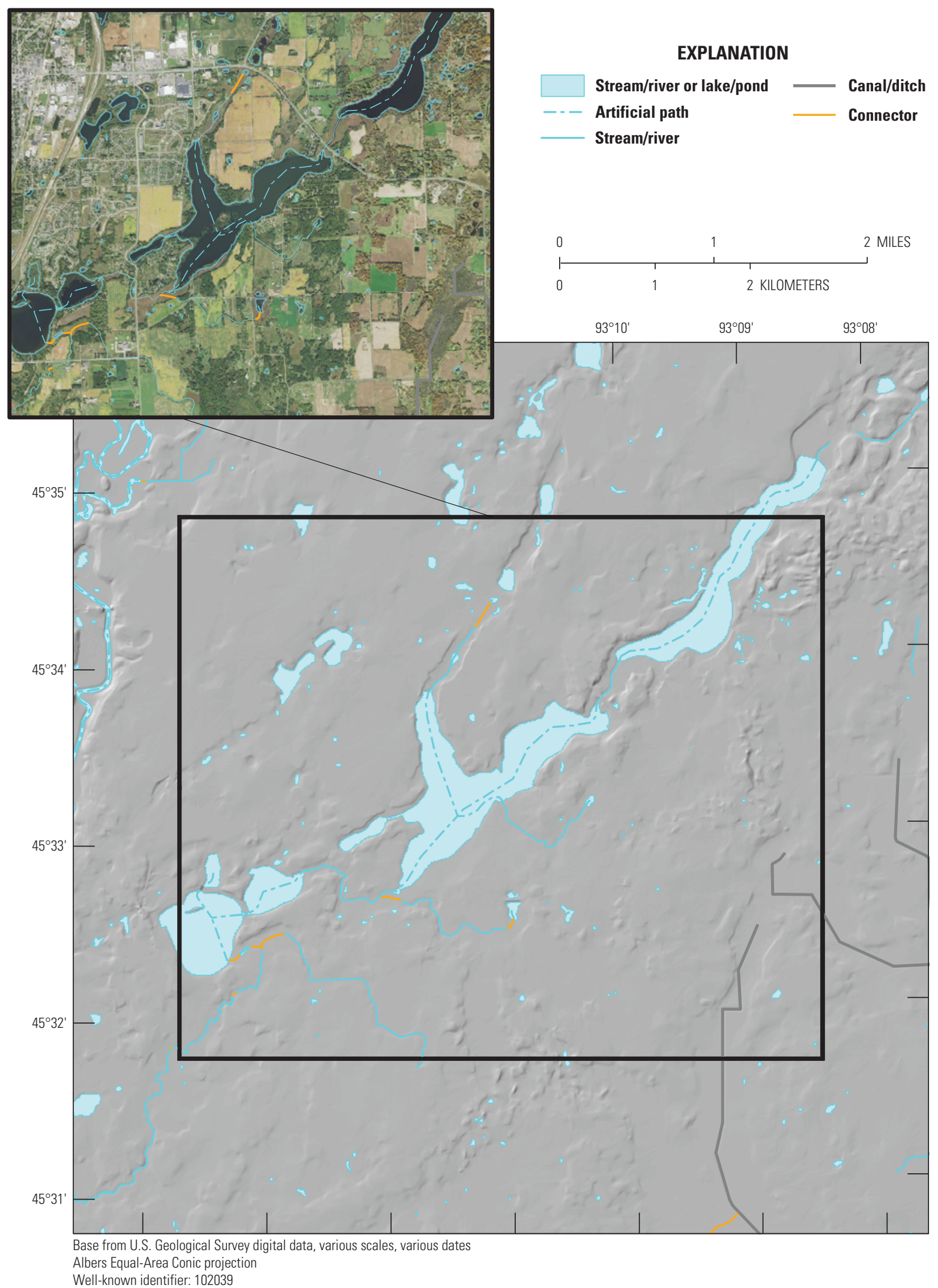

Figure 5. Example of artificial path features in Lake Fannie in Minnesota. Source data are from the National Hydrography Dataset (U.S. Geological Survey, 2020), which is used to provide examples of hydrographic feature types but may not have the same density and other characteristics of elevation-derived hydrography. 
Table 4. Artificial path domain codes and attributes.

[FClass, Feature Class; FCode, Feature Code; EClass, Elevation Class; --, no data]

\begin{tabular}{|c|c|c|c|c|c|c|}
\hline FClass & FCode & EClass & Description & Source & Method & UserCode \\
\hline 1 & 55800 & 2 & Artificial path & Required & Required & -- \\
\hline
\end{tabular}

Table 5. Artificial path representation rules.

$[--$, no data $]$

\begin{tabular}{lccc}
\hline \multicolumn{1}{c}{ Kind of feature object } & Area & Shortest axis & Longest axis \\
\hline 0-dimensional (point) & -- & -- & -- \\
1-dimensional (line) & -- & greater than 0 & -- \\
2-dimensional (polygon) & -- & -- & -- \\
\hline
\end{tabular}

\section{Attribute Information}

FClass 1-NHD Feature (will be used for conflation).

FCode 55800 - Artificial path (abstraction to facilitate hydrologic modeling through open waterbodies).

EClass 2-Hydrographic feature used for elevation purposes, other than culverts or those used for hydroflattening.

\section{Source Interpretation Guidelines}

None. 


\section{Canal/Ditch}

An artificial open waterway constructed to transport water, irrigate or drain land, connect two or more bodies of water, or serve as a waterway for watercraft (figs. 6, 7, and 8).

\section{Attribute/Attribute Value}

Each feature requires domain codes and attributes to be entered into the attribute table for the feature class (table 6). See "Field Definitions and Domain Values for Attributes" section for more information on EDH code definitions.

For canal/ditch not conforming to representation conditions, or meeting the criteria of the exceptions noted in the capture conditions, refer to information in table 6 .

For canal/ditches not conforming to representation conditions, refer to information in table 7 .

\section{Delineation}

The limit of canal/ditch is the top of the banks of the artificial waterway.

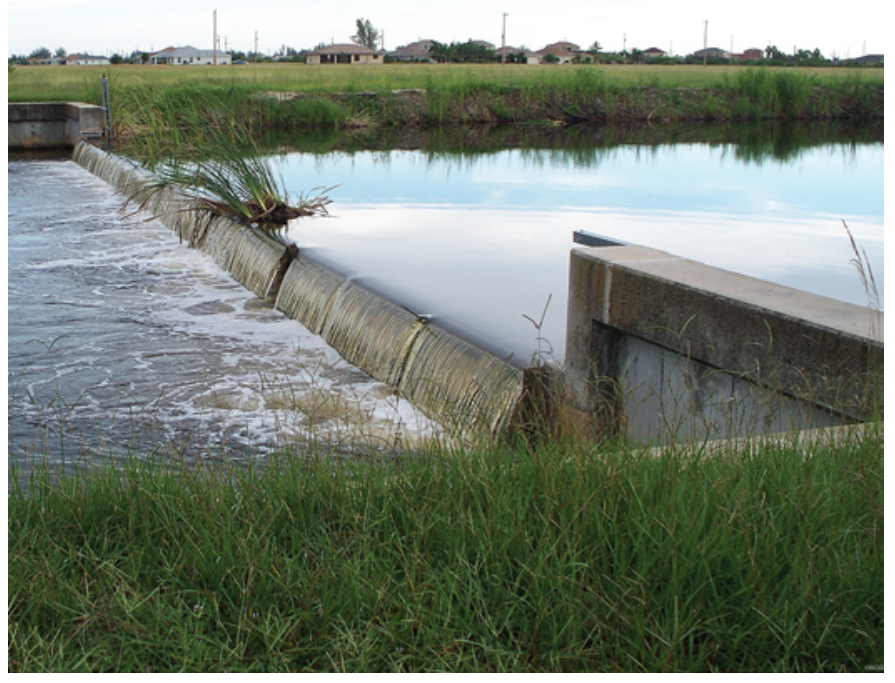

Figure 6. Shadroe Canal Weir, Cape Coral, Florida, as an example of a canal. Photograph by Shane Prorok, U.S. Geological Survey.

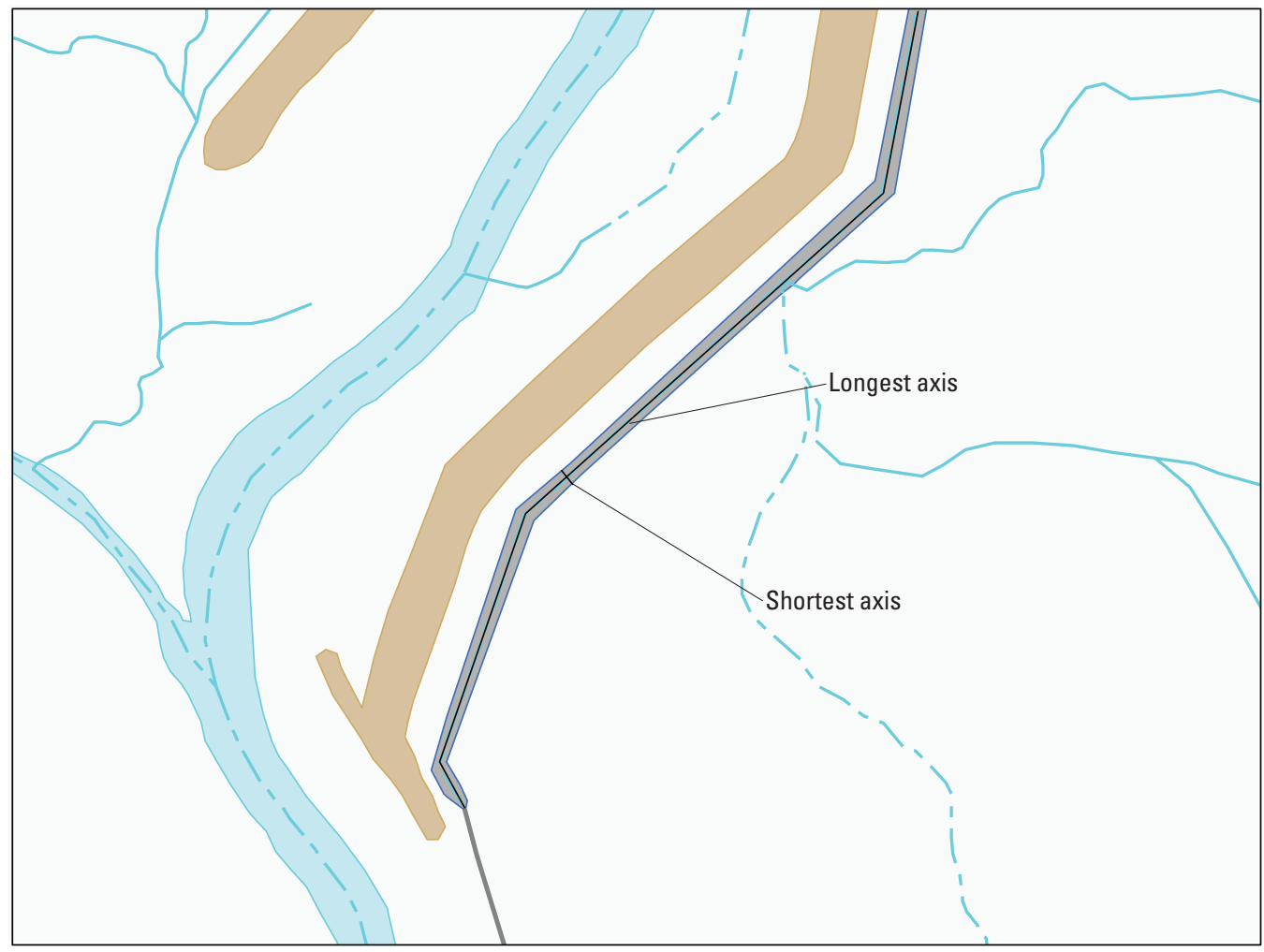

EXPLANATION

Stream/river

Levee

Canal/ditch

Artificial path

Stream/river

Canal/ditch

Figure 7. Diagram showing shortest and longest axes of a canal/ditch feature. 


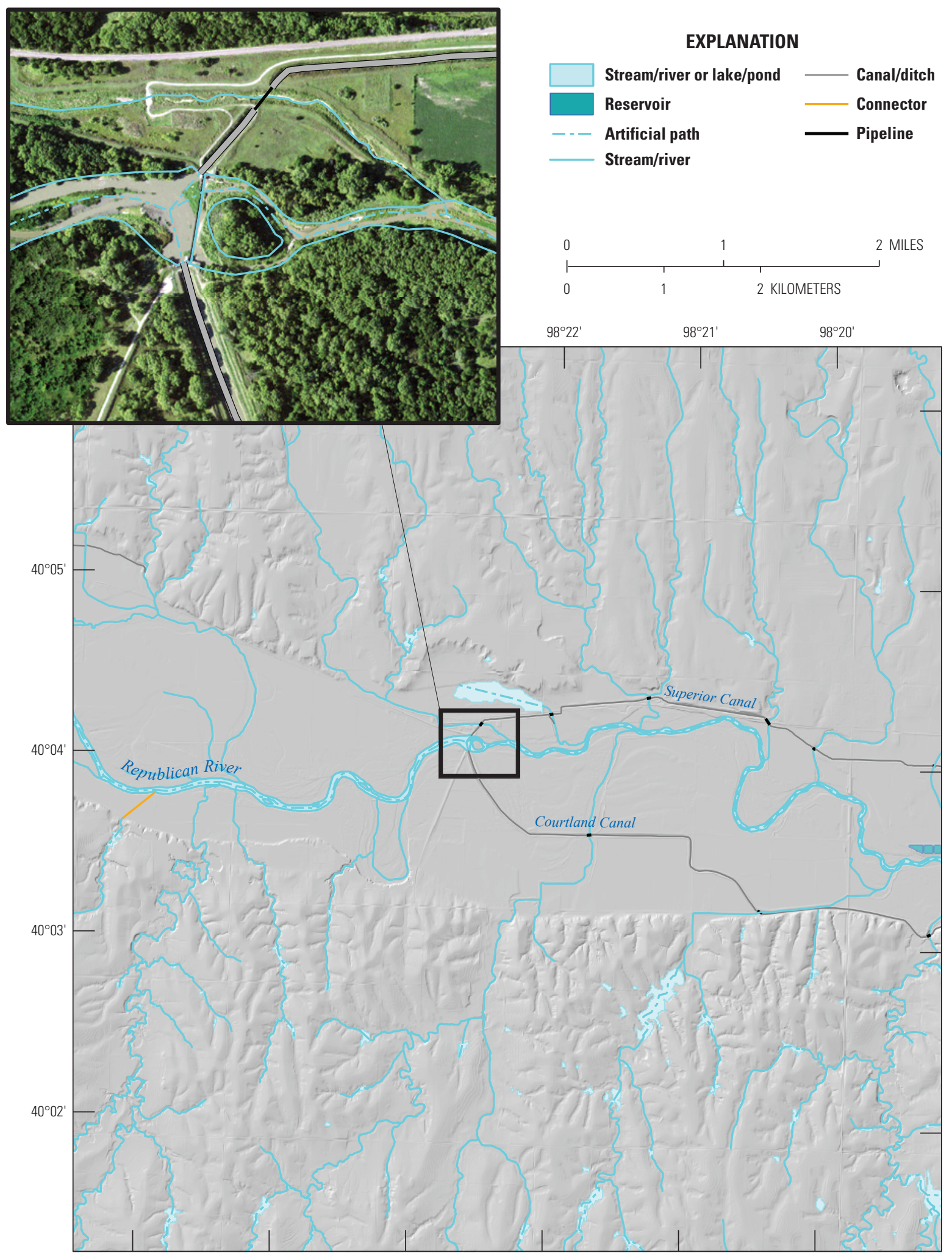

Base from U.S. Geological Survey digital data, various scales, various dates Albers Equal-Area Conic projection Well-known identifier: 102039

Figure 8. Courtland and Superior Canals near the Nebraska-Kansas Stateline, shown as examples of canal/ditch features. Source data are from the National Hydrography Dataset (U.S. Geological Survey, 2020), which is used to provide examples of hydrographic feature types, but may not have the same density and other characteristics of elevation-derived hydrography. 
Table 6. Canal/ditch domain codes and attributesfor non-National Hydrography Dataset features (outside of collection criteria) that are not used for elevation derivatives.

[FClass, Feature Class; FCode, Feature Code; EClass, Elevation Class]

\begin{tabular}{ccccccr}
\hline FClass & FCode & EClass & Description & Source & Method & UserCode \\
\hline 2 & 33600 & 0 & Canal/ditch & Required & Required & Required \\
\hline
\end{tabular}

Table 7. Canal/ditch domain codes and attributes for National Hydrography Dataset features (will be used for conflation) that are used for elevation purposes other than culverts or those used for hydroflattening.

[FClass, Feature Class; FCode, Feature Code; EClass, Elevation Class; --, no data]

\begin{tabular}{|c|c|c|c|c|c|c|}
\hline FClass & FCode & EClass & Description & Source & Method & UserCode \\
\hline 1 & 33600 & 2 & Canal/ditch & Required & Required & -- \\
\hline
\end{tabular}

\section{Representation Rules}

When delineating a feature, it must be created with the appropriate geometry, either point, line, or polygon, which is determined by the size of the feature or the length along different axes of the feature (table 8).

Special conditions:

To accommodate variations in the shortest axis of canal/ditch:

If the shortest axis (table 7) of canal/ditch is:

- less than 50 feet (15 meters) but greater than or equal to 20 feet (6 meters) for a distance less than 1 mile (1.6 kilometers), and is connected at both ends to a 2-dimensionalcanal/ditch,

then canal/ditch is represented as a 2-dimensional basic feature object.

- greater than or equal to 50 feet (15 meters) but less than 20 feet (6 meters) for a distance less than 1 mile (1.6 kilometers), or less than 20 feet (6 meters) regardless of distance, and is connected at both ends to a 2-dimensional (polygon) canal/ditch,

then canal/ditch is represented as a 1-dimensional (line) basic feature object.

Table 8. Canal/ditch representation rules.
- greater than or equal to 50 feet (15 meters) but less than 80 feet ( 24 meters) for a distance less than 1 mile (1.6 kilometers), and is connected at both ends to a 1-dimensional (line) canal/ditch,

then canal/ditch is represented as a 1 -dimensional (line) basic feature object.

- greater than or equal to 50 feet (15 meters) but less than 80 feet ( 24 meters) for a distance greater than or equal to 1 mile (1.6 kilometers), or greater than or equal to 80 feet (24 meters) regardless of distance, and is connected at both ends to a 1-dimensional (line) canal/ditch,

then canal/ditch is represented as a 2-dimensional (polygon) basic feature object.

\section{Data Extraction}

Data extraction rules fall into three categories: capture conditions, attribute information, and source interpretation guidelines. The capture conditions explain the requirements for a feature to be collected, and other pertinent information about acquisition. The attribute information explains the definitions of the codes and attributes that must be applied to a feature if acquired, and the source interpretation guidelines

$[--$, no data $]$

\begin{tabular}{lccc}
\hline \multicolumn{1}{c}{ Kind of feature object } & Area & Shortest axis & Longest axis \\
\hline 0-dimensional (point) & -- & -- & -- \\
1-dimensional (line) & -- & less than 50 feet & -- \\
& & $(15$ meters $)$ & -- \\
2-dimensional (polygon) & -- & $(15$ meters $)$ & \\
\hline
\end{tabular}


give additional information for special circumstances to help determine whether a feature should be acquired or not. Not all features have source interpretation guidelines, and if this is the case, this will be indicated with "None."

\section{Capture Conditions}

If canal/ditch is named, or

if canal/ditch is greater than or equal to 984 feet

(300 meters) along the longest axis,

then capture.

If canal/ditch is needed to provide network connectivity, then capture.

If canal/ditch is within agricultural fields and drains to

another canal/ditch or other hydrologic feature,

then do not capture (see following exception).

The exception is if a project has a special need for canals and ditch features that are within agricultural fields and drain to another canal/ditch or other hydrologic feature, then these features should be coded with a separate Fcode (user defined) so that they can be excluded from the features to conflate to NHD.

Note that a hydrologic network should not be broken if features are excluded.

\section{Attribute Information}

FClass 2-Non-NHD Feature (outside of collection criteria).

FCode 33600 — Canal/ditch (an artificial open waterway constructed to transport water, to irrigate or drain land, to connect two or more bodies of water, or to serve as a waterway for watercraft. May be a named feature).

EClass 0-Not used for elevation derivatives.

Another possibility is the following:

FClass 1-NHD Feature (will be used for conflation).

FCode 33600 — Canal/ditch (an artificial open waterway constructed to transport water, to irrigate or drain land, to connect two or more bodies of water, or to serve as a waterway for watercraft. May be a named feature).

EClass 2-Hydrographic feature used for elevation purposes, other than culverts or those used for hydroflattening.

\section{Source Interpretation Guidelines}

Do not capture underground aqueducts as canal/ditch. See "Pipeline" section.

Do not capture rivers that have been channelized to control flooding or erosion, or to maintain flow for navigation as canal/ditch. See "Stream/River" section (for example, Los Angeles River is a large channelized river, and coded as stream/river).

Do capture as canal/ditch only those inland navigation waterways that are cut through land to bypass outcrops or rapids, or to connect two bodies of water.
If a canal or ditch passes through a siphon that meets capture conditions for pipeline,

then do not capture canal/ditch. See "Pipeline" section.

Do not capture canal/ditch associated with a cranberry bog or rice paddy. 


\section{Connector}

A known, but nonspecific, connection between two nonadjacent network segments. Connector feature types are used when two constructed surface-water features appear to interact but there is no discernable evidence of the interaction on the surface. A connector is used to show the connection between the lake/pond and the stream output through a dam (figs. 9 and 10).

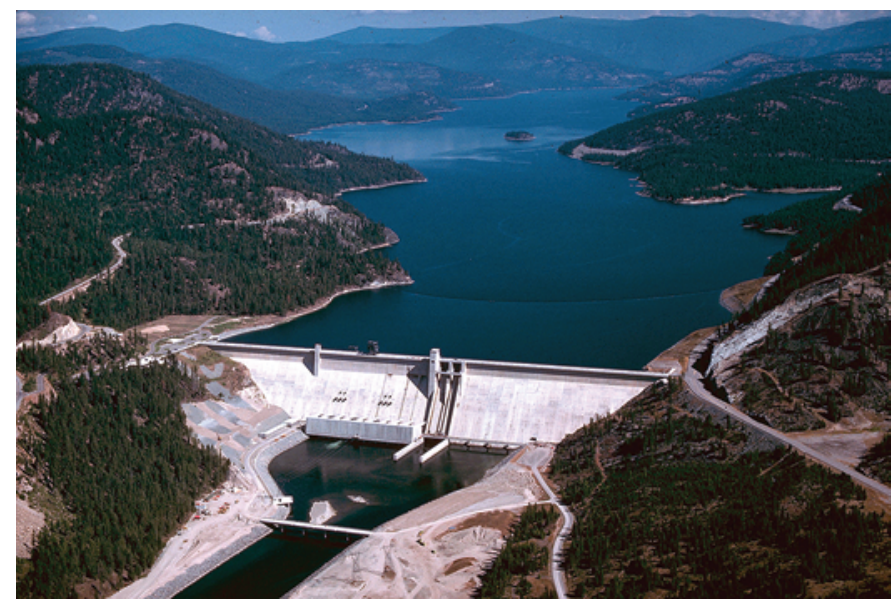

Figure 9. New Libby Dam, Kootenai River, Libby, Montana, is shown as an example of where a connector could be used to connect the flow of the river from the bottom left side of the image to the lake on the top right side of the image. Photograph by U.S. Army Corps of Engineers.

\section{Attribute/Attribute Value}

Each feature requires domain codes and attributes to be entered into the attribute table for the feature class (table 9). See "Field Definitions and Domain Values for Attributes" section for more information on EDH code definitions.

\section{Delineation}

The limit of connector is the virtual line connecting two nonadjacent network segments.

\section{Representation Rules}

When delineating a feature, it must be created with the appropriate geometry, either point, line, or polygon, which is determined by the size of the feature or the length along different axes of the feature (table 10).

Special conditions: none.

\section{Data Extraction}

Data extraction rules fall into three categories: capture conditions, attribute information, and source interpretation guidelines. The capture conditions explain the requirements for a feature to be collected, and other pertinent information about acquisition. The attribute information explains the definitions of the codes and attributes that must be applied to a feature if acquired, and the source interpretation guidelines give additional information for special circumstances to help determine whether a feature should be acquired or not. Not all features have source interpretation guidelines, and if this is the case, this will be indicated with "None."

\section{Capture Conditions}

If connector is required to maintain connectivity between two network feature objects that represent area of complex channels, canal/ditch, lake/pond, reservoir, sea/ocean, or stream/river,

then capture.

\section{Attribute Information}

FClass 1-NHD Feature (will be used for conflation).

FCode 34400 - Connector (a known, but nonspecific, invisible connection between two nonadjacent network segments).

EClass 2-Hydrographic feature used for elevation purposes, other than culverts or those used for hydroflattening.

\section{Source Interpretation Guidelines}

The following list of conditions indicates when and why the capture of connector is required:

1. When connector is part of a network that is represented as being connected.

2. When there is a gap with no collected network feature object between pieces of the network; for example, at a 2-dimensional (polygon) dam/weir that causes a gap between an upstream lake/pond and a downstream stream/river. 


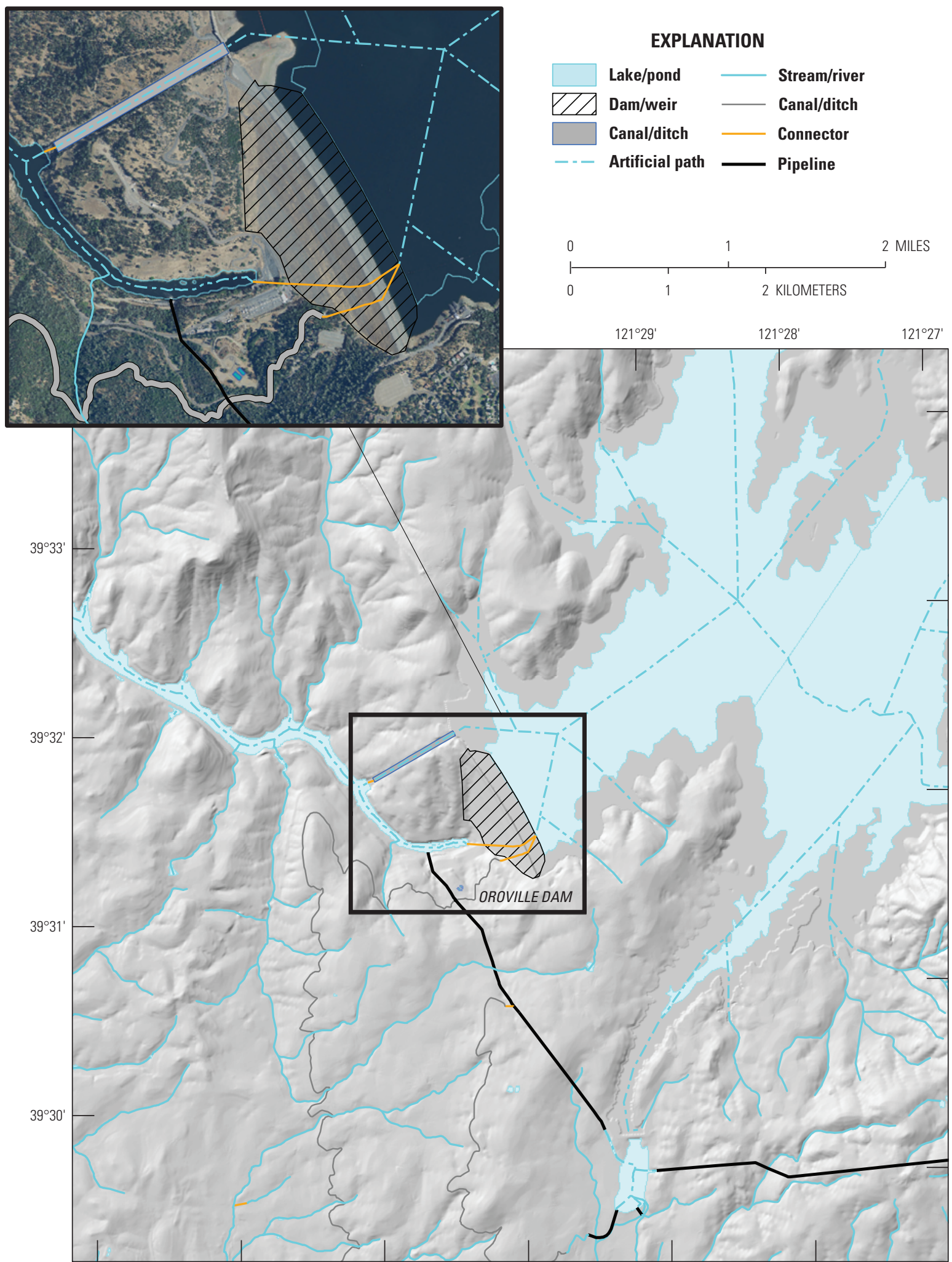

Base from U.S. Geological Survey digital data, various scales, various dates Albers Equal-Area Conic projection

Well-known identifier: 102039

Figure 10. Oroville Dam, California, is shown to provide an example of a connector hydrographic feature. Source data are from the National Hydrography Dataset (U.S. Geological Survey, 2020), which is used to provide examples of hydrographic feature types, but may not have the same density and other characteristics of elevation-derived hydrography. 
Table 9. Connector domain codes and attributes.

[FClass, Feature Class; FCode, Feature Code; EClass, Elevation Class; --, no data]

\begin{tabular}{|c|c|c|c|c|c|c|}
\hline FClass & FCode & EClass & Description & Source & Method & UserCode \\
\hline 1 & 33400 & 2 & Connector & Required & Required & -- \\
\hline
\end{tabular}

Table 10. Connector representation rules.

[--, no data]

\begin{tabular}{|c|c|c|c|}
\hline Kind of feature object & Area & Shortest axis & Longest axis \\
\hline 0-dimensional (point) & -- & -- & -- \\
\hline 1-dimensional (line) & -- & $\begin{array}{l}\text { greater than } 0 \\
\text { but less than } 50 \text { feet } \\
\text { (15 meters) }\end{array}$ & -- \\
\hline 2-dimensional (polygon) & -- & $\begin{array}{l}\text { greater than } 50 \text { feet } \\
(15 \text { meters })\end{array}$ & -- \\
\hline
\end{tabular}




\section{Culvert}

Subsurface water conveyances under a transportation feature (figs. 11 and 12).

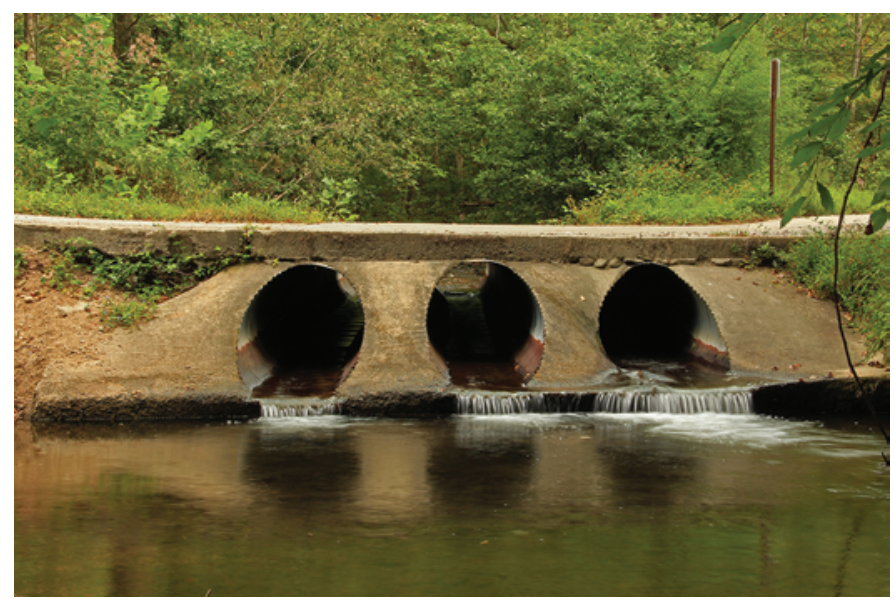

Figure 11. Example of a culvert on Town Creek, White County, Georgia. Photograph by Alan Cressler, U.S. Geological Survey.

\section{Attribute/Attribute Value}

Each feature requires domain codes and attributes to be entered into the attribute table for the feature class (table 11). See "Field Definitions and Domain Values for Attributes" section for more information on EDH code definitions.

\section{Delineation}

The limit of the culvert is the edges of the water conveyance structure. If the culvert does not extend completely across the higher elevation part of the DEM, hydroenforcement may fail at that location.

\section{Representation Rules}

When delineating a feature, it must be created with the appropriate geometry, either point, line, or polygon, which is determined by the size of the feature or the length along different axes of the feature (table 12).

Special conditions:

Culvert water conveyances may take many forms, such as a corrugated metal pipe running under a driveway, a massive concrete box under a superhighway, or a platform suspended over flowing water. The purpose of the culvert feature in the stream network is to connect the water flowing across the conveyance to the flowing water without breaking the downstream flow in the network; therefore, culvert features will be delineated as simple lines connecting the upstream and downstream segments of single-line streams or as a segment of an artificial path within 2-dimensional features.

\section{Data Extraction}

Data extraction rules fall into three categories: capture conditions, attribute information, and source interpretation guidelines. The capture conditions explain the requirements for a feature to be collected, and other pertinent information about acquisition. The attribute information explains the definitions of the codes and attributes that must be applied to a feature if acquired, and the source interpretation guidelines give additional information for special circumstances to help determine whether a feature should be acquired or not. Not all features have source interpretation guidelines, and if this is the case, this will be indicated with "None."

\section{Capture Conditions}

If the culvert is greater than 5 feet ( 1.5 meters) along the longest axis,

then capture.

\section{Attribute Information}

FClass 1-NHD Feature (will be used for conflation).

EClass 3-Culvert - Used for hydroenforcement.

FCode 0000-(See below).

The rules for determining the correct FCode for a culvert are based on a priority ranking system. When a culvert separates two or more features with different FCodes, the FCode of the culvert is selected based on the priority ranking of the features separated by the culvert (see Terziotti and Archuleta, 2020, for more information and examples).

For single feature types entering and flowing out of a culvert:

1. connector (FCode 33400),

2. pipeline (FCode 42800),

3. canal/ditch (FCode 33600),

4. stream/river (FCode 46000),

5. drainageway (FCode 46800), and

6. artificial path (FCode 55800).

If more than two features flow into and out from a culvert, the prioritization of the FCodes is ranked to maintain the connection of the primary features flowing through the culvert, as follows:

1. stream/river (FCode 46000),

2. canal/ditch (FCode 33600),

3. pipeline (FCode 428000), and

4. connector (FCode 33400).

If no feature exists on both sides of the culvert, follow the priority ranking for two features separated by a culvert. 


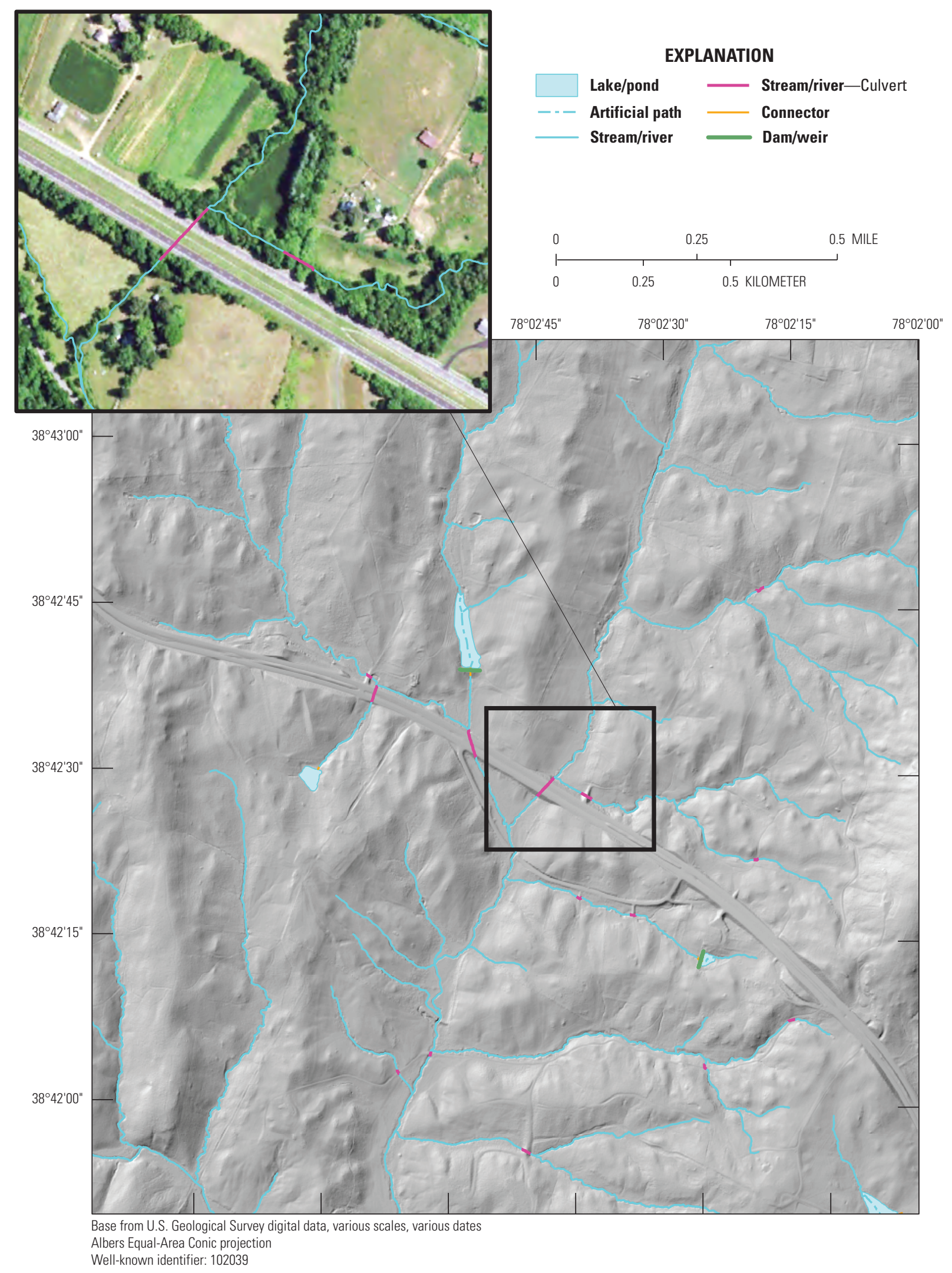

Figure 12. Highway 211 in Virginia crossing unnamed streams as examples of a culvert hydrographic feature. Source data are from the National Hydrography Dataset (U.S. Geological Survey, 2020), which is used to provide examples of hydrographic feature types but may not have the same density and other characteristics of elevation-derived hydrography. 


\section{Source Interpretation Guidelines}

None.

Table 11. Culvert domain codes and attributes.

[FClass, Feature Class; FCode, Feature Code; EClass, Elevation Class; --, no data]

\begin{tabular}{ccccccc}
\hline FClass & FCode & EClass & Description & Source & Method & UserCode \\
\hline 1 & $\begin{array}{c}\text { Dependent on connecting features } \\
\text { (see special conditions below) }\end{array}$ & 3 & $\begin{array}{c}\text { Culvert - used for } \\
\text { hydroenforcement }\end{array}$ & Required & Required & -- \\
\hline
\end{tabular}

Table 12. Culvert representation rules.

$[--$, no data $]$

\begin{tabular}{lccc}
\hline \multicolumn{1}{c}{ Kind of feature object } & Area & Shortest axis & Longest axis \\
\hline 0-dimensional (point) & -- & -- & -- \\
1-dimensional (line) & -- & greater than 0 & -- \\
2-dimensional (polygon) & -- & -- & -- \\
\hline
\end{tabular}




\section{Dam/Weir}

A barrier constructed to control the flow or raise the level of water (figs. 13 and 14).

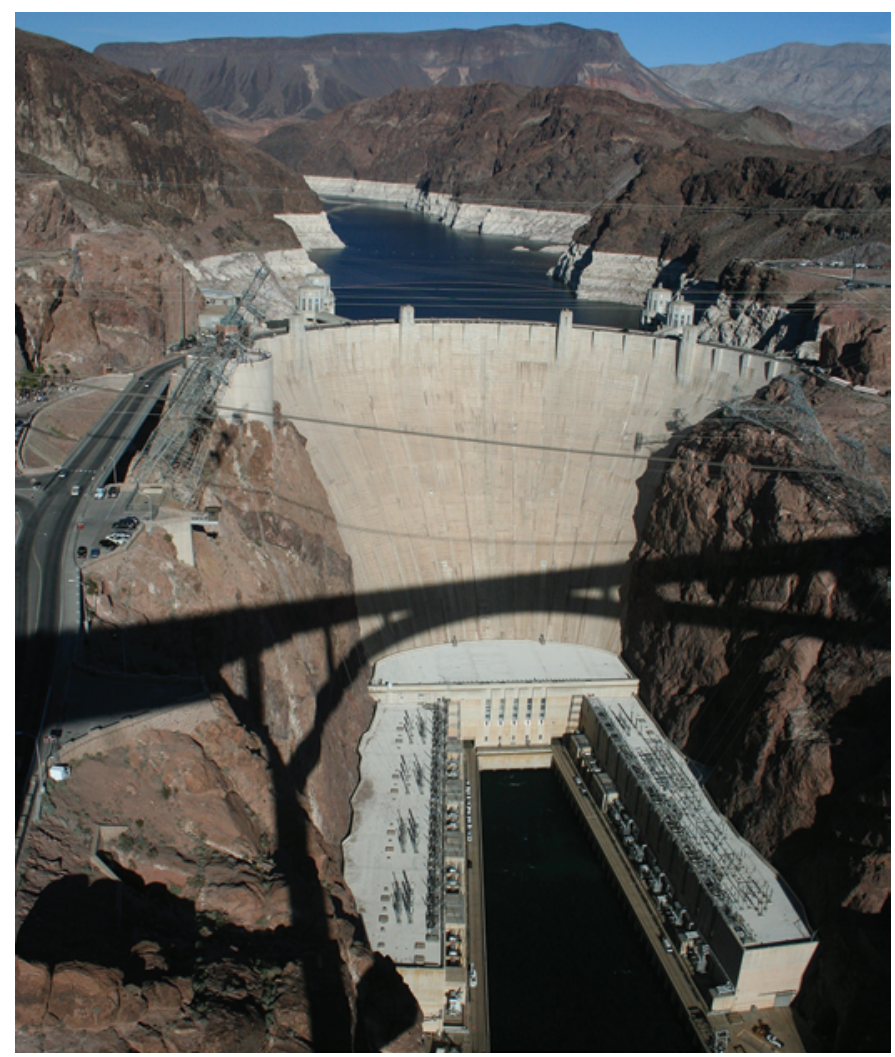

Figure 13. Hoover Dam on Lake Mead, Arizona, as an example of a dam feature. Photograph by Michael R. Rosen, U.S. Geological Survey.

\section{Attribute/Attribute Value}

Each feature requires domain codes and attributes to be entered into the attribute table for the feature class (table 13). See "Field Definitions and Domain Values for Attributes" section for more information on EDH code definitions.

Another possible option is shown in table 14.

\section{Representation Rules}

When delineating a feature, it must be created with the appropriate geometry, either point, line, or polygon, which is determined by the size of the feature or the length along different axes of the feature (table 15).

Special conditions: none.

\section{Data Extraction}

Data extraction rules fall into three categories: capture conditions, attribute information, and source interpretation guidelines. The capture conditions explain the requirements for a feature to be collected, and other pertinent information about acquisition. The attribute information explains the definitions of the codes and attributes that must be applied to a feature if acquired, and the source interpretation guidelines give additional information for special circumstances to help determine whether a feature should be acquired or not. Not all features have source interpretation guidelines, and if this is the case, this will be indicated with "None."

\section{Capture Conditions}

If dam/weir is greater than or equal to 240 feet (73 meters) along the longest axis, then capture.

\section{Attribute Information}

FClass 2-Non-NHD Feature (outside of collection criteria)

FCode 34300 - Dam/Weir (a barrier constructed to control the flow or raise the level of water. No information on the predominant construction material).

EClass 0-Not used for elevation derivatives.

Another possibility is the following:

FClass 1-NHD Feature (will be used for conflation).

FCode 34300 — Dam/weir (a barrier constructed to control the flow or raise the level of water. No information on the predominant construction material).

EClass 0-Not used for elevation derivatives.

\section{Source Interpretation Guidelines}

None. 


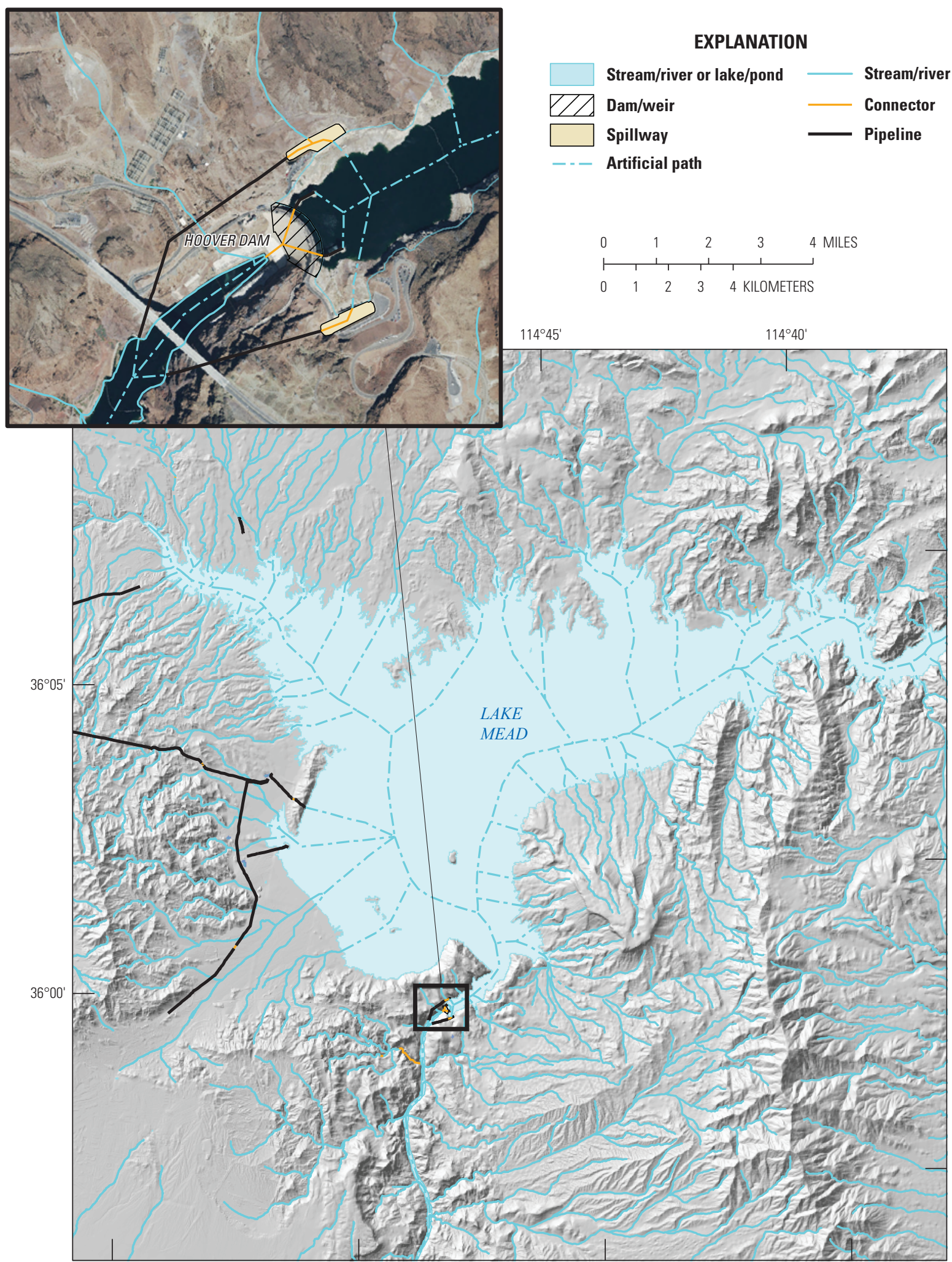

Base from U.S. Geological Survey digital data, various scales, various dates Albers Equal-Area Conic projection Well-known identifier: 102039

Figure 14. Hoover Dam on Lake Mead in Arizona, shown as an example of a dam/weir feature. Source data are from the National Hydrography Dataset (U.S. Geological Survey, 2020), which is used to provide examples of hydrographic feature types, but may not have the same density and other characteristics of elevation-derived hydrography. 
Table 13. Dam/weir domain codes and attributes for non-National Hydrography Dataset features (outside of collection criteria).

[FClass, Feature Class; FCode, Feature Code; EClass, Elevation Class]

\begin{tabular}{|c|c|c|c|c|c|c|}
\hline FClass & FCode & EClass & Description & Source & Method & UserCode \\
\hline 2 & 34300 & 0 & Dam/weir & Required & Required & Required \\
\hline
\end{tabular}

Table 14. Dam/weir domain codes and attributes for National Hydrography Dataset features (will be used for conflation). [FClass, Feature Class; FCode, Feature Code; EClass, Elevation Class; --, no data]

\begin{tabular}{|c|c|c|c|c|c|c|}
\hline FClass & FCode & EClass & Description & Source & Method & UserCode \\
\hline 1 & 34300 & 0 & Dam/weir & Required & Required & -- \\
\hline
\end{tabular}

Table 15. Dam/weir representation rules.

$[--$, no data $]$

\begin{tabular}{lccc}
\hline \multicolumn{1}{c}{ Kind of feature object } & Area & Shortest axis & Longest axis \\
\hline 0-dimensional (point) & -- & less than 40 feet \\
(for use on lines) & -- \\
1-dimensional (line) & -- & less than 40 feet & (for use on polygon \\
& & waterbody features) & - \\
2-dimensional (polygon) & -- & greater than 40 feet & (for use on polygon \\
& & waterbody features) \\
\hline
\end{tabular}




\section{Drainageway}

A watercourse that conveys or is likely to convey water but lacks a clearly defined channel or banks differentiating it from an ephemeral stream/river. Drainageways typically convey water for limited periods of time and do not carry perennial flow except when flow is the result of contributions from constructed subsurface or other human-induced drainage (for example, foundation drains or storm drains that intercept groundwater). Drainageways may follow natural topographic flow paths or be the results of human-made flow paths.

\section{Attribute/Attribute Value}

Each feature requires domain codes and attributes to be entered into the attribute table for the feature class (tables 16 and 17). See "Field Definitions and Domain Values for Attributes" section for more information on EDH code definitions.

Another possible option is shown in table 17.

\section{Delineation}

The limit of a drainageway is the topographic flowpath or the approximate overland flow path between two disconnected drainage network features. May be determined by modelling techniques, but a clearly defined channel may not be easily recognized.

\section{Representation Rules}

When delineating a feature, it must be created with the appropriate geometry, either point, line, or polygon, which is determined by the size of the feature or the length along different axes of the feature (table 18).

Special conditions: none.

To accommodate variations in the shortest axis of drainageway:

FOR EDH: If shortest axis of drainageway is

less than 20 feet (6 meters) regardless of distance, and is connected at both ends to a 2-dimensional (polygon) stream/river,

then drainageway is represented as a 1-dimensional (line) basic feature object.
If shortest axis of drainageway is greater than or equal to 50 feet (15 meters) and does not meet drainageway criteria, collect as appropriate feature for capture conditions (stream/ river, area of complex channels, playa, and others as needed).

\section{Data Extraction}

Data extraction rules fall into three categories: capture conditions, attribute information, and source interpretation guidelines. The capture conditions explain the requirements for a feature to be collected, and other pertinent information about acquisition. The attribute information explains the definitions of the codes and attributes that must be applied to a feature if acquired, and the source interpretation guidelines give additional information for special circumstances to help determine whether a feature should be acquired or not. Not all features have source interpretation guidelines, and if this is the case, this will be indicated with "None."

\section{Capture Conditions}

Drainageways have no clearly defined capture conditions. Modelling techniques (flow models, elevation surface models, logistic regression models, and so on) expose features and, therefore, require further investigation to determine their status and categorization as hydrographic features.

\section{Attribute Information}

FClass 1-NHD Feature (will be used for conflation). FCode 46800 - Drainageway (a flowpath without a clearly defined channel).

EClass 2-Hydrographic feature used for elevation purposes, other than culverts or those used for hydroflattening.

Another possibility is the following:

FClass 1-NHD Feature (will be used for conflation).

FCode 46800 - Drainageway (a flowpath without a clearly defined channel).

EClass $0-$ Not used for elevation derivatives. 
Table 16. Drainageway domain codes and attributes-feature is appropriate for use in hydroenforcement.

[FClass, Feature Class; FCode, Feature Code; EClass, Elevation Class; --, no data]

\begin{tabular}{ccccccc}
\hline FClass & FCode & EClass & Description & Source & Method & UserCode \\
\hline 1 & 46800 & 2 & Drainageway & Required & Required & -- \\
\hline
\end{tabular}

Table 17. Drainageway domain codes and attributes—-feature should not be used for hydroenforcement.

[FClass, Feature Class; FCode, Feature Code; EClass, Elevation Class; --, no data]

\begin{tabular}{ccccccc}
\hline FClass & FCode & EClass & Description & Source & Method & UserCode \\
\hline 1 & 46800 & 0 & Drainageway & Required & Required & -- \\
\hline
\end{tabular}

Table 18. Drainageway representation rules.

$[--$, no data $]$

\begin{tabular}{lccc}
\hline \multicolumn{1}{c}{ Kind of feature object } & Area & Shortest axis & Longest axis \\
\hline 0-dimensional (point) & -- & -- & -- \\
1-dimensional (line) & -- & greater than 0 & -- \\
2-dimensional (polygon) & -- & -- & -- \\
\hline
\end{tabular}




\section{Ice Mass}

A field of ice formed in regions of perennial frost (figs. 15 and 16).

\section{Attribute/Attribute Value}

Each feature requires domain codes to be entered into the attribute table for the feature class (table 19). See "Field Definitions and Domain Values for Attributes" section for more information on EDH code definitions.

\section{Delineation}

The limit of ice mass is the extent of ice or snow.

\section{Representation Rules}

When delineating a feature, it must be created with the appropriate geometry, either point, line, or polygon, which is determined by the size of the feature or the length along different axes of the feature (table 20).

Special conditions: none.

\section{Data Extraction}

Data extraction rules fall into three categories: capture conditions, attribute information, and source interpretation guidelines. The capture conditions explain the requirements for a feature to be collected, and other pertinent information about acquisition. The attribute information explains the definitions of the codes and attributes that must be applied to a feature if acquired, and the source interpretation guidelines give additional information for special circumstances to help determine whether a feature should be acquired or not. Not all features have source interpretation guidelines, and if this is the case, this will be indicated with "None."

\section{Capture Conditions}

If ice mass is greater than or equal to 246 feet along the shortest axis (or approximately 75 meters), then capture.

Z-values (elevation values at a particular location) are measured at the boundary of the feature.

\section{Attribute Information}

FClass 1-NHD Feature (will be used for conflation).

FCode 37800 - Ice mass (a field of ice usually formed in regions of perennial frost. Ice Mass primarily consists of glaciers).

EClass 0 - Not used for elevation derivatives.

\section{Source Interpretation Guidelines}

None.

If glaciers are contiguous,

then the dividing line is the approximate line of divergence or confluence, as determined by the topography of the ice masses, or by the changes in color or texture, or both.

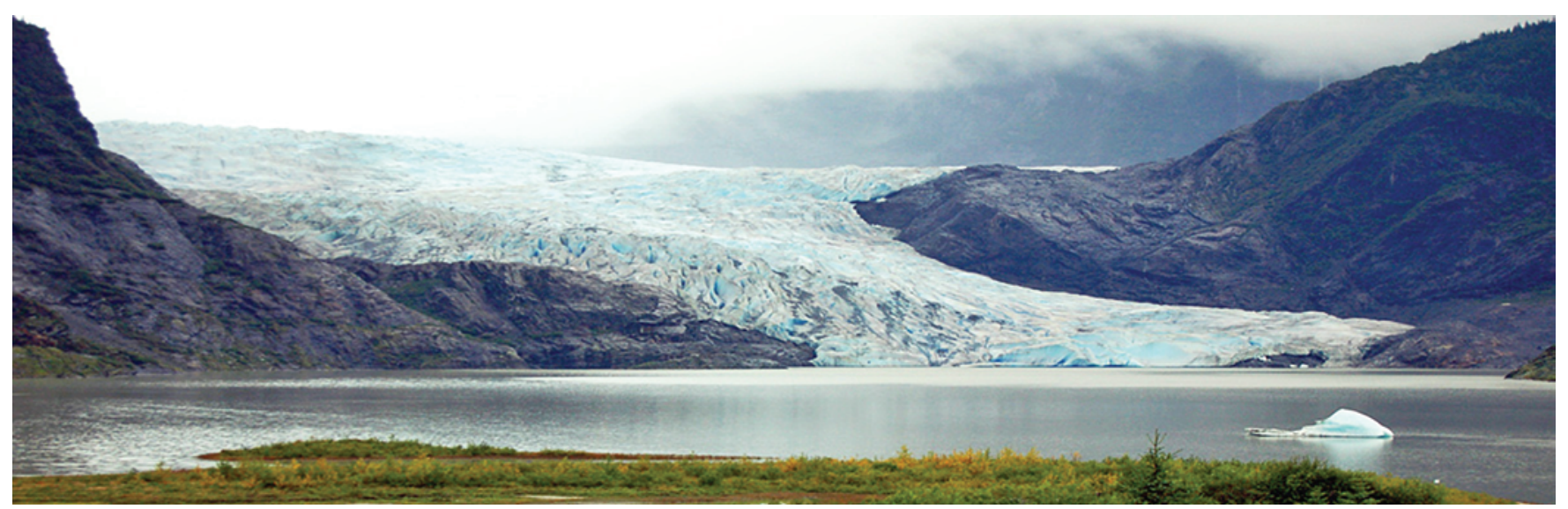

Figure 15. Mendenhall Glacier, Alaska, shown as an example of ice mass feature type. Photograph by Matt Artz, U.S. Geological Survey. 


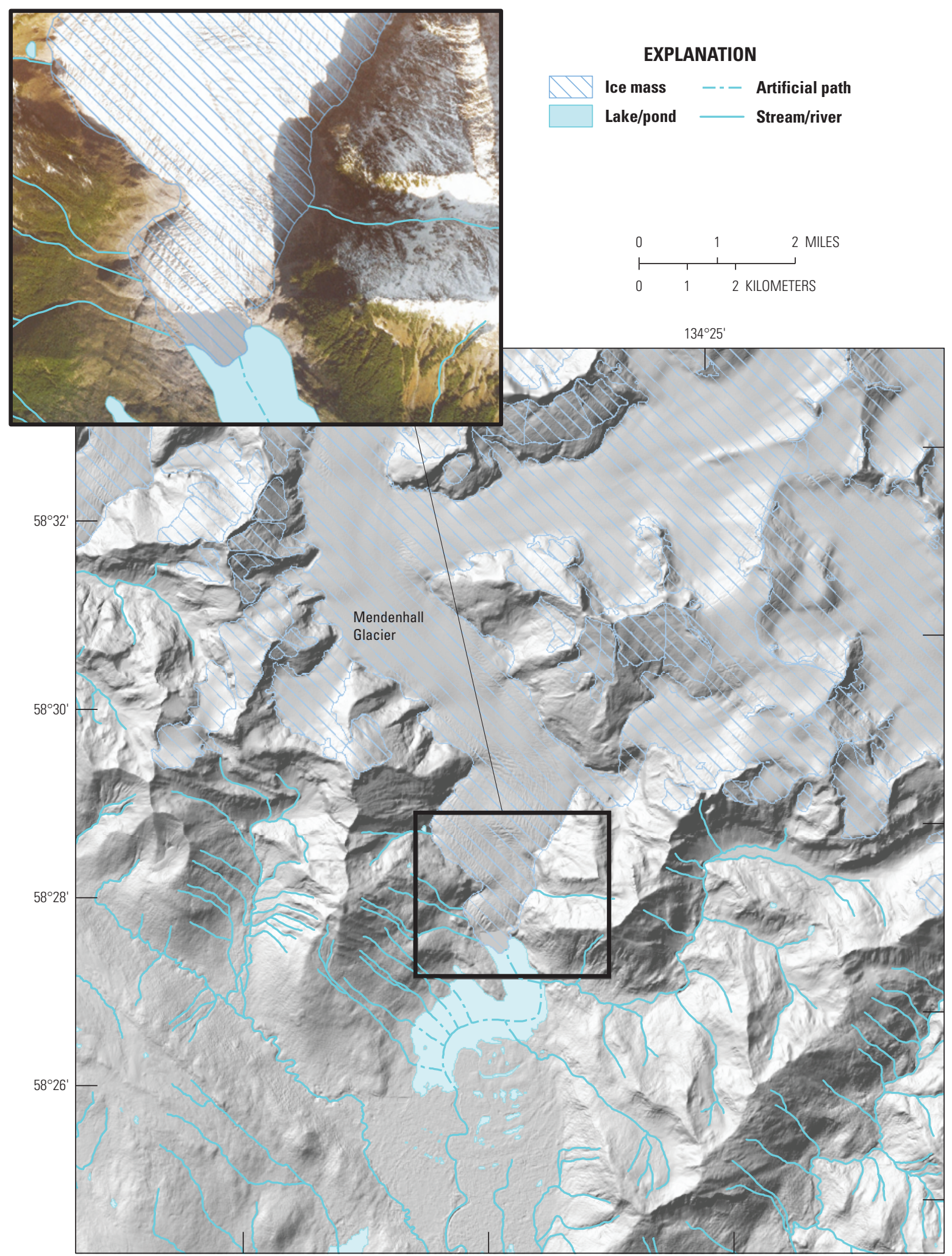

Base from U.S. Geological Survey digital data, various scales, various dates Albers Equal-Area Conic projection Well-known identifier: 102039

Figure 16. Mendenhall Glacier in Alaska is shown as an example of an ice mass feature. Source data are from the National Hydrography Dataset (U.S. Geological Survey, 2020), which is used to provide examples of hydrographic feature types, but may not have the same density and other characteristics of elevation-derived hydrography. 
Table 19. Ice mass domain codes and attributes.

[FClass, Feature Class; FCode, Feature Code; EClass, Elevation Class; --, no data]

\begin{tabular}{cccccccc}
\hline FClass & FCode & EClass & & Description & Source & Method & UserCode \\
\hline 1 & 37800 & 0 & Ice mass & Required & Required & -- \\
\hline
\end{tabular}

Table 20. Ice mass representation rules.

[--, no data]

\begin{tabular}{lccc}
\hline \multicolumn{1}{c}{ Kind of feature object } & Area & Shortest axis & Longest axis \\
\hline 0-dimensional (point) & -- & -- & -- \\
1-dimensional (line) & -- & -- & -- \\
2-dimensional (polygon) & greater than 0 & -- & -- \\
\hline
\end{tabular}




\section{Lake/Pond}

A standing body of water with a predominantly natural shoreline surrounded by land (figs. 17 and 18).

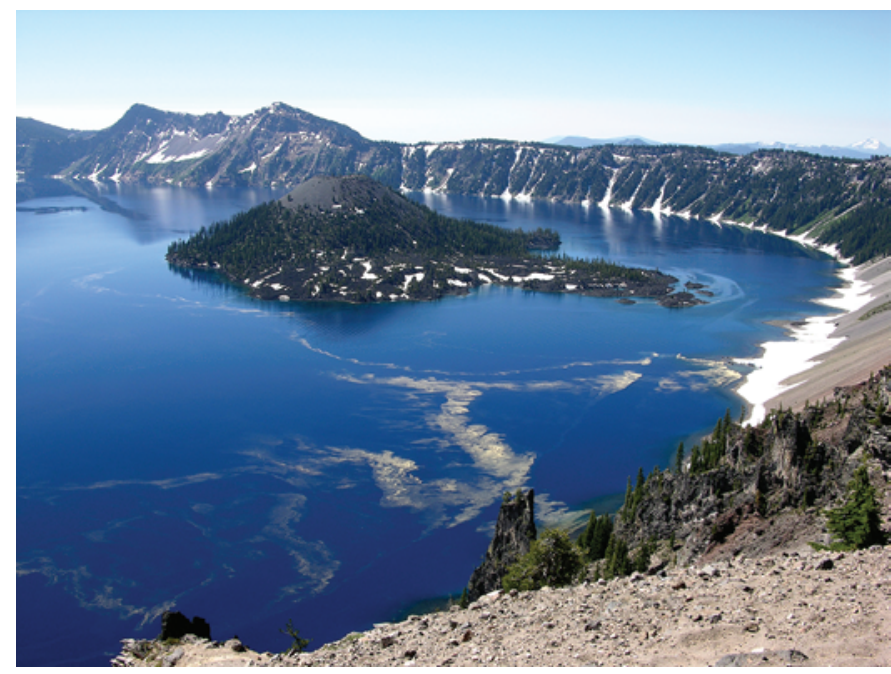

Figure 17. Crater Lake, Oregon, shown as an example of a lake/ pond feature. Photograph by Willie Scott, U.S. Geological Survey.

\section{Attribute/Attribute Value}

Each feature requires domain codes to be entered into the attribute table for the feature class (table 21). See "Field Definitions and Domain Values for Attributes" section for more information on EDH code definitions.

\section{Delineation}

The limit of lake/pond where stream/river enters or leaves is determined by the conformation of the land.

The limit of lake/pond is the position of the visible edge of the waterbody (date of lidar collection).

\section{Representation Rules}

When delineating a feature, it must be created with the appropriate geometry, either point, line, or polygon, which is determined by the size of the feature or the length along different axes of the feature (table 22).

Special conditions: none.

\section{Data Extraction}

Data extraction rules fall into three categories: capture conditions, attribute information, and source interpretation guidelines. The capture conditions explain the requirements for a feature to be collected, and other pertinent information about acquisition. The attribute information explains the definitions of the codes and attributes that must be applied to a feature if acquired, and the source interpretation guidelines give additional information for special circumstances to help determine whether a feature should be acquired or not. Not all features have source interpretation guidelines, and if this is the case, this will be indicated with "None."

\section{Capture Conditions}

For required lidar base specification breakline acquisition, waterbodies with a surface area of 2 acres ( 0.8 hectare) or greater (approximately equal to a round pond 328 feet [100 meters] in diameter) at the time of collection shall be flattened.

For EDH feature collection, if lake/pond is greater than or equal to 100 feet (30 meters) along the shortest axis (or approximately 0.1 hectare), then capture (for required hydroflattening breaklines, not applicable).

\section{Attribute Information}

FClass 1-NHD Feature (will be used for conflation).

FCode 39000 - Lake/pond (a standing body of water with a predominantly natural shoreline surrounded by land or a flooded river system where a dam has been built to withhold water).

EClass 1-Use for hydroflattening (3-dimensional polygon).

\section{Source Interpretation Guidelines}

Do not capture dry lakes as lake/pond. See "Playa" section.

Refer to the feature definition to decide how to categorize a given feature instance. Do not use the proper name of the feature as a guide. Many features that are known as "Reservoirs" or labeled on the topographic map as "Reservoirs" will be captured as lake/pond. "Stock Tanks" may be reservoir or lake/pond depending on their form. As a general rule, if a waterbody has a geometric shape or other information indicates it is contained by a constructed basin, capture it as reservoir. If it does not appear to be contained by a constructed basin, capture it as lake/pond.

The minimum size for islands within lake/pond is 60 feet (18 meters) along the shortest axis.

For lidar base specification hydroflattening, permanent islands 1 acre ( 0.4 hectare) (approximately equal to a round island 236 feet [72 meters] in diameter) or larger shall be delineated within all waterbodies and excluded from hydroflattening.

For examples of islands and intermittently submerged islands that may be apparent on elevation surface, see "Additional Elevation-Derived Hydrography Treatments and Elevation Specific Features" section. 
A

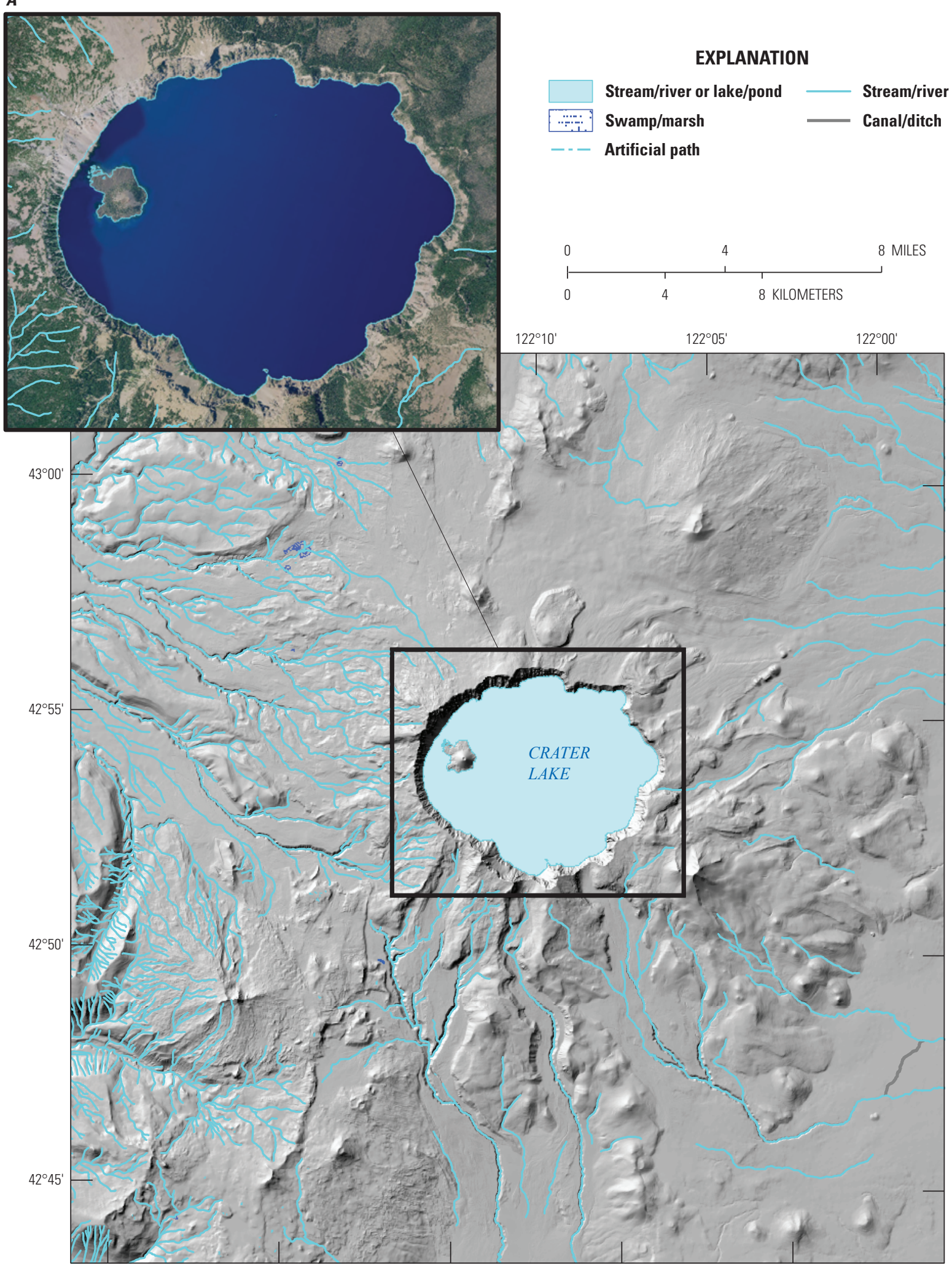

Base from U.S. Geological Survey digital data, various scales, various dates Albers Equal-Area Conic projection

Figure 18. Examples of natural lake/pond feature. A, Crater Lake on Mount Mazama, Oregon, is shown as an example of natural lake/pond feature. $B$, North Fork Reservoir, North Carolina, is shown as an example of constructed lake/pond feature. Source data are from the National Hydrography Dataset (U.S. Geological Survey, 2020), which is used to provide examples of hydrographic feature types, but may not have the same density and other characteristics of elevation-derived hydrography. 
B

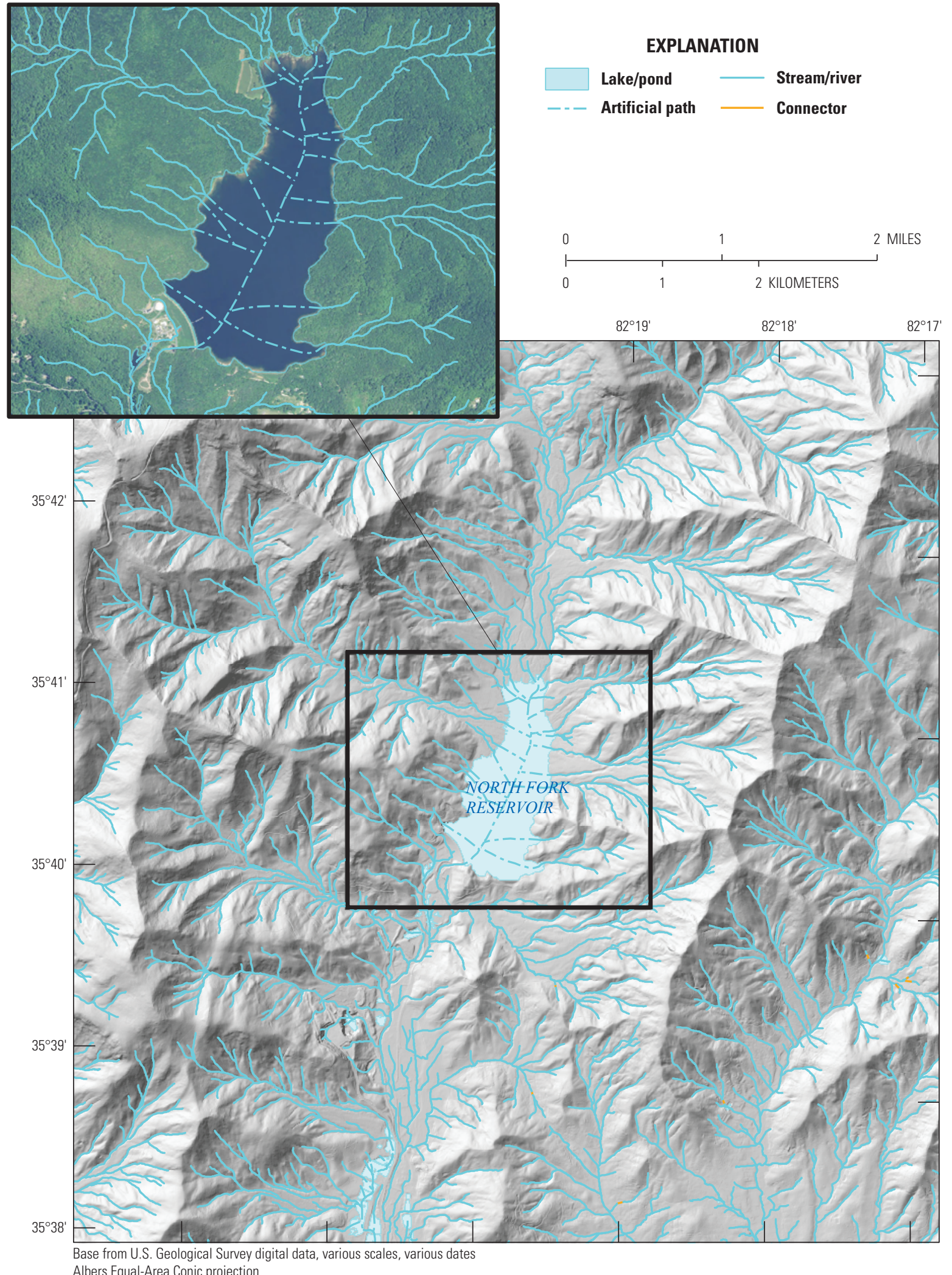

Figure 18. Examples of natural lake/pond feature. A, Crater Lake on Mount Mazama, Oregon, is shown as an example of natural lake/pond feature. $B$, North Fork Reservoir, North Carolina, is shown as an example of constructed lake/pond feature. Source data are from the National Hydrography Dataset (U.S. Geological Survey, 2020), which is used to provide examples of hydrographic feature types, but may not have the same density and other characteristics of elevation-derived hydrography.-Continued 
Table 21. Lake/pond domain codes and attributes.

[FClass, Feature Class; FCode, Feature Code; EClass, Elevation Class; --, no data]

\begin{tabular}{ccccccc}
\hline FClass & FCode & EClass & Description & Source & Method & UserCode \\
\hline 1 & 39000 & 1 & Lake/pond & Required & Required & -- \\
\hline
\end{tabular}

Table 22. Lake/pond representation rules.

$[--$, no data $]$

\begin{tabular}{lccc}
\hline \multicolumn{1}{c}{ Kind of feature object } & Area & Shortest axis & Longest axis \\
\hline 0-dimensional (point) & -- & -- & -- \\
1-dimensional (line) & -- & -- & -- \\
2-dimensional (polygon) & greater than 0 & -- & -- \\
\hline
\end{tabular}




\section{Pipeline}

A surface or subsurface, closed or open, constructed conduit for conveying water (figs. 19 and 20).

\section{Attribute/Attribute Value}

Each feature requires domain codes to be entered into the attribute table for the feature class (table 23). See "Field Definitions and Domain Values for Attributes" section for more information on EDH code definitions.

Another possible option is shown in table 24 .

\section{Delineation}

The limit of an underground pipeline is the edge of the ground scars or linear clearings, or other above ground artifacts that can be detected from ancillary data or other methods.

The limit of a near-ground or elevated pipeline is the extent of the structure.

\section{Representation Rules}

When delineating a feature, it must be created with the appropriate geometry, either point, line, or polygon, which is determined by the size of the feature or the length along different axes of the feature (table 25).

Special conditions: none.

\section{Data Extraction}

Data extraction rules fall into three categories: capture conditions, attribute information, and source interpretation guidelines. The capture conditions explain the requirements for a feature to be collected, and other pertinent information about acquisition. The attribute information explains the definitions of the codes and attributes that must be applied to a feature if acquired, and the source interpretation guidelines give additional information for special circumstances to help determine whether a feature should be acquired or not. Not all features have source interpretation guidelines, and if this is the case, this will be indicated with "None."

\section{Capture Conditions}

If pipeline conveys water between natural water features such as stream/river or lake/pond features, is above ground, is not underwater, and is greater than or equal to 5 feet (1.5 meters) along the longest axis,

then capture.

Note that the pipeline must connect to existing water features or water conveyance on both ends.

If pipeline conveys water underground, and the pipeline is greater than 50 feet in length, then capture.

Note that the only required pipelines to capture are those that are above ground, but if an ancillary source is used, an underground pipeline can be added to connect above ground features. Source of the ancillary data must be cited.

If pipeline conveys water under a road, and the road is less than 50 feet in width, then capture as a culvert (add EClass of 3) see culvert description for FCode, and not as pipeline.

\section{Attribute Information}

FClass 1-NHD Feature (will be used for conflation). FCode 42800-Pipeline (a closed conduit, with pumps, valves and control devices, for conveying water).

EClass 0 - Not used for elevation derivatives.

OR

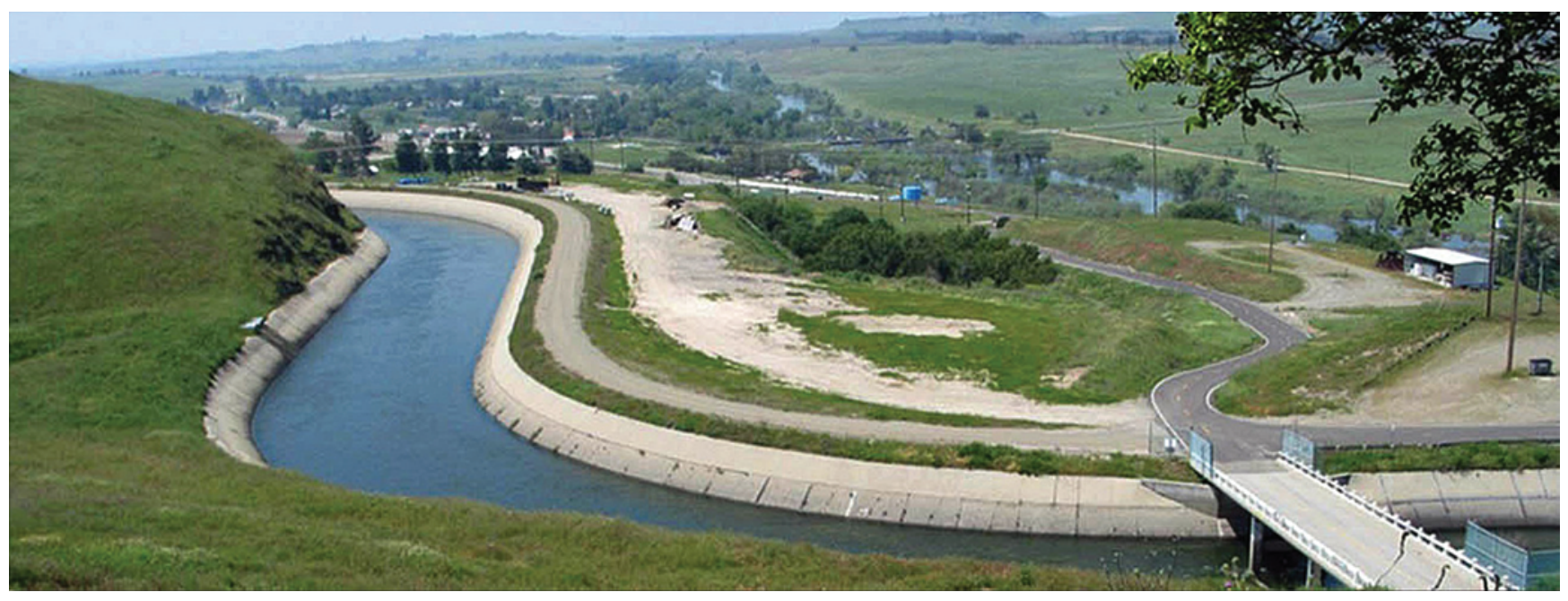

Figure 19. Example of a pipeline feature. This example of a pipeline is an aqueduct pipeline feature in San Juaquin Valley, California. Photograph by U.S. Geological Survey. 


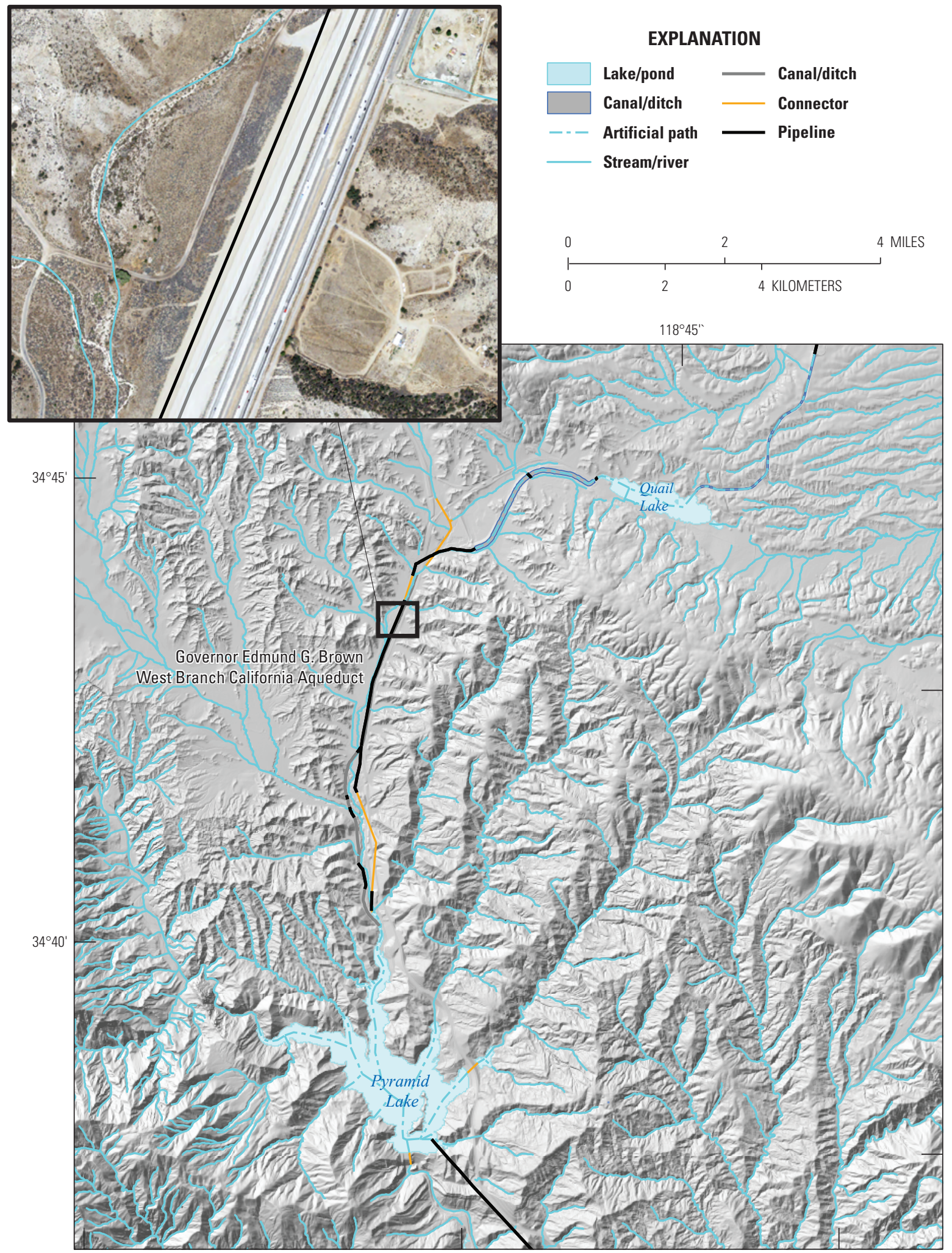

Base from U.S. Geological Survey digital data, various scales, various dates Albers Equal-Area Conic projection

Well-known identifier: 102039

Figure 20. The various pipelines that form the Governor Edmund G. Brown West Branch California Aqueduct are shown as an example of pipeline features. Source data are from the National Hydrography Dataset (U.S. Geological Survey, 2020), which is used to provide examples of hydrographic feature types, but may not have the same density and other characteristics of elevation-derived hydrography. 


\section{Elevation-Derived Hydrography—Representation, Extraction, Attribution, and Delineation Rules}

FClass 1-NHD Feature (will be used for conflation).

FCode 42800 - Pipeline (a closed conduit, with pumps, valves and control devices, for conveying water).

EClass 2-Hydrographic feature used for elevation purposes, other than culverts or those used for hydroflattening.

\section{Source Interpretation Guidelines}

None.

Table 23. Pipeline domain codes and attributes-feature should not be used for hydroenforcement.

[FClass, Feature Class; FCode, Feature Code; EClass, Elevation Class; --, no data]

\begin{tabular}{|c|c|c|c|c|c|c|}
\hline FClass & FCode & EClass & Description & Source & Method & UserCode \\
\hline 1 & 42800 & 0 & Pipeline & Required & Required & -- \\
\hline
\end{tabular}

Table 24. Pipeline domain codes and attributes-feature is appropriate for use in hydroenforcement.

[FClass, Feature Class; FCode, Feature Code; EClass, Elevation Class; --, no data]

\begin{tabular}{|c|c|c|c|c|c|c|}
\hline FClass & FCode & EClass & Description & Source & Method & UserCode \\
\hline 1 & 42800 & 2 & Pipeline & Required & Required & -- \\
\hline
\end{tabular}

Table 25. Pipeline representation rules.

$[--$, no data $]$

\begin{tabular}{lccc}
\hline \multicolumn{1}{c}{ Kind of feature object } & Area & Shortest axis & Longest axis \\
\hline 0-dimensional (point) & -- & -- & -- \\
1-dimensional (line) & -- & greater than 0 & -- \\
2-dimensional (polygon) & -- & -- & -- \\
\hline
\end{tabular}




\section{Playa}

The flat area at the lowest part of an undrained desert basin, generally devoid of vegetation (figs. 21 and 22).

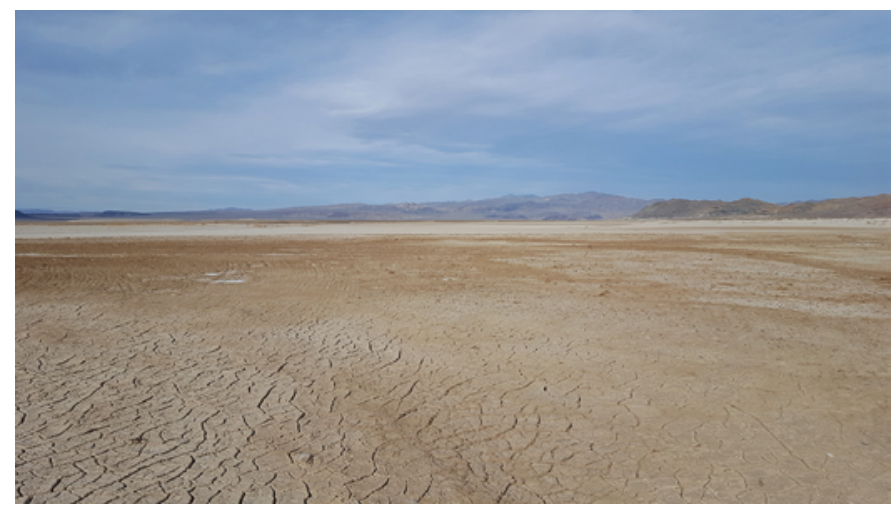

Figure 21. Clayton Valley Playa, Nevada, as an example of a playa feature. Photograph by Lisa Stillings, U.S. Geological Survey.

\section{Attribute/Attribute Value}

Each feature requires domain codes to be entered into the attribute table for the feature class (table 26). See "Field Definitions and Domain Values for Attributes" section for more information on EDH code definitions.

\section{Delineation} the basin.

The limit of playa is the extent of the lowest part of

\section{Representation Rules}

When delineating a feature, it must be created with the appropriate geometry, either point, line, or polygon, which is determined by the size of the feature or the length along different axes of the feature (table 27).

Special conditions: none.

\section{Data Extraction}

Data extraction rules fall into three categories: capture conditions, attribute information, and source interpretation guidelines. The capture conditions explain the requirements for a feature to be collected, and other pertinent information about acquisition. The attribute information explains the definitions of the codes and attributes that must be applied to a feature if acquired, and the source interpretation guidelines give additional information for special circumstances to help determine whether a feature should be acquired or not. Not all features have source interpretation guidelines, and if this is the case, this will be indicated with "None."

\section{Capture Conditions}

If playa is greater than or equal to 200 feet (61 meters) along the shortest axis, then capture.

\section{Attribute Information}

FClass 1-NHD Feature (will be used for conflation).

FCode 36100-Playa (the flat area at the lowest part of an undrained desert basin, generally devoid of vegetation. May be a named feature).

EClass $0-$ Not used for elevation derivatives.

\section{Source Interpretation Guidelines}

None.

Table 26. Playa domain codes and attributes.

[FClass, Feature Class; FCode, Feature Code; EClass, Elevation Class; --, no data]

\begin{tabular}{cccccccc}
\hline FClass & FCode & EClass & & Description & Source & Method & UserCode \\
\hline 1 & 36100 & 0 & Playa & & Required & Required & -- \\
\hline
\end{tabular}

Table 27. Playa representation rules.

$[--$, no data $]$

\begin{tabular}{lccc}
\hline \multicolumn{1}{c}{ Kind of feature object } & Area & Shortest axis & Longest axis \\
\hline 0-dimensional (point) & -- & -- & -- \\
1-dimensional (line) & -- & -- & -- \\
2-dimensional (polygon) & greater than 0 & -- & -- \\
\hline
\end{tabular}




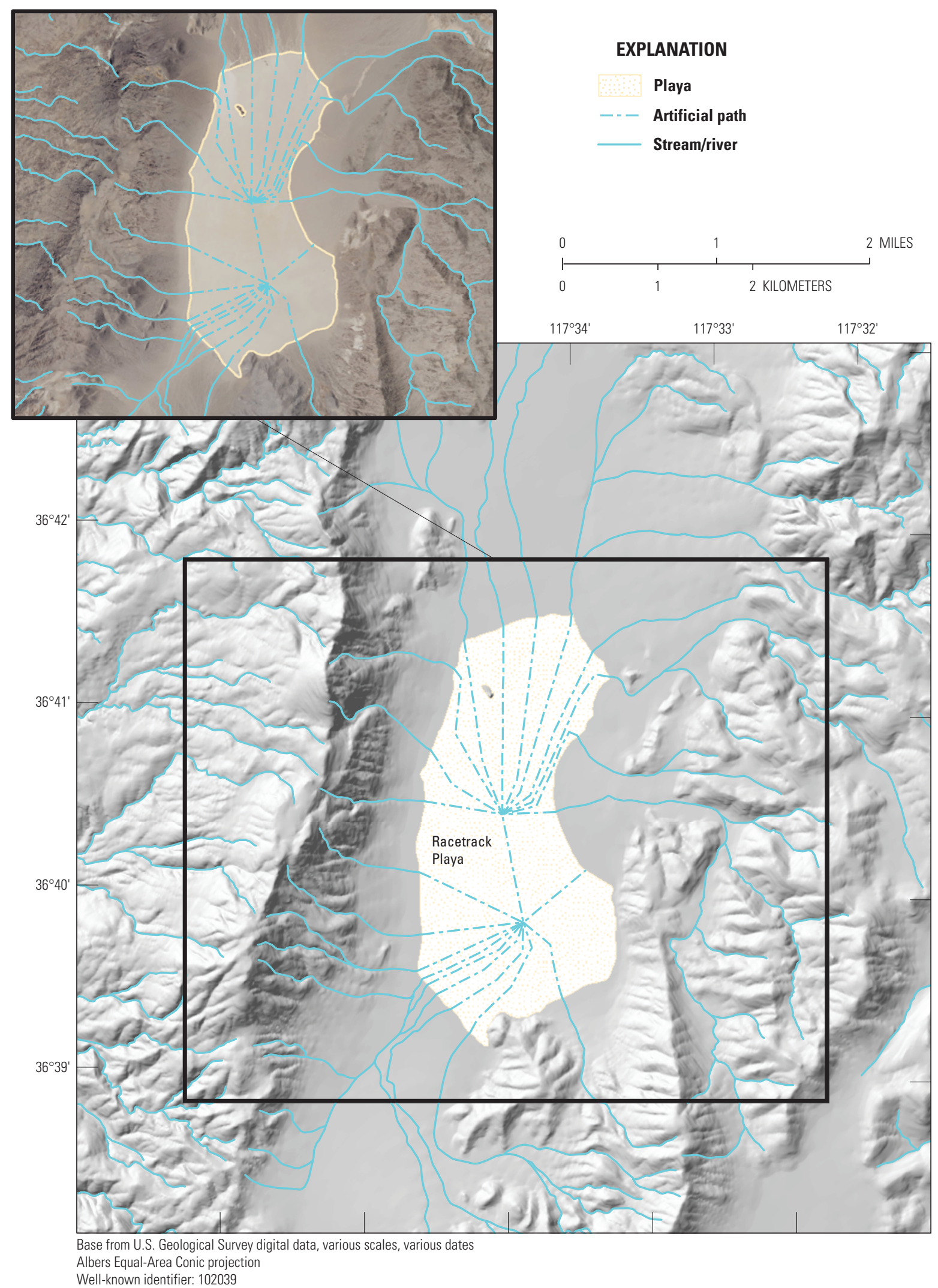

Figure 22. Racetrack Playa in Death Valley, California, is shown as an example of playa feature. Source data are from the National Hydrography Dataset (U.S. Geological Survey, 2020), which is used to provide examples of hydrographic feature types, but may not have the same density and other characteristics of elevation-derived hydrography. 


\section{Reservoir}

A constructed basin formed to contain water or other liquids (figs. 23 and 24).

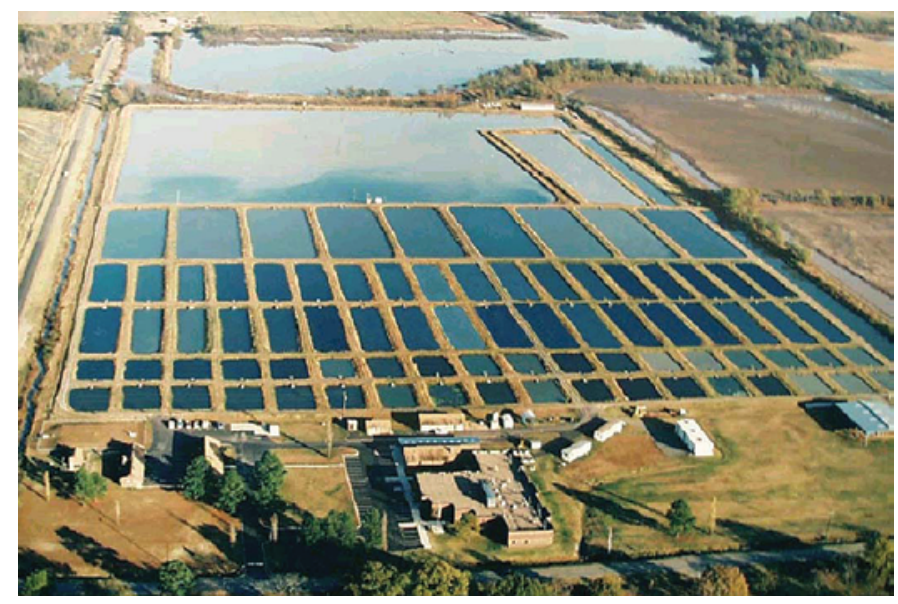

Figure 23. U.S. Department of Agriculture Harry K. Dupree Stuttgart National Aquaculture Research Center, Arkansas, shown as an example of a reservoir feature. In the example, the reservoir is an aquaculture pond with a constructed shoreline. Photograph by U.S. Geological Survey.

\section{Attribute/Attribute Value}

Each feature requires domain codes to be entered into the attribute table for the feature class (table 28). See "Field Definitions and Domain Values for Attributes" section for more information on EDH code definitions.

\section{Delineation}

The limit of reservoir is the rim of the constructed basin.

\section{Representation Rules}

When delineating a feature, it must be created with the appropriate geometry, either point, line, or polygon, which is determined by the size of the feature or the length along different axes of the feature (table 29).

Special conditions: none.

\section{Data Extraction}

Data extraction rules fall into three categories: capture conditions, attribute information, and source interpretation guidelines. The capture conditions explain the requirements for a feature to be collected, and other pertinent information about acquisition. The attribute information explains the definitions of the codes and attributes that must be applied to a feature if acquired, and the source interpretation guidelines give additional information for special circumstances to help determine whether a feature should be acquired or not. Not all features have source interpretation guidelines, and if this is the case, this will be indicated with "None."

\section{Capture Conditions}

For required lidar base specification hydroflattening breakline acquisition, waterbodies with a surface area of 2 acres ( 0.8 hectare) or greater (approximately equal to a round pond 328 feet [ 100 meters] in diameter) at the time of collection shall be flattened.

For EDH feature collection, if reservoir is greater than or equal to 100 feet along the shortest axis (or approximately 0.1 hectare), then capture (for required hydroflattening breaklines, not applicable).

\section{Attribute Information}

FClass 1-NHD Feature (will be used for conflation).

FCode 43600 - Reservoir (a constructed basin formed to contain water or other liquids. Function or purpose of reservoir is unknown. Predominant construction material used to build the reservoir is unknown. The portion of the year the feature contains water is unknown).

EClass 1-Use for hydroflattening (3D polygon).

\section{Source Interpretation Guidelines}

Refer to the feature definition to decide how to categorize a given feature instance. Do not use the proper name of the feature as a guide. Many features that are known as "Reservoirs" or labeled on the topographic map as "Reservoirs" will be captured as lake/ponds. "Stock Tanks" may be reservoir or lake/pond depending on their form. As a general rule, if a waterbody has a geometric shape or other information indicates it is contained by a constructed basin, capture it as reservoir. If it does not appear to be contained by a constructed basin, capture it as lake/pond.

If reservoir is less than 100 feet along the shortest axis and is within 40 feet of another reservoir with the same attribute values,

then capture as one reservoir only if the combined areas are greater than or equal to 100 feet along the shortest axis.

For lidar base specification hydroflattening, permanent islands 1 acre ( 0.4 hectare) (approximately equal to a round island 236 feet [ 72 meters] in diameter) or larger shall be delineated within all waterbodies.

For examples of islands and intermittently submerged islands that may be apparent on elevation surface, see "Additional EDH Related Treatments and Elevation Specific Features" section. 


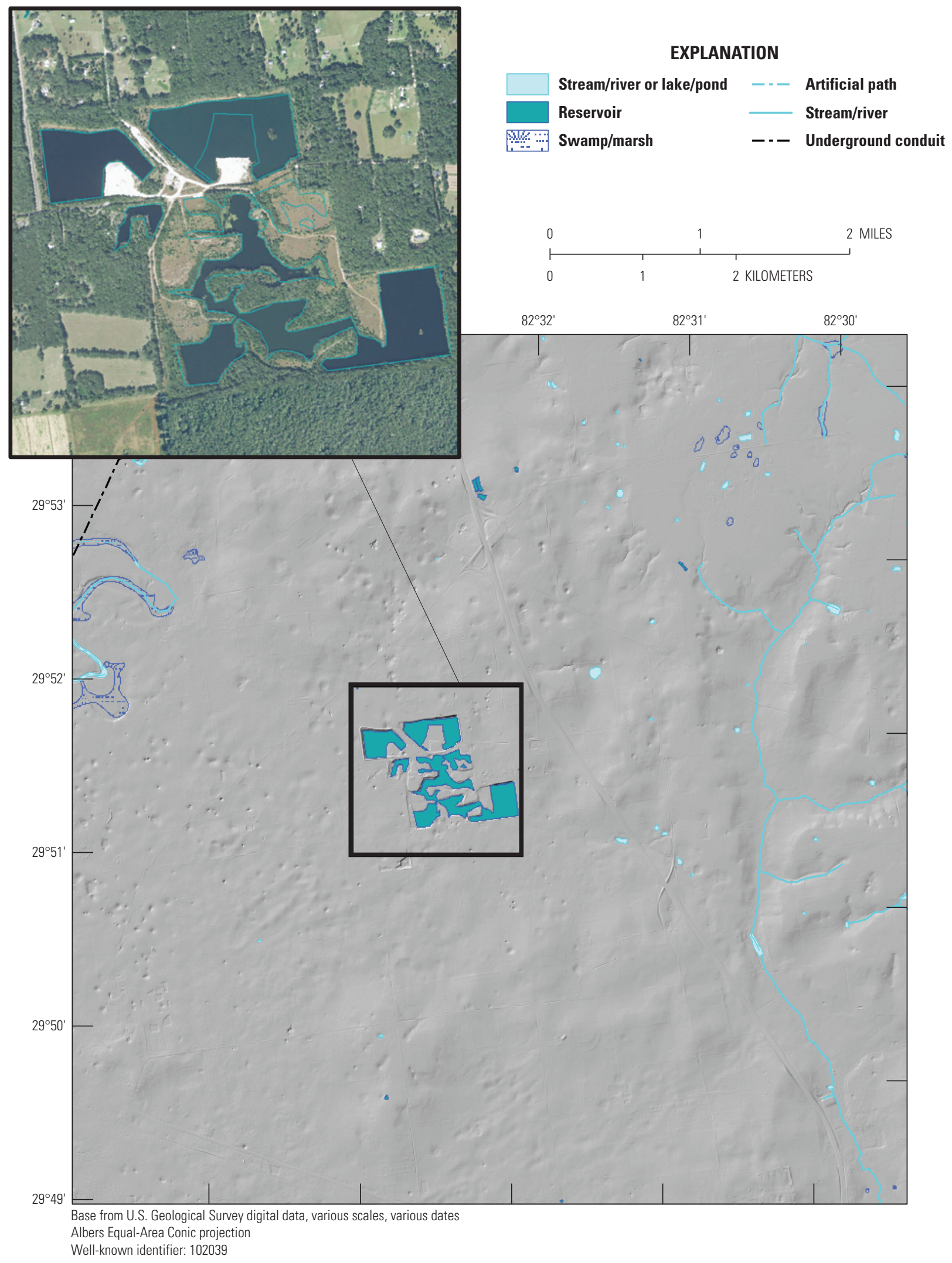

Figure 24. Unnamed reservoir in Florida shown as an example of reservoir hydrographic feature. Source data are from the National Hydrography Dataset (U.S. Geological Survey, 2020), which is used to provide examples of hydrographic feature types, but may not have the same density and other characteristics of elevation-derived hydrography. 
Table 28. Reservoir domain codes and attributes.

[FClass, Feature Class; FCode, Feature Code; EClass, Elevation Class; --, no data]

\begin{tabular}{|c|c|c|c|c|c|c|}
\hline FClass & FCode & EClass & Description & Source & Method & UserCode \\
\hline 1 & 43600 & 1 & Reservoir & Required & Required & -- \\
\hline
\end{tabular}

Table 29. Reservoir representation rules.

[--, no data]

\begin{tabular}{lccc}
\hline \multicolumn{1}{c}{ Kind of feature object } & Area & Shortest axis & Longest axis \\
\hline 0-dimensional (point) & -- & -- & -- \\
1-dimensional (line) & -- & -- & -- \\
2-dimensional (polygon) & greater than 0 & -- & -- \\
\hline
\end{tabular}




\section{Sea/Ocean}

The great body of saltwater that covers much of the Earth (figs. 25 and 26).

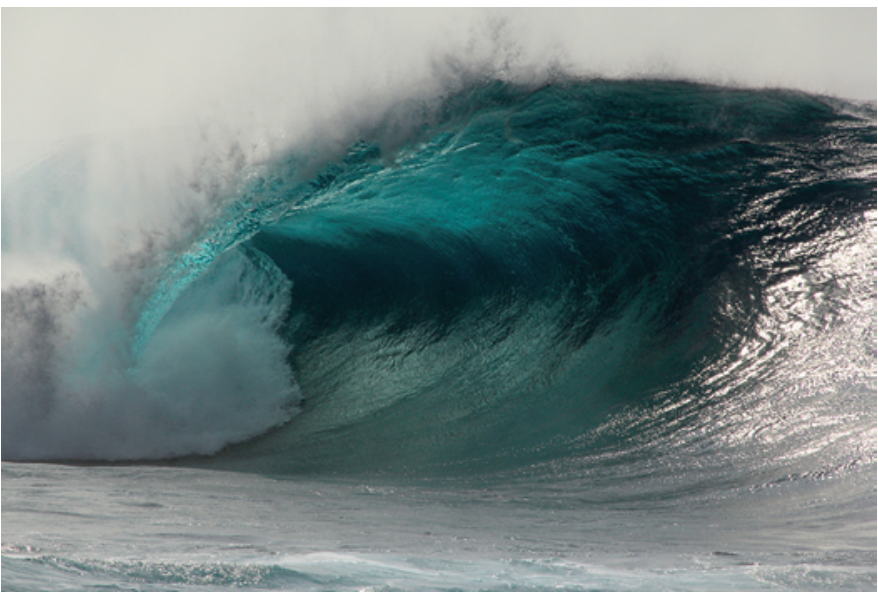

Figure 25. Photograph of an ocean wave (Photograph by S. Lee, National Park Service, 2015).

\section{Attribute/Attribute Value}

Each feature requires domain codes to be entered into the attribute table for the feature class (table 30). See "Field Definitions and Domain Values for Attributes" section for more information on EDH code definitions.

\section{Delineation}

The limit of sea/ocean is the approximate line of mean high water.

In areas where rivers enter sea/ocean, the limit is where the conformation of the land and water makes the division obvious, or, if the land and water do not suggest an obvious limit, the limit is where the river reaches a width of 1 nautical mile $(6,076.1$ feet or 1.15 statute miles) with no further constrictions.

A boundary waterbody is any waterbody that contains the boundary of the collection (that is, the actual opposite bank or shore is not being mapped). Boundary waterbodies may be a single water surface elevation (for example, lake) or gradient (for example, river). Boundary waterbodies will contain either a centerline or an Elevation Terminus line, depending on circumstances.

\section{Representation Rules}

When delineating a feature, it must be created with the appropriate geometry, either point, line, or polygon, which is determined by the size of the feature or the length along different axes of the feature (table 31).

Special conditions: none.

\section{Data Extraction}

Data extraction rules fall into three categories: capture conditions, attribute information, and source interpretation guidelines. The capture conditions explain the requirements for a feature to be collected, and other pertinent information about acquisition. The attribute information explains the definitions of the codes and attributes that must be applied to a feature if acquired, and the source interpretation guidelines give additional information for special circumstances to help determine whether a feature should be acquired or not. Not all features have source interpretation guidelines, and if this is the case, this will be indicated with "None."

\section{Capture Conditions}

Capture all.

\section{Attribute Information}

FClass 1-NHD Feature (will be used for conflation). FCode 44500 - Sea/ocean (the great body of saltwater that covers much of the Earth. May be a named feature).

EClass 1-Use for hydroflattening (3D polygon).

\section{Source Interpretation Guidelines}

The minimum size for islands within sea/ocean is 1 acre (0.4 hectare) along the shortest axis.

For lidar base specification hydroflattening, permanent islands 1 acre ( 0.4 hectare) (approximately equal to a round island 236 feet [ 72 meters] in diameter) or larger shall be delineated within all waterbodies.

For examples of islands and intermittently submerged islands, which may be apparent on elevation surface, see "Additional Elevation-Derived Hydrography Treatments and Elevation Specific Features" section. 


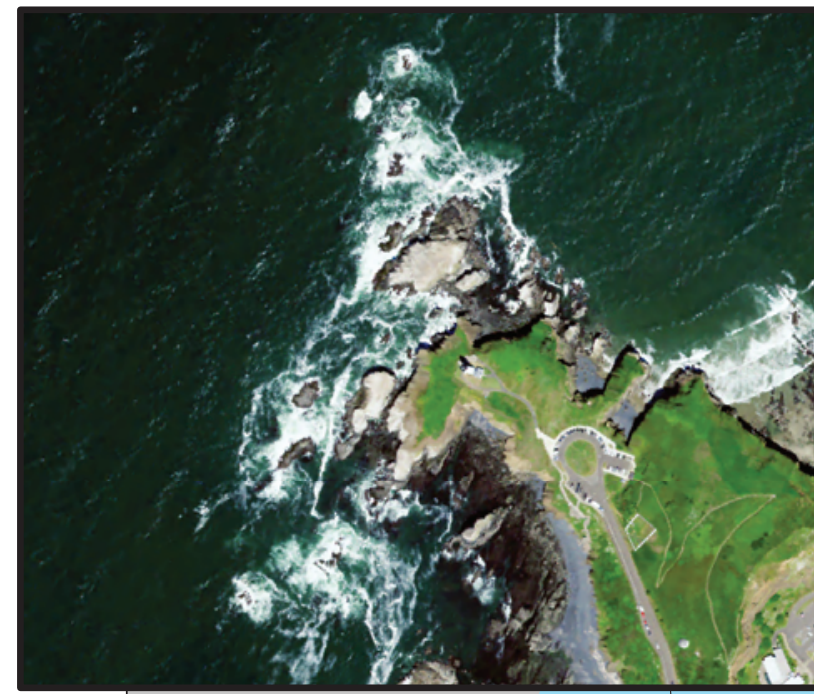

\section{EXPLANATION}
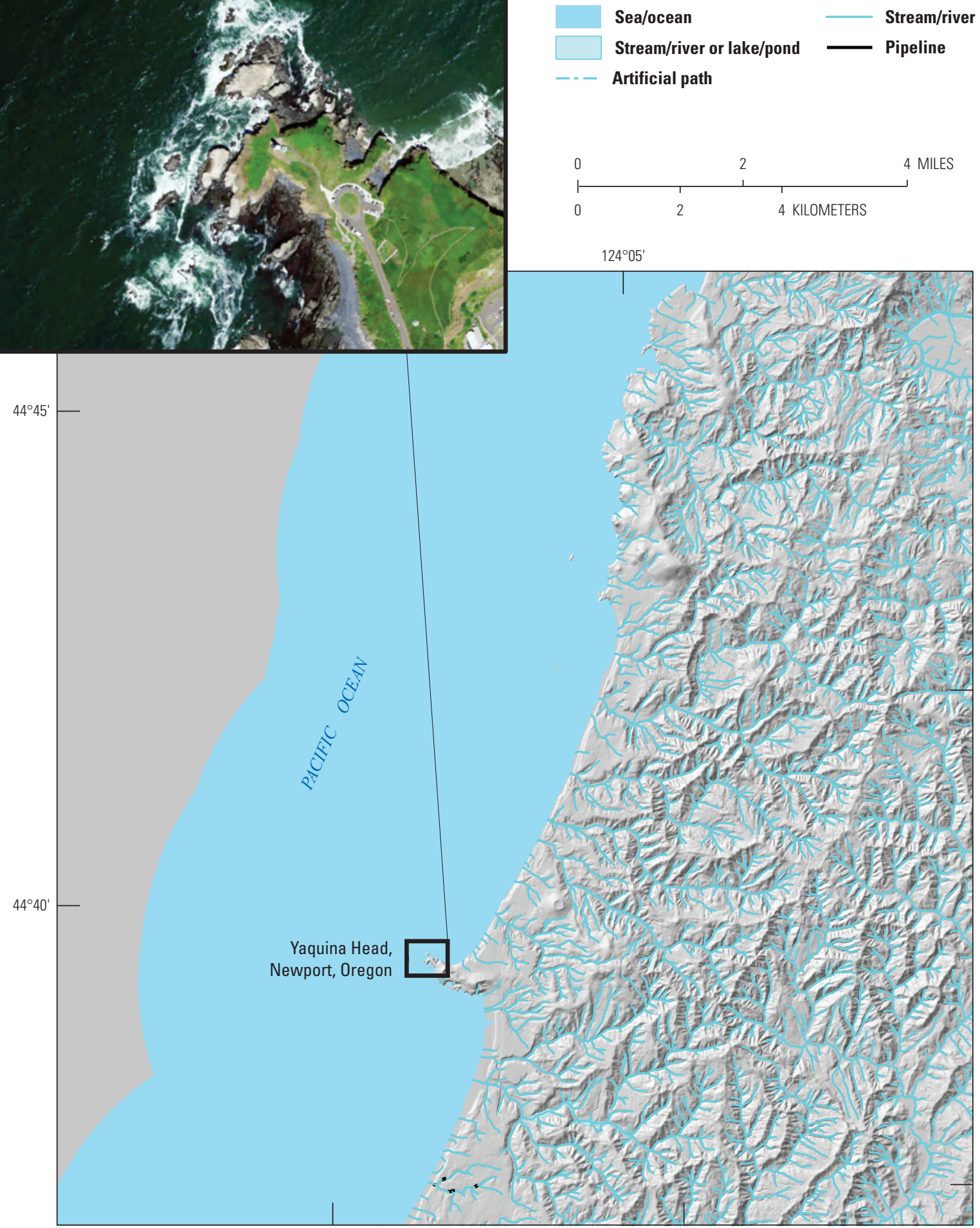

Base from U.S. Geological Survey digital data, various scales, various dates Albers Equal-Area Conic projection

Well-known identifier: 102039

Figure 26. The Pacific Ocean near Yaquina Head, Newport, Oregon, is shown as an example of a sea/ocean hydrographic feature. Source data are from the National Hydrography Dataset (U.S. Geological Survey, 2020), which is used to provide examples of hydrographic feature types, but may not have the same density and other characteristics of elevation-derived hydrography. 
Table 30. Sea/ocean domain codes and attributes.

[FClass, Feature Class; FCode, Feature Code; EClass, Elevation Class; --, no data]

\begin{tabular}{|c|c|c|c|c|c|c|}
\hline FClass & FCode & EClass & Description & Source & Method & UserCode \\
\hline 1 & 44500 & 1 & Sea/ocean & Required & Required & -- \\
\hline
\end{tabular}

Table 31. Sea/ocean representation rules.

[--, no data]

\begin{tabular}{lccc}
\hline \multicolumn{1}{c}{ Kind of feature object } & Area & Shortest axis & Longest axis \\
\hline 0-dimensional (point) & -- & -- & -- \\
1-dimensional (line) & -- & -- & -- \\
2-dimensional (polygon) & greater than 0 & -- & -- \\
\hline
\end{tabular}




\section{Sink/Rise}

The place at which a stream disappears into an underground conduit or reappears at the surface from an underground conduit, or an isolated depression where the network ends (figs. 27 and 28).

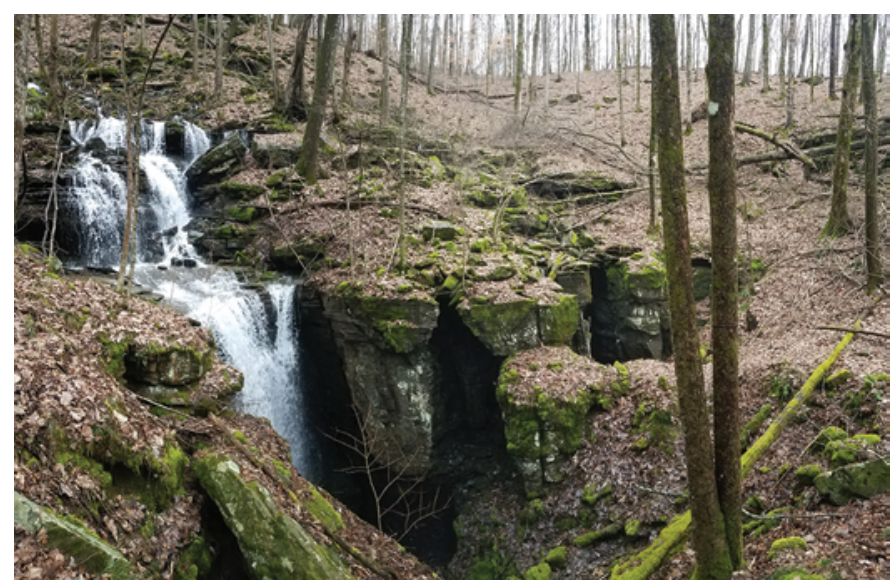

Figure 27. Ephemeral sinking stream in Winchester, Virginia. Photograph by Benjamin V. Miller, U.S. Geological Survey.

\section{Attribute/Attribute Value}

Each feature requires domain codes to be entered into the attribute table for the feature class (table 32). See "Field Definitions and Domain Values for Attributes" section for more information on EDH code definitions.

\section{Delineation}

The limit of sink/rise is the place at which a stream disappears underground or reappears at the surface.

\section{Representation Rules}

When delineating a feature, it must be created with the appropriate geometry, either point, line, or polygon, which is determined by the size of the feature or the length along different axes of the feature (table 33).

Special conditions: none.

\section{Data Extraction}

Data extraction rules fall into three categories: capture conditions, attribute information, and source interpretation guidelines. The capture conditions explain the requirements for a feature to be collected, and other pertinent information about acquisition. The attribute information explains the definitions of the codes and attributes that must be applied to a feature if acquired, and the source interpretation guidelines give additional information for special circumstances to help determine whether a feature should be acquired or not. Not all features have source interpretation guidelines, and if this is the case, this will be indicated with "None."

\section{Capture Conditions}

If stream disappears and reappears downstream on stream/river,

then capture at the point of disappearance and reappearance.

\section{Attribute Information}

FClass 1-NHD Feature (will be used for conflation).

FCode 45000 - Sink/rise (the place at which a stream disappears underground or reappears at the surface in a karst area. SinkRise also exists as an NHDPoint. May be a named feature).

EClass 0-Not used for elevation derivatives.

\section{Source Interpretation Guidelines}

None. 

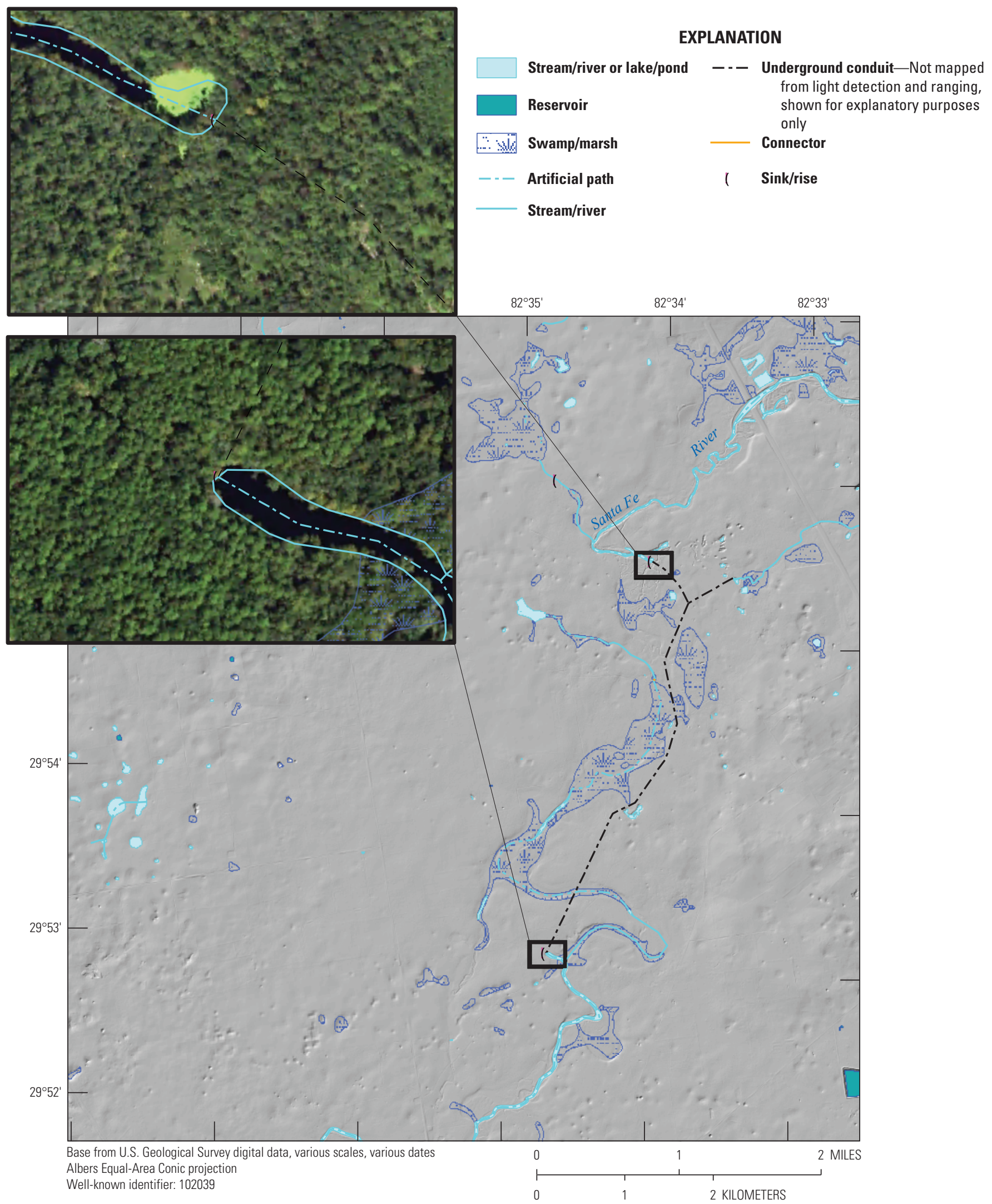

Figure 28. Sink and rise features on Santa Fe River, Florida, shown as examples of sink/rise hydrographic features. Source data are from the National Hydrography Dataset (U.S. Geological Survey, 2020), which is used to provide examples of hydrographic feature types, but may not have the same density and other characteristics of elevation-derived hydrography. 
Table 32. Sink/rise domain codes and attributes.

[FClass, Feature Class; FCode, Feature Code; EClass, Elevation Class; --, no data]

\begin{tabular}{|c|c|c|c|c|c|c|}
\hline FClass & FCode & EClass & Description & Source & Method & UserCode \\
\hline 1 & 45000 & 0 & Sink/rise & Required & Required & -- \\
\hline
\end{tabular}

Table 33. Sink/rise representation rules.

$[--$, no data $]$

\begin{tabular}{lccc}
\hline \multicolumn{1}{c}{ Kind of feature object } & Area & Shortest axis & Longest axis \\
\hline 0-dimensional (point) & greater than 0 & -- & -- \\
1-dimensional (line) & -- & -- & -- \\
2-dimensional (polygon) & -- & -- & -- \\
\hline
\end{tabular}




\section{Stream/River}

A body of flowing water (figs. 29, 30, and 31).

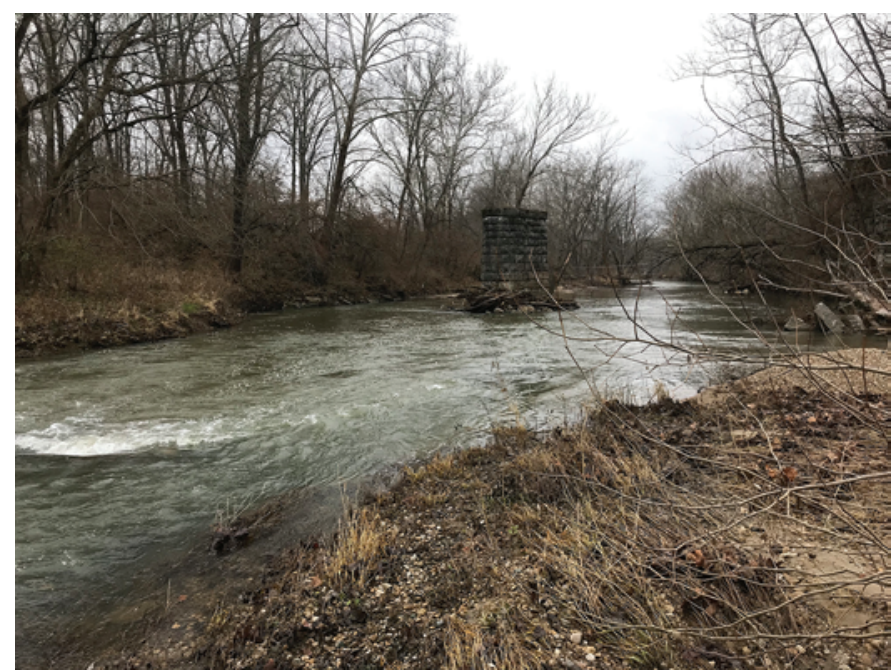

Figure 29. Eagle Creek at Zionsville, Indiana, shown as an example of a river. Photograph by U.S. Geological Survey.

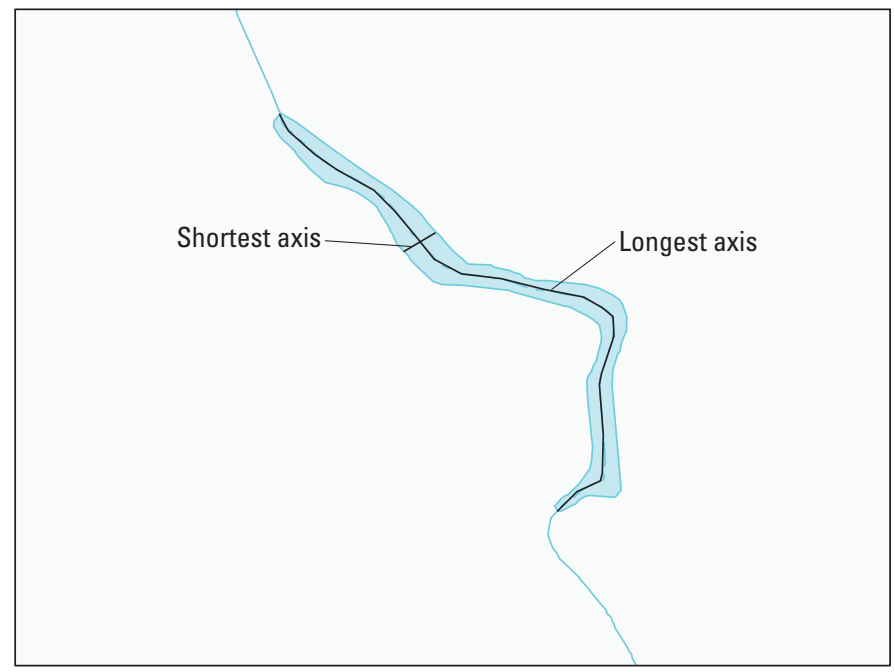

Figure 30. Diagram showing shortest and longest axes of a stream/river feature.

\section{Attribute/Attribute Value}

Each feature requires domain codes to be entered into the attribute table for the feature class (table 34). See "Field Definitions and Domain Values for Attributes" section for more information on EDH code definitions.

Another possibility is shown in table 35 .

\section{Delineation}

The delineation of stream/river features should adhere to the following rules, describing the boundary limits of the feature, and other delineation rules:

- The boundary limit of stream/river:

$\mathrm{o}$ is determined by the position of the visible edge of the banks as depicted on the digital elevation model (as of date of lidar collection).

o where it enters or leaves lake/pond

- is determined by the conformation of the land.

o where it enters sea/ocean

- is determined by the location where the conformation of the land and water makes the division obvious, or, if the land and water do not suggest an obvious limit, the limit is where the stream reaches a width of 1 nautical mile $(6,076.1$ feet or 1.15 statute miles) with no further constrictions.

o Where flattening is required,

- flattened streams and rivers shall present a flat and level water surface bank-to-bank (perpendicular to the apparent flow centerline).

- flattened streams and rivers shall present a gradient downhill water surface, following the immediately surrounding terrain.

- Other delineation rules

o The upper limit of stream/river is where the feature first becomes evident as a channel.

o In cases of sharp turns of rapidly moving water, where the natural water surface is notably not level bank-to-bank, the water surface will be represented as it exists while maintaining an aesthetic cartographic appearance.

o The entire water surface edge shall be at or below the immediately surrounding terrain.

o Stream channels shall break at culvert locations leaving the roadway over the culvert intact.

o Streams shall be continuous at bridge locations.

\section{Representation Rules}

When delineating a feature, it must be created with the appropriate geometry, either point, line, or polygon, which is determined by the size of the feature or the length along different axes of the feature (table 36). 


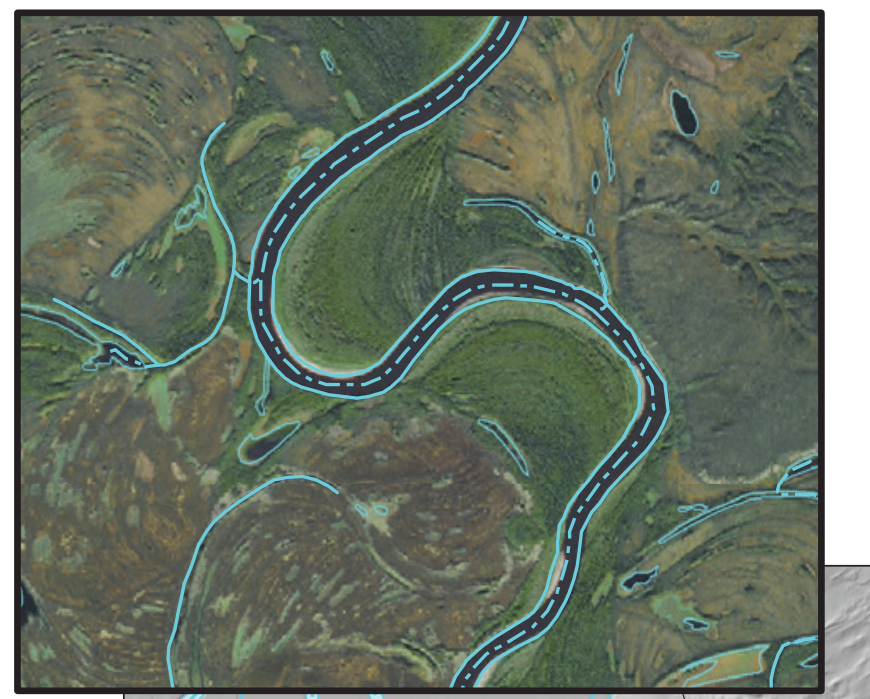

\section{EXPLANATION}

Stream/river or lake/pond

Artificial path

Stream/river

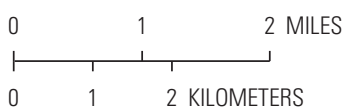

$154^{\circ} 15^{\prime}$

$154^{\circ} 10^{\prime}$

$154^{\circ} 05^{\prime}$

$64^{\circ} 3$

$4^{\circ} 30^{\prime}$
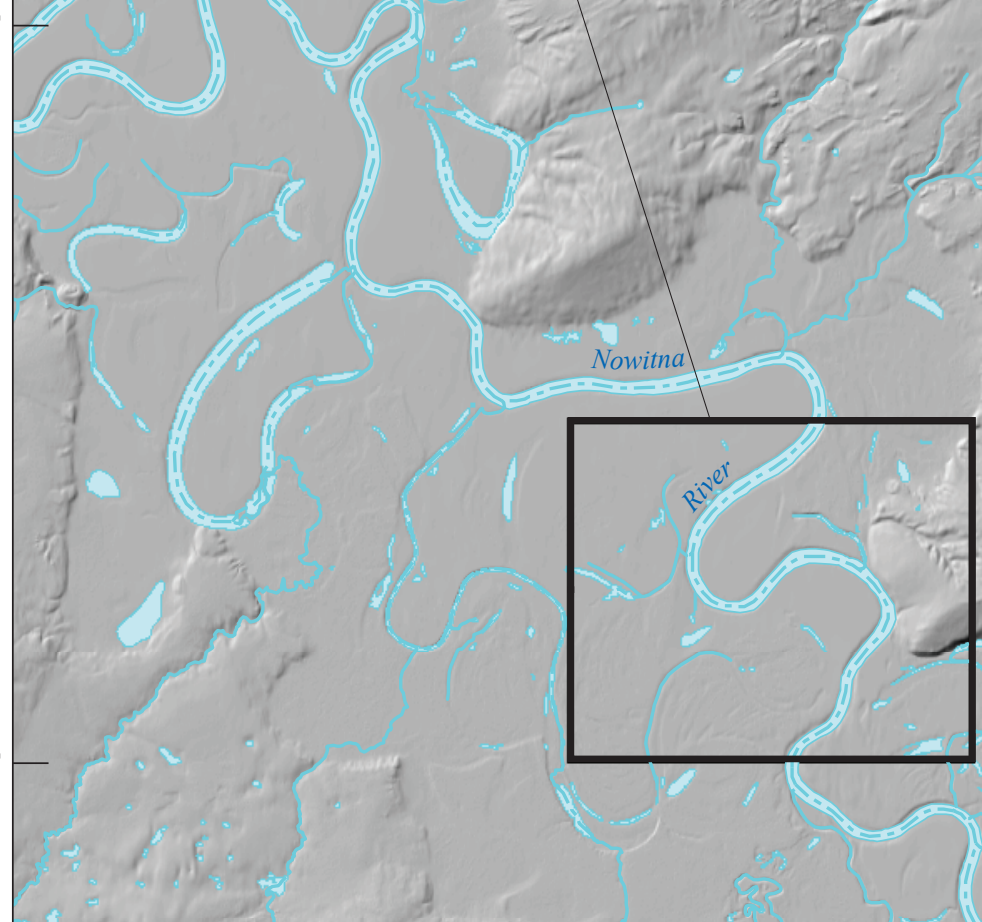

1

\section{1}
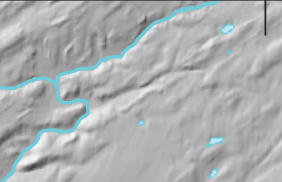
Table 34. Stream/river domain codes and attributes-feature is appropriate for use in hydroenforcement.

[FClass, Feature Class; FCode, Feature Code; EClass, Elevation Class; --, no data]

\begin{tabular}{ccccccc}
\hline FClass & FCode & EClass & Description & Source & Method & UserCode \\
\hline 1 & 46000 & 2 & Stream/river & Required & Required & -- \\
\hline
\end{tabular}

Table 35. Stream/river domain codes and attributes - feature is appropriate for use in hydroflattening (three-dimensional polygon)

[FClass, Feature Class; FCode, Feature Code; EClass, Elevation Class; --, no data]

\begin{tabular}{ccccccc}
\hline FClass & FCode & EClass & Description & Source & Method & UserCode \\
\hline 1 & 46000 & 1 & Stream/river & Required & Required & -- \\
\hline
\end{tabular}

Table 36. Stream/river representation rules.

[--, no data; NHD, National Hydrography Dataset]

\begin{tabular}{lccc}
\hline \multicolumn{1}{c}{ Kind of feature object } & Area & Shortest axis & Longest axis \\
\hline 0-dimensional (point) & -- & -- & -- \\
1-dimensional (line) & -- & less than 50 feet & $(15$ meters) NHD \\
& & less than 98 feet (30 \\
& & meters) hydroflatten- & ing breakline \\
& & greater than 50 feet & (15 meters) NHD \\
2-dimensional (polygon) & -- & greater than 98 feet & (30 meters) hydroflat- \\
& & tening breakline \\
\hline
\end{tabular}

Special conditions:

To accommodate variations in the shortest axis of stream/river:

- For lidar base specification collection (not collecting optional features), streams and rivers of approximately 100 feet (30 meters) or greater nominal width shall be flattened (captured as a polygon).

- For EDH feature collection, if shortest axis of stream/river is

less than 50 feet ( 15 meters) but greater than or equal to 20 feet ( 6 meters) for a distance less than 0.6 mile ( 1 kilometer), and is connected at both ends to a 2-dimensional (polygon) stream/river,

then stream/river is represented as a 2-dimensional (polygon) basic feature object.

- less than 50 feet (15 meters) but greater than or equal to 20 feet (6 meters) for a distance greater than or equal to 0.6 mile ( 1 kilometer), or less than 20 feet (6 meters) regardless of distance, and is connected at both ends to a 2-dimensional (polygon) stream/river, then stream/river is represented as a 1-dimensional (line) basic feature object.

- greater than or equal to 50 feet (15 meters) but less than 80 feet ( 24 meters) for a distance less than 0.6 mile (1 kilometer), and is connected at both ends to a 1-dimensional (line) stream/river,

then stream/river is represented as a 1-dimensional (line) basic feature object.

- greater than or equal to 50 feet (15 meters) but less than 80 feet ( 24 meters) for a distance greater than or equal to 0.6 mile (1 kilometer), or greater than or equal to 80 feet (24 meters) regardless of distance, and is connected at both ends to a 1-dimensional (line) stream/river,

then stream/river is represented as a 2-dimensional (polygon) basic feature object. 


\section{Data Extraction}

Data extraction rules fall into three categories: capture conditions, attribute information, and source interpretation guidelines. The capture conditions explain the requirements for a feature to be collected, and other pertinent information about acquisition. The attribute information explains the definitions of the codes and attributes that must be applied to a feature if acquired, and the source interpretation guidelines give additional information for special circumstances to help determine whether a feature should be acquired or not. Not all features have source interpretation guidelines, and if this is the case, this will be indicated with "None."

\section{Capture Conditions}

If stream/river flows from lake/pond or spring/seep, or if stream/river is greater than or equal to 984 feet

(300 meters) along the longest axis, then capture.

\section{Attribute Information}

FClass 1-NHD Feature (will be used for conflation). FCode 46000 - Stream/river (a body of flowing water. Portion of the year the feature contains water unknown).

EClass 2-Hydrographic feature used for elevation purposes, other than culverts or those used for hydroflattening. Another possible option is the following:

FClass 1 -NHD Feature (will be used for conflation). FCode 46000 - Stream/river (a body of flowing water. Portion of the year the feature contains water unknown).

EClass 1-Used for hydroflattening (3D polygon).

\section{Source Interpretation Guidelines}

The minimum size for islands within stream/river is 60 feet (18 meters) along the shortest axis.

If a stream flows in a braided pattern, then see "Area of Complex Channels" section.

For lidar base specification hydrographic breakline, permanent islands 1 acre ( 0.4 hectare) (approximately equal to a round island 236 feet [ 72 meters] in diameter) or larger shall be delineated within all waterbodies. 


\section{Additional Elevation-Derived Hydrography Treatments and Elevation Specific Features}

The following describes treatments and additional features that should be applied during the acquisition of reservoirs, sea/ocean, and other waterbody features and should be taken into consideration as treatments for the depiction of waterbodies. The treatments and additional features can also be used to convey additional information about the level of confidence for elevation data in certain acquisition areas.

\section{Island}

A permanent island is an area of exposed land, surrounded by water (figs. 32 and 33). These are features to be collected in and of themselves but also are a treatment. Islands need to be erased from lake/pond features.

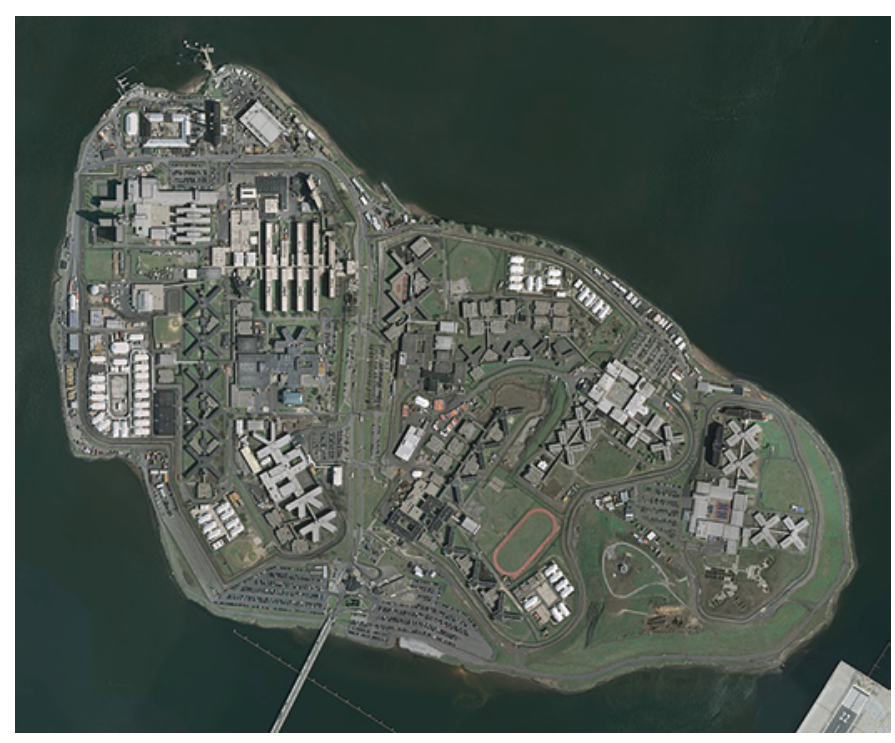

Figure 32. Image of Rikers Island, New York. The National Map Viewer, U.S. Geological Survey.

\section{Delineation}

\section{Lake/Pond}

The minimum size for islands within lake/pond is 60 feet (18 meters) along the shortest axis.

For lidar base specification hydroflattening, permanent islands 1 acre ( 0.4 hectare) (approximately equal to a round island 236 feet [72 meters] in diameter) or larger shall be delineated within all waterbodies and excluded from hydroflattening.

\section{Sea/Ocean}

The minimum size for islands within sea/ocean is 1 acre (0.4 hectare) along the shortest axis.

For lidar base specification hydroflattening, permanent islands 1 acre ( 0.4 hectare) (approximately equal to a round island 236 feet [ 72 meters] in diameter) or larger shall be delineated within all waterbodies.

\section{Stream/River}

The minimum size for islands within stream/river is 60 feet (18 meters) along the shortest axis.

If a stream flows in a braided pattern, then see "Area of Complex Channels" section.

For lidar base specification hydrographic breakline, permanent islands 1 acre $(0.4$ hectare) (approximately equal to a round island 236 feet [ 72 meters] in diameter) or larger shall be delineated within all waterbodies. 


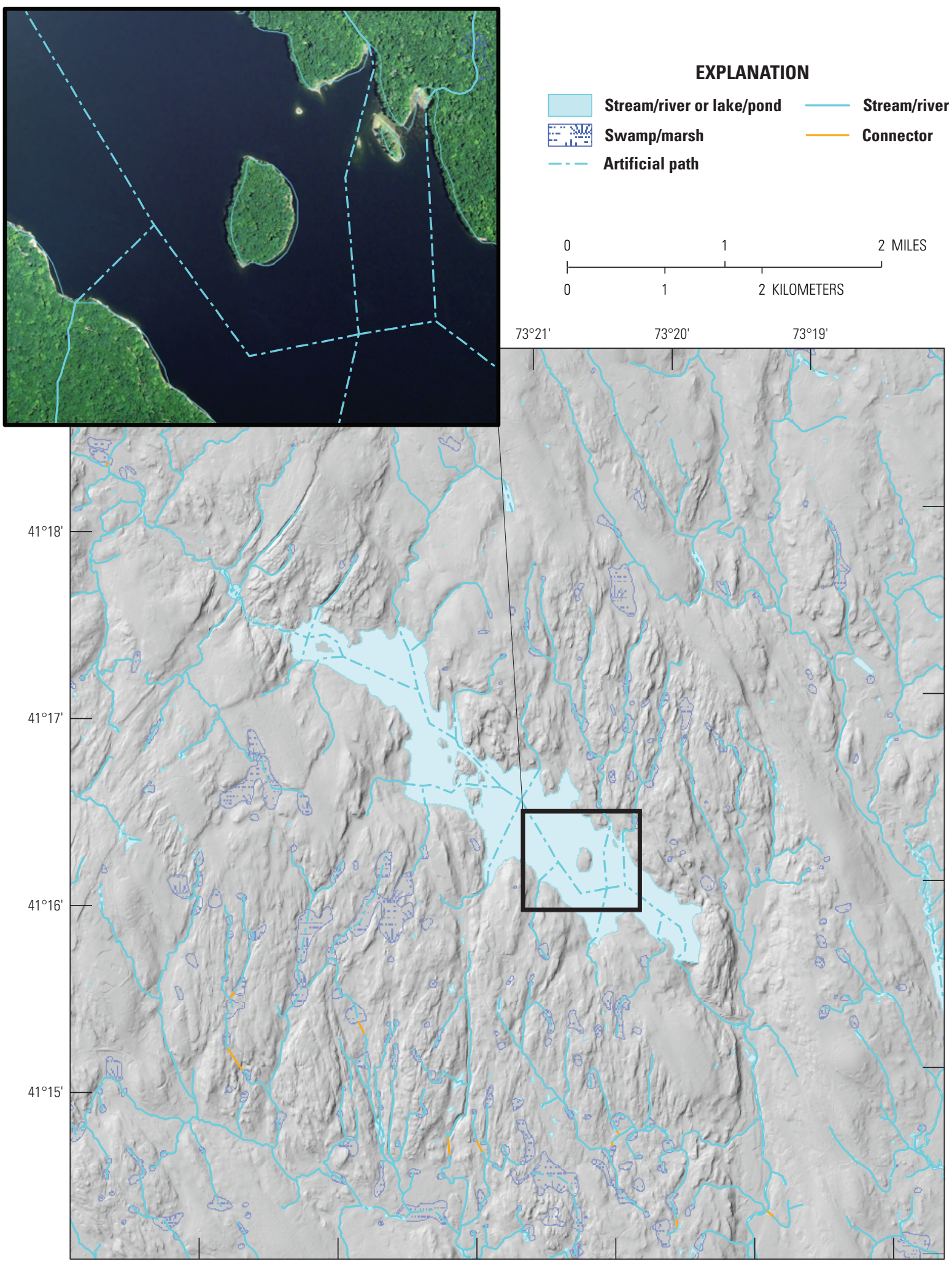

Base from U.S. Geological Survey digital data, various scales, various dates Albers Equal-Area Conic projection

Well-known identifier: 102039

Figure 33. An island in the Saugatuck Reservoir in Connecticut shown as an example of treatment for lake/pond features. Source data are from the National Hydrography Dataset (U.S. Geological Survey, 2020), which is used to provide examples of hydrographic feature types, but may not have the same density and other characteristics of elevation-derived hydrography. 


\section{Island/Sandbar}

Intermittently/partially submerged islands or parts of islands are submerged at the time of collection (fig. 34). These are most often found in coastal areas because of tidal variations during the collection, or in rivers collected while at a high flow. If island/sandbar is disconnected from the shore or is visible at the time of collection, then treat as an island (remove from lake/pond or sea/ocean feature). Otherwise, treat as shoreline.

\section{Low-Confidence Area, Predetermined}

A reference polygon used by the 3D Elevation Program (3DEP) to define an area where lidar penetration to the bareearth surface is expected to be difficult to determine. These areas would be established prior to the collection and agreed upon by the data producer and the customer. Examples might include known areas of mangroves or triple-canopy tropical rainforest (figs. 35 and 36). Low-confidence areas may overlap other hydrographic features.

\section{Attribute/Attribute Value}

Each feature requires domain codes to be entered into the attribute table for the feature class (table 37). See "Field Definitions and Domain Values for Attributes" section for more information on EDH code definitions.

\section{Representation Rules}

When delineating a feature, it must be created with the appropriate geometry, either point, line, or polygon, which is determined by the size of the feature or the length along different axes of the feature (table 38).

Special conditions: none.

\section{Data Extraction}

Data extraction rules fall into three categories: capture conditions, attribute information, and source interpretation guidelines. The capture conditions explain the requirements for a feature to be collected, and other pertinent information about acquisition. The attribute information explains the definitions of the codes and attributes that must be applied to a feature if acquired, and the source interpretation guidelines give additional information for special circumstances to help determine whether a feature should be acquired or not. Not all features have source interpretation guidelines, and if this is the case, this will be indicated with "None."

\section{Capture Conditions}

Established prior to the collection and agreed upon by the data producer and the customer.

Topology rules for adjacent features do not apply to lowconfidence areas. For instance, they do not need to be snapped to adjacent features.

\section{Attribute Information}

FClass 9-Non-Hydrography Feature (elevation dataset limitation).

FCode 991-Low-confidence area (pre-determined).

EClass 9-Elevation dataset limitation.

\section{Source Interpretation Guidelines}

None. 


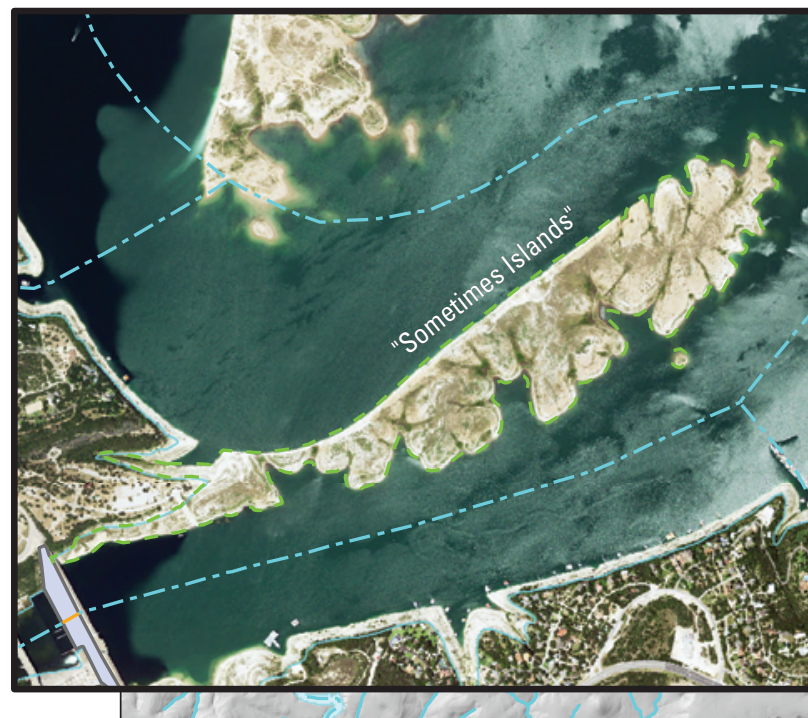

\section{EXPLANATION}

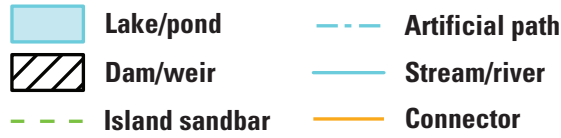

0

4 MILES

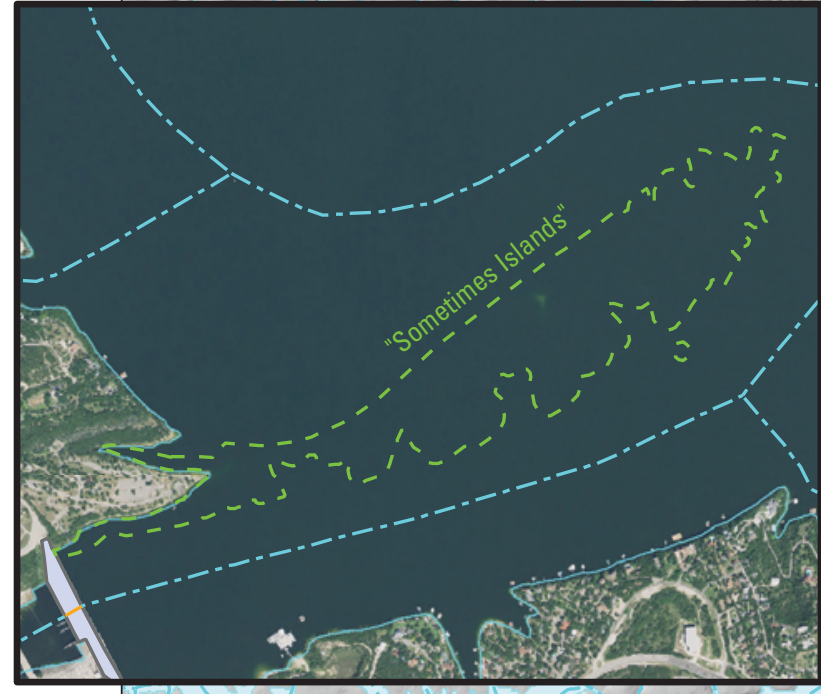

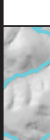

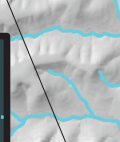




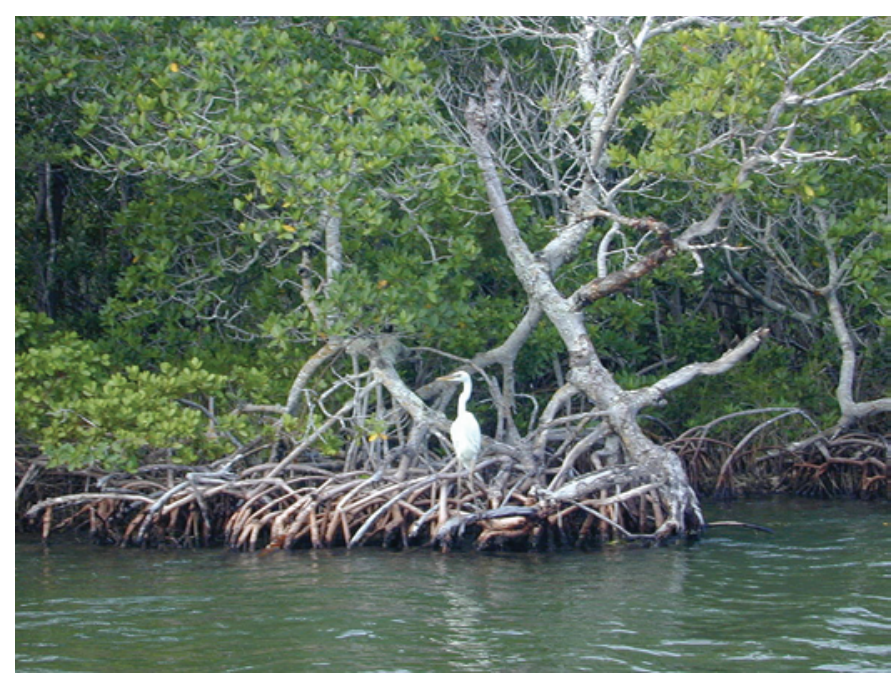

Figure 35. A great white heron standing atop mangrove roots, Boggy Key, a Florida Island. Photograph by Heather Henkel, U.S. Geological Survey.

Table 37. Low-confidence area, predetermined, domain codes and attributes.

[FClass, Feature Class; FCode, Feature Code; EClass, Elevation Class; --, no data]

\begin{tabular}{ccccccc}
\hline FClass & FCode & EClass & Description & Source & Method & UserCode \\
\hline 9 & 991 & 9 & $\begin{array}{c}\text { Low-confidence area, } \\
\text { predetermined }\end{array}$ & Required & Required & -- \\
\hline
\end{tabular}

Table 38. Low-confidence area, predetermined, representation rules.

$[--$, no data $]$

\begin{tabular}{lccc}
\hline \multicolumn{1}{c}{ Kind of feature object } & Area & Shortest axis & Longest axis \\
\hline 0-dimensional (point) & -- & -- & -- \\
1-dimensional (line) & -- & -- & -- \\
2-dimensional (polygon) & greater than 0 & -- & -- \\
\hline
\end{tabular}




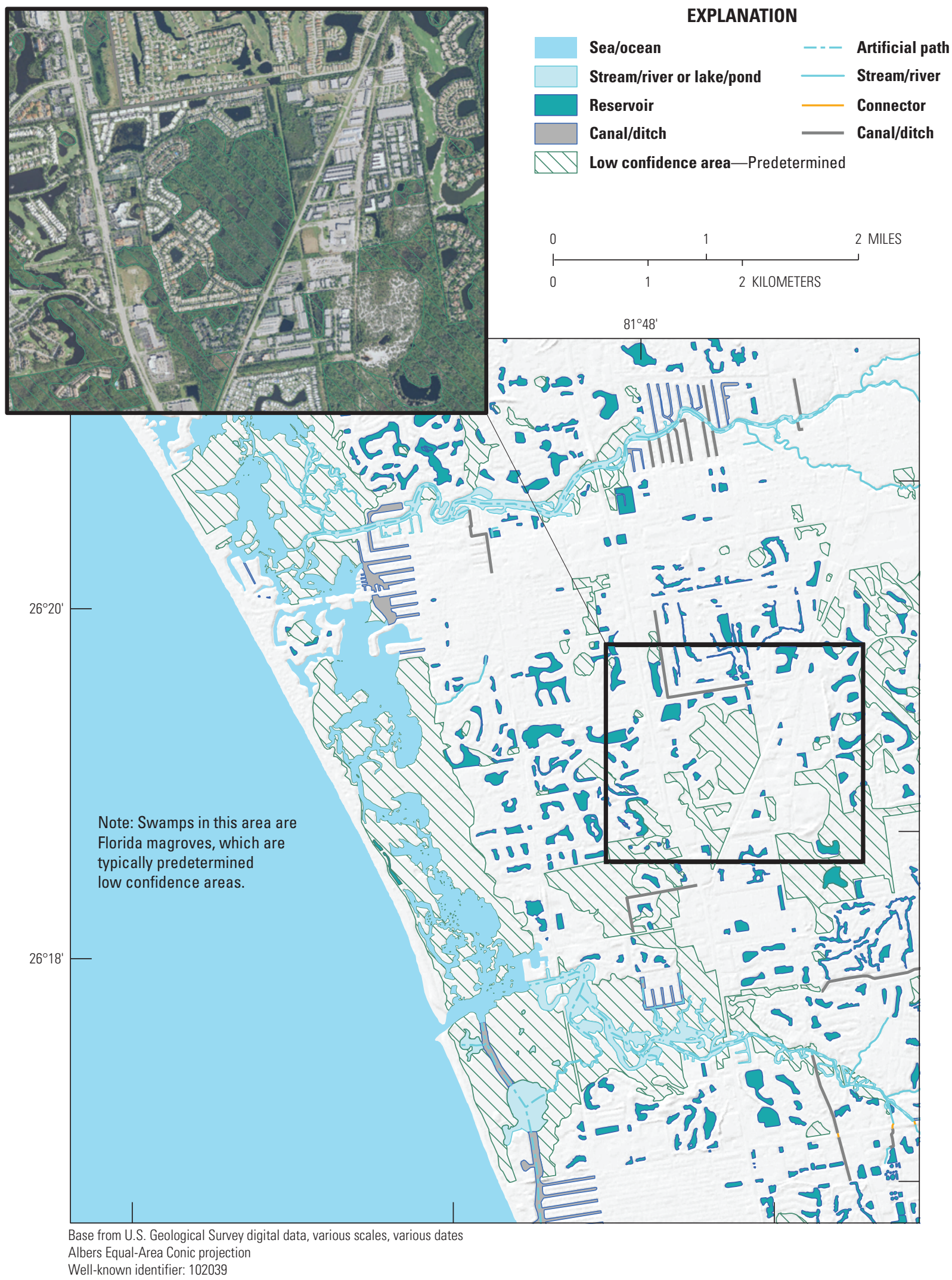

Figure 36. A mangrove forest in western Florida shown as an example of a predetermined area of low confidence. Source data are from the National Hydrography Dataset (U.S. Geological Survey, 2020), which is used to provide examples of hydrographic feature types, but may not have the same density and other characteristics of elevation-derived hydrography. 


\section{Low-Confidence Area, Sparse Bare}

\section{Earth}

At this time (2020), the 3DEP does not have a criterion for defining areas of low confidence based on the point cloud ground surface or derived DEM rasters. Any criteria for "low confidence," including how these areas shall be delineated, shall be established prior to the collection and agreed upon by the data producer, the customer, and the U.S. Geological Survey National Geospatial Program. Low-confidence areas may overlap other hydrographic features

\section{Attribute/Attribute Value}

Each feature requires domain codes to be entered into the attribute table for the feature class (table 39). See "Field Definitions and Domain Values for Attributes" section for more information on EDH code definitions.

\section{Representation Rules}

When delineating a feature, it must be created with the appropriate geometry, either point, line, or polygon, which is determined by the size of the feature or the length along different axes of the feature (table 40).

Special conditions: none.

\section{Data Extraction}

Data extraction rules fall into three categories: capture conditions, attribute information, and source interpretation guidelines. The capture conditions explain the requirements for a feature to be collected, and other pertinent information about acquisition. The attribute information explains the definitions of the codes and attributes that must be applied to a feature if acquired, and the source interpretation guidelines give additional information for special circumstances to help determine whether a feature should be acquired or not. Not all features have source interpretation guidelines, and if this is the case, this will be indicated with "None."

\section{Capture Conditions}

Topology rules for adjacent features do not apply to lowconfidence areas. For instance, they do not need to be snapped to adjacent features.

\section{Attribute Information}

FClass 9-Non-Hydrography Feature (elevation dataset limitation).

FCode 992-Low-confidence area, sparse bare earth.

EClass 9-Elevation dataset limitation.

Table 39. Low-confidence area, sparse bare earth, domain codes and attributes.

[FClass, Feature Class; FCode, Feature Code; EClass, Elevation Class; --, no data]

\begin{tabular}{ccccccc}
\hline FClass & FCode & EClass & Description & Source & Method & UserCode \\
\hline 9 & 992 & 9 & $\begin{array}{c}\text { Low-confidence area - sparse } \\
\text { bare earth }\end{array}$ & Required & Required & -- \\
\hline
\end{tabular}

Table 40. Low-confidence area, sparse bare earth, representation rules.

$[--$, no data $]$

\begin{tabular}{lccc}
\hline \multicolumn{1}{c}{ Kind of feature object } & Area & Shortest axis & Longest axis \\
\hline 0-dimensional (point) & -- & -- & - \\
1-dimensional (line) & -- & -- & -- \\
2-dimensional (polygon) & greater than 0 & -- & -- \\
\hline
\end{tabular}




\section{Low-Confidence Area, Snow-Cover}

A reference polygon used by the 3DEP to define where it can be determined that there was snow on the ground at the time of collection. Light dusting of snow that does not alter the ground elevation more than about 0.8 inch ( 2 centimeters) is inconsequential and should not be delineated. Low-confidence areas may overlap other hydrographic features (figs. 37 and 38).

\section{Attribute/Attribute Value}

Each feature requires domain codes to be entered into the attribute table for the feature class (table 41). See "Field Definitions and Domain Values for Attributes" section for more information on EDH code definitions.

\section{Representation Rules}

When delineating a feature, it must be created with the appropriate geometry, either point, line, or polygon, which is determined by the size of the feature or the length along different axes of the feature (table 42).

Special conditions: none.

\section{Data Extraction}

Data extraction rules fall into three categories: capture conditions, attribute information, and source interpretation guidelines. The capture conditions explain the requirements for a feature to be collected, and other pertinent information about acquisition. The attribute information explains the definitions of the codes and attributes that must be applied to a feature if acquired, and the source interpretation guidelines give additional information for special circumstances to help determine whether a feature should be acquired or not. Not all features have source interpretation guidelines, and if this is the case, this will be indicated with "None."

\section{Capture Conditions}

If snow is greater than approximately 2 centimeters deep, then capture.

Topology rules for adjacent features do not apply to lowconfidence areas. For instance, they do not need to be snapped to adjacent features.

\section{Attribute Information}

FClass 9-Non-Hydrography Feature (elevation dataset limitation).

FCode 993-Low-confidence area, snow-cover.

EClass 9-Elevation dataset limitation.

\section{Source Interpretation Guidelines}

None.

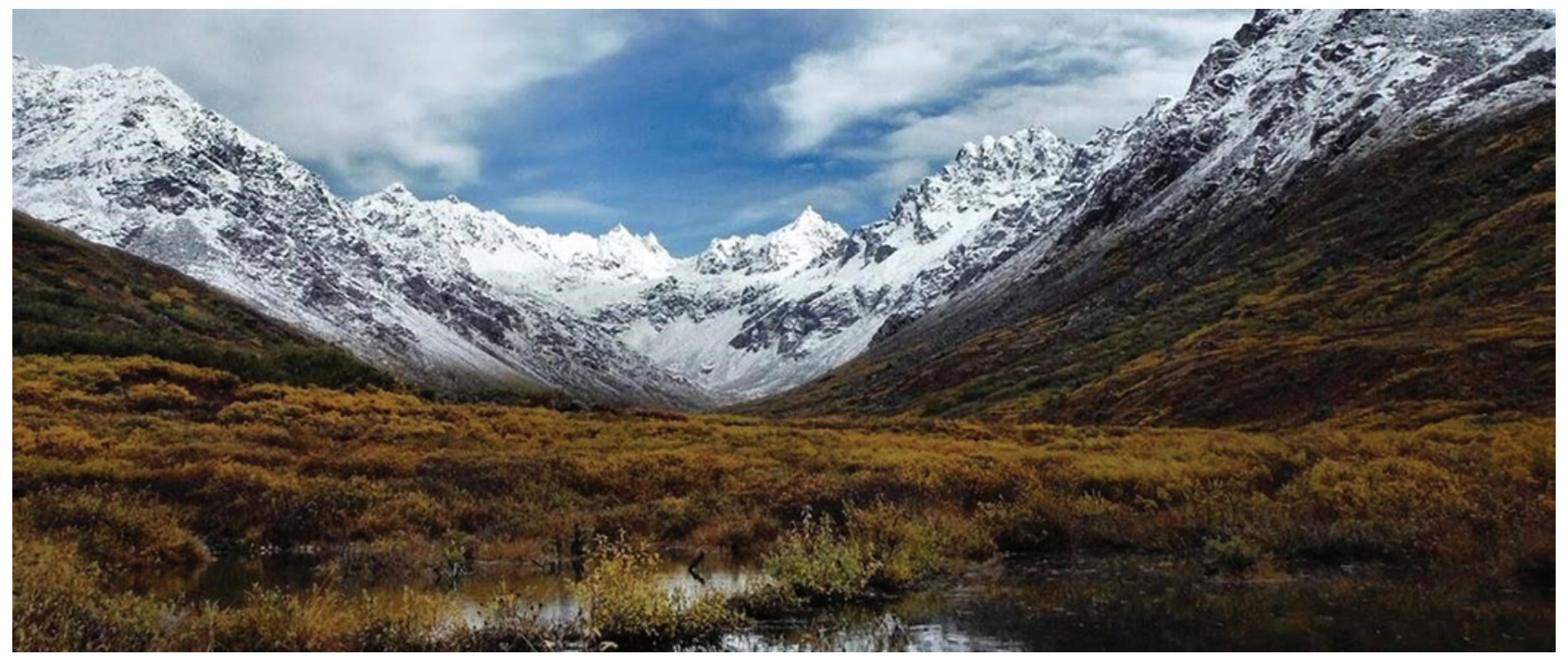

Figure 37. Snow cover in the Alaska Interior Mountain Range. Photograph by Shawn Carter, U.S. Geological Survey. 


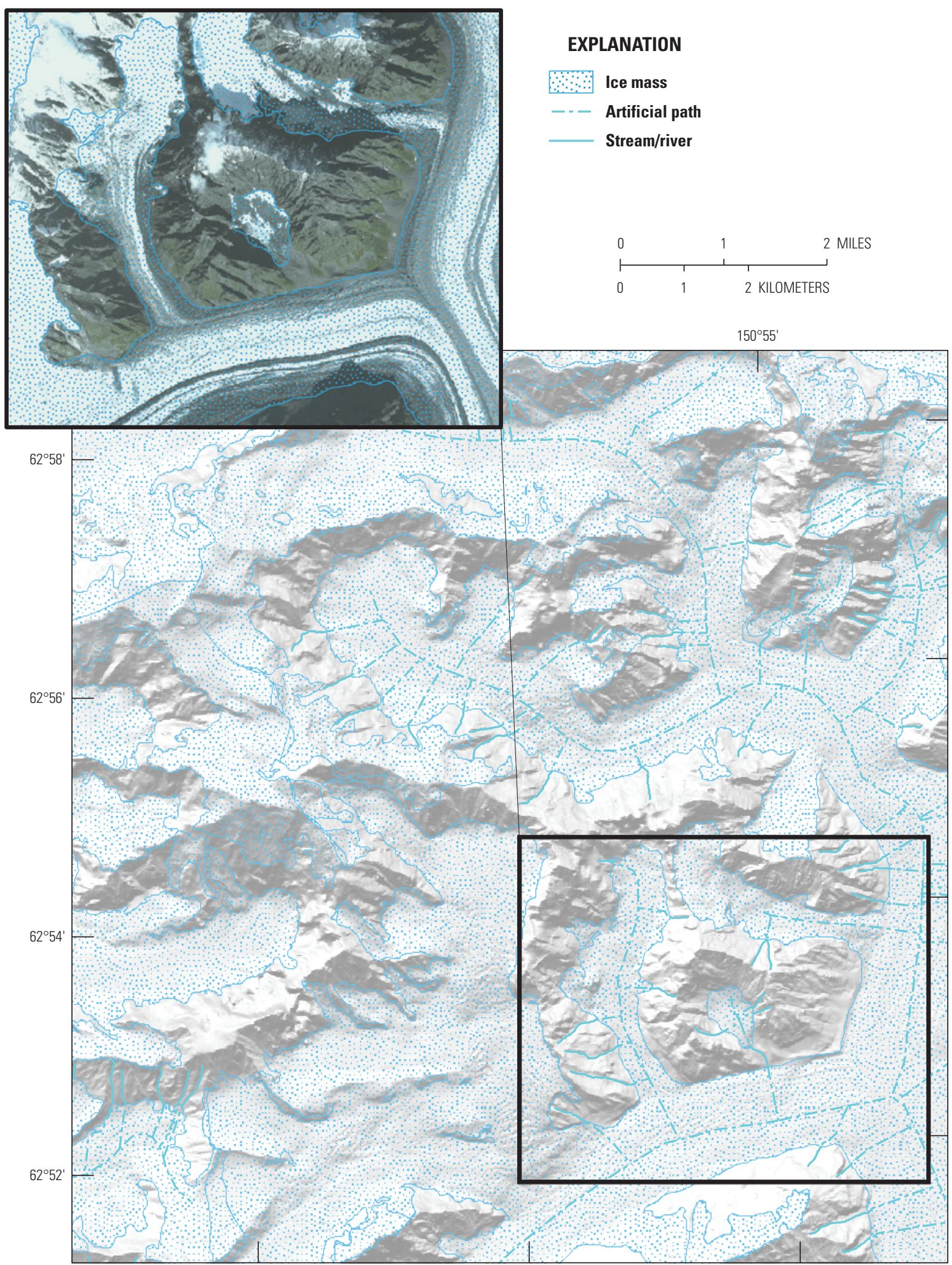

Base from U.S. Geological Survey digital data, various scales, various dates Albers Equal-Area Conic projection

Well-known identifier: 102039

Figure 38. An area in the Alaska Range $\left(150.8094829^{\circ} \mathrm{W} 62.9773695^{\circ} \mathrm{N}\right)$ shown as an example of a low-confidence area, snow-cover. Source data are from the National Hydrography Dataset (U.S. Geological Survey, 2020), which is used to provide examples of hydrographic feature types, but may not have the same density and other characteristics of elevation-derived hydrography. 
Table 41. Low-confidence area, snow-cover, domain codes and attributes.

[FClass, Feature Class; FCode, Feature Code; EClass, Elevation Class; --, no data]

\begin{tabular}{ccccccc}
\hline FClass & FCode & EClass & \multicolumn{1}{c}{ Description } & Source & Method & UserCode \\
\hline 9 & 993 & 9 & $\begin{array}{c}\text { Low-confidence area - snow } \\
\text { cover }\end{array}$ & Required & Required & -- \\
\hline
\end{tabular}

Table 42. Low-confidence area, snow-cover, representation rules.

$[--$, no data $]$

\begin{tabular}{lccc}
\hline \multicolumn{1}{c}{ Kind of feature object } & Area & Shortest axis & Longest axis \\
\hline 0-dimensional (point) & -- & -- & -- \\
1-dimensional (line) & -- & -- & -- \\
2-dimensional (polygon) & greater than 0 & -- & -- \\
\hline
\end{tabular}




\section{Acknowledgments}

The authors would like to acknowledge the expertise and research contributions of Hans Karl Heidemann, Kristina Yamamoto, Karen Adkins, Stephen Aichele, Robert Wheelwright, David Anderson, Lori Phillips, and Al Rea.

\section{References Cited}

Terziotti, S., and Archuleta, C.M., 2020, Elevation-derived hydrography acquisition specifications: U.S. Geological Survey Techniques and Methods, book 11, chap. B11, 74 p., accessed May 2020 at https://doi.org/10.3133/ tm11B11.

U.S. Geological Survey, 2020, USGS TNM

Hydrography (NHD): accessed February 28, 2020, at https://hydro.nationalmap.gov/arcgis/rest/services/nhd/ MapServer. 
For more information about this publication, contact:

Director, USGS National Geospatial Technical Operations Center 1400 Independence Road

Rolla, M0 65401

573-308-3500

For additional information, visit:

https://www.usgs.gov/core-science-systems/ngp/ngtoc

Publishing support provided by the

Rolla Publishing Service Center 


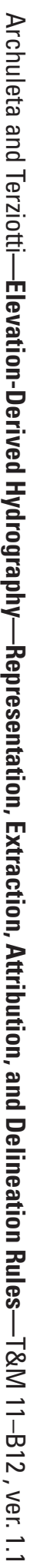

